Portland State University

PDXScholar

$1-1-1983$

\title{
A descriptive predictive model for the employment of computer-based management information systems for the government of a developing country: case, Iran
}

Hossein Bidgoli

Portland State University

Follow this and additional works at: https://pdxscholar.library.pdx.edu/open_access_etds Let us know how access to this document benefits you.

\section{Recommended Citation}

Bidgoli, Hossein, "A descriptive predictive model for the employment of computer-based management information systems for the government of a developing country: case, Iran" (1983). Dissertations and Theses. Paper 482.

https://doi.org/10.15760/etd.482

This Dissertation is brought to you for free and open access. It has been accepted for inclusion in Dissertations and Theses by an authorized administrator of PDXScholar. Please contact us if we can make this document more accessible: pdxscholar@pdx.edu. 


\section{A DESCRIPTIVE/PREDICTIVE MODEL FOR THE EMPLOYMENT OF COMPUTER-BASED MANAGEMENT INFORMATION SYSTEMS \\ FOR THE GOVERNMENT OF A DEVELOPING COUNTRY \\ CASE : IRAN}

by Hossein Bidgoli

A dissertation submitted in partial fulfillment of the requirements for the degree of

\section{DOCTOR OF PHILOSOPHY \\ in \\ SYSTEMS SCIENCE}

Portland State University

(C) 1983 Hossein Bidgoli 
TO THE OFFICE OF GRADUATE STUDIES AND RESEARCH:

The members of the Committee approve the dissertation of Hossein Bidgoli, presented August 26, 1983.

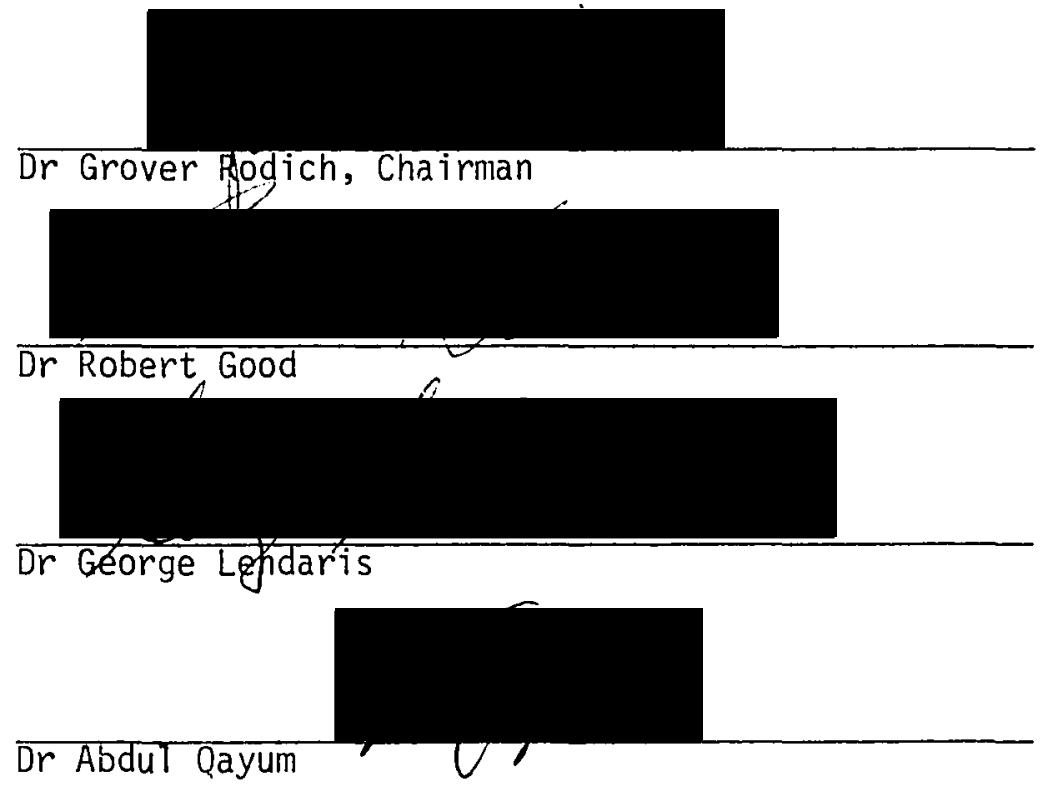

APPROVED :

Dr S E Rauch, Dean, Graduate Studies and Research 
AN ABSTRACT OF THE DISSERTATION OF Hossein Bidgoli for the Doctor of Philosophy in Systems Science presented August 26, 1983.

Title: A Descriptive/Predictive Madel for the Employment of Computer-Based Management Information Systems for the Government of a Developing Country--Case: Iran

APPROVED BY MEMBERS OF THE DISSERTATION COMMITTEE:

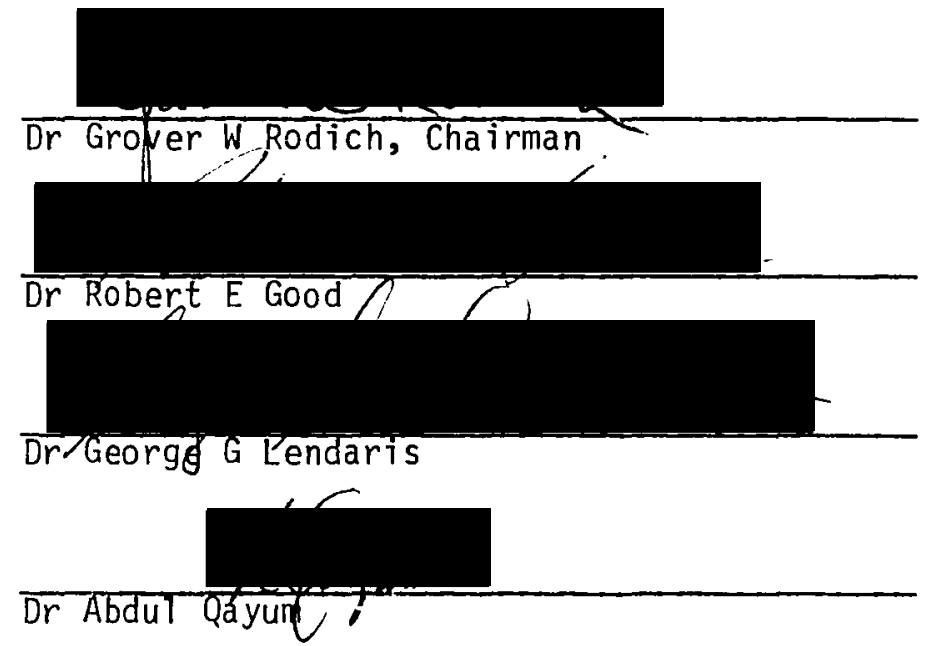

This study was undertaken to identify the most decisive variables involved in the successful employment of a Computer-Based Management Information System (CBMIS) in a developing country such as Iran.

A descriptive model was designed; using a series of predictive models, different dimensions of successful CBMIS employment were investigated. Necessary data was collected via a questionnaire sent to 79 Iranian governmental computer installations.

Questions initially posed by the study are: 
1. Under what conditions should a developing country such as Iran continue to operate manually?

2. If computerization is feasible, what should the acquisition criteria be?

3. What are some of the most important variables for optimum uti]ization of existing computers?

4. What are some of the most important variables for the timely and efficient implementation of a CBMIS?

5. Should a developing country employ standardization in data collection? In data transmission? In hardware selection? In software selection?

6. How should a developing country choose the manufacturer of computer technology?

7. How can the level of experience sharing among the installations be improved?

8. How can the reliability of the provided information be improved? The usefulness? The responsiveness of the CBMIS? Utilization of the provided information? The adaptability of the existing CBMIS to the growing technology?

In order to answer these questions, a series of multiple regression models were run, using four different methods: forced entry, backward 
elimination, forward entry, and stepwise selection. The analyses showed that of the 54 original variables hypothesized to be significant, 24 were, in fact, significant at the $5 \%$ level. It also cemonstrated seven circumstances linder which a change to automation in a developing country such as Iran would not be advisable. 


\section{ACKNOWLEDGEMENTS}

I am indebted to many people for their support and assistance in the completion of this project.

I gratefully express my thanks to my committee: first to my Chairman, Dr Grover Rodich, whose continued advice and encouragement through all phases of my career here has meant so much; to Dr Robert E Good, who reviewed my work several times and made valuable suggestions for improvement; to Dr George Lendaris, particularly for his assistance with the questionnaire; and to $\mathrm{Dr}$ Abdul Qayum for his thoughtful support throughout the project. Mr Edward Schafer, Director of the Population Center at PSU, also deserves special mention. His assistance in the data analysis section of this project was invaluable.

I send a very special thanks to my family in Iran--to my brother and sisters, who have assisted me in so many ways; to my brother-in-law, for his help in the dissemination and collection of the questionnaire; and, foremost, to my parents, whose uncompromising bel ief in the power of education has motivated me to continually reach for what seems impossible.

Finally, I thank two dear friends: Bahram Ahanin, who has buoyed my spirits many times in the past few years; and Sally Lopez, without whose practical advice and editorial assistance I would have found it difficult to finish the project. 
TABLE OF CONTENTS

PAGE

ACKNOWLEDGEMENTS ...........................

LIST OF TABLES ..................... . . viji

LIST OF FIGURES . . . . . . . . . . . . . . . . . xiii

CHAPTER

I STATEMENT OF THE PROBLEM . . . . . . . . . . . 1

Computer Technology in Developing Countries: 4

Some Background Information ....... .

The Role of Computer Technology in Economic and Social Development

The Economic Gap Between Developing Countries and the Industrialized World

The Status of Computers in Developing Countries

Problems Encountered in Computer Utilization in

Developing Countries ....... . 12

Objectives of the Study .......... 14

Research Questions........... 15

Expected Contributions of the Study . . . . . 17

Sources ............... . . 17

II LITERATURE REVIEW ............... . 19

A general Definition of Information Technology . . 19

Electronic Data Processing (EDP), Management

Information Systems (MIS), and Decision

Support Systems (DSS) ........ 20

Management Information Systems . . . . . . 22 
Definition

Components of a CBMIS

Centralization and Decentralization in MIS Organization

The Human Factor in MIS Design and Implementation

Computer-Based Management Information Systems as a Transferred Technology

Project Management as a Tool for Design and Implementation of a CBMIS

Cost/Benefit Analysis in the Design and Implementation of a CBMIS

The Future of the CBMIS and Its Implications for Developing Countries

Summary . . . . . . . . . . . . .

II I DEVELOPMENT OF A DESCRIPTIVE MODEL FOR A COMPUTERBASED MANAGEMENT INFORMATION SYSTEM (CBMIS) FOR DEVELOPING COUNTRIES ............

General Models for a Computer-Based Management

Information System ......... . 43

Other Work Relating to the Proposed CBMIS . . . 48

Developmental Phases of the Proposed CBMIS . . 52

The Acquisition Phase

The Design Phase

The Implementation Phase

The Operational Phase

Summary ................. . 81

IV RESEARCH METHODOLOGY, PHASE I . . . . . . . 32

Introduction ............ 82

Elements of the Descriptive Model . . . . . 82 
The Predictive Models . . . . . . . . 87

Relationship Between the Descriptive and Predictive Models.......... 89

Background for the Predictive Models . . . . 89

Predictive Mode1 \#1: Efficiency and Effectiveness of the Organization Due to the Acquisition of Computer Technology

Predictive Model \#2: Utilization of Existing Computers

Predictive Mode1 \#3: Delays in Computer Installation and Utilization

Predictive Model \#4: Cooperation and Coordination Among the Installations

Predictive Model \#5: Migration of Data from Place to Place

Predictive Model \#6: Reliability of the Provided Information

Predictive Model \#7: Usefulness of the Provided Information

Predictive Model \#8: Responsiveness of the CBMIS

Predictive Model \#9: Utilization of the Provided Information

Predictive Mode 1 \#10: Adaptability of the Present CBMIS to the Growing Technology

Predictive Model \#11: Physical Acquisition of Computer Technology

Predictive Model \#12: Manufacturer Satisfaction

Summary ................... 
$\checkmark$ RESEARCH METHODOLOGY, PHASE II . . . . . . . 98

Introduction ............ 98

Rationale for the Employment of Multiple Linear Regressions .......... . 98

Multiple Linear Regression as a Theory Building Technique ........... 100

Test of Hypotheses and Research Questions . . 103

Summary ............... 108

VI ANALYSIS ............................ 109

Introduction ........... . . 109

Relationships Between Dependent and Independent Variables ............... 109

Test of Hypotheses . . . . . . . . 128

Choosing the Best Predictive Model . . . . . 130

Summary of Significant Final Statistics for the 12 Predictive Models........ 136

Assumptions of Multiple Regression ...... 141

Summary ............... . . 146

VII SUMMARY AND CONCLUSION ............. 147

Summary of the Research ......... . 147

Answer to the Research Questions ...... 147

Recommendation for Future Areas of Research . . 154

REFERENCES ....................... 155

APPENDIX A .................................... 161

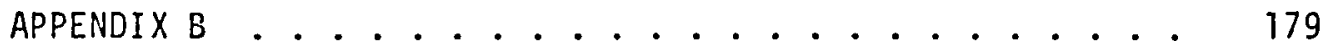


LIST OF TABLES

TABLE

PAGE

I Computer Statistics: Breakdown by Number and Usage .............. . . 9

II Growth in Numbers of Computers in Selected Countries............. 10

II General Classification of Computer Utilization in Developing Countries ........ 11

IV Comparative Advantages of Centralization vs Decentralization .......... 26

V Centralization vs Decentralization . . . . 27

VI Possible Information System Benefits . . . . 37

VII Possible Information System Costs . . . . 38

VIII Overal1 Development of Hardware Technology . . 40

IX Summary of Riehl's Normative-Reference Model • 50

$X$ A Conceptual Model for the Computer-Based Information System for the Dept of Statistics, Sudan . . . . . . . . . . . 51

XI The Systems Life Cycle . . . . . . . . 67

XII The Relationship Between the Dependent and Independent Variables ......... 90

XIII Mean and Standard Deviation for Predictive Mode1 \#1 .......................... 110 
TABLE

PAGE

XIV Pairwise Correlation for Dependent Variable $v_{55}$.............................. 111

XV Mean and Standard Deviation for Predictive Model \#2 ............... 112

XVI Pairwise Correlation for Dependent Variable

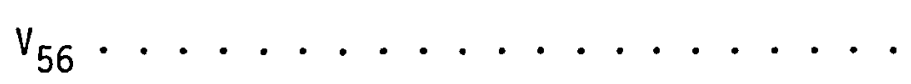

XVII Mean and Standard Deviation for Predictive Model \#3 ................... 114

XVIII Pairwise Correlation for Dependent Variable

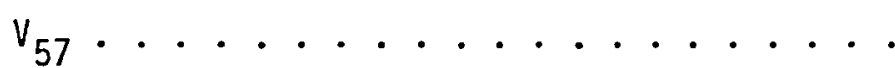

XIX Mean and Standard Deviation for Predictive Model \#4 ...............

$X X$ Pairwise Correlation for Dependent Variable

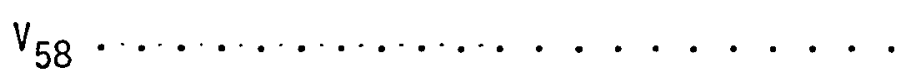

XXI Mean and Standard Deviation for Predictive Model \#5 .................

XXII Pairwise Correlation for Dependent Variable

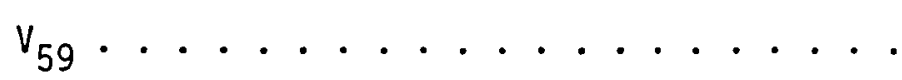

XXIII Mean and Standard Deviation for Predictive Model \#6..............

XXIV Pairwise Correlation for Dependent Variable

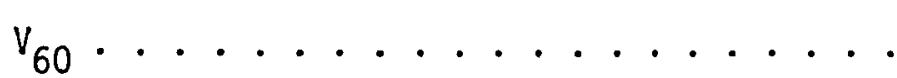

XXV Mean and Standard Deviation for Predictive

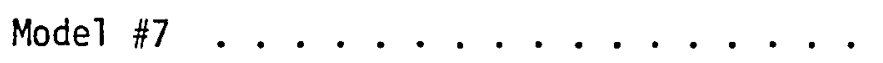


TABLE

PAGE

XXVI Pairwise Correlation for Dependent Variable

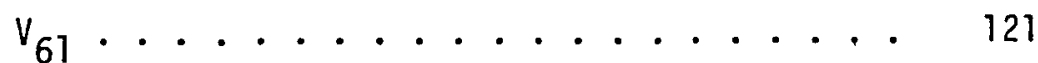

XXVII Mean and Standard Deviation for Predictive Model \#8................... 122

XXVIII Pairwise Correlation for Dependent Variable

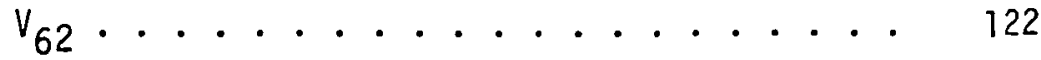

XXIX Mean and Standard Deviation for Predictive Model \#9................... 123

$X X X$ Pairwise Correlation for Dependent Variable

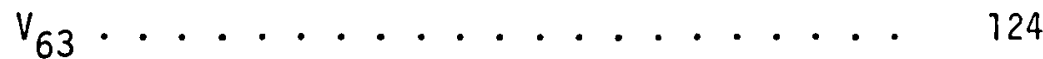

XXXI Mean and Standard Deviation for Predictive Mode1 \#10................... 125

XXXII Pairwise Correlation for Dependent Variable

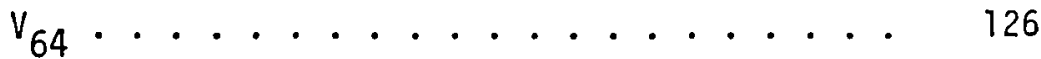

XXXIII Mean and Standard Deviation for Predictive

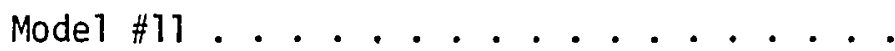

XXXIV Pairwise Correlation for Dependent Variable

$$
v_{65} \cdot \text {. . . . . . . . . . . . . }
$$

XXXV Mean and Standard Deviation for Predictive Mode1 \#12..................... 128

XXXVI Pairwise Correlation for Dependent Variable

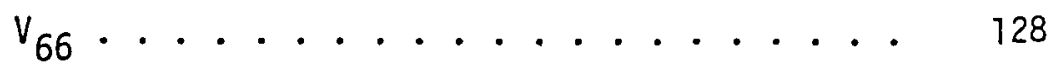

XXXVII Hypotheses Testing for the Twelve Predictive

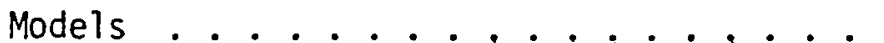


XXXVIII Forward Entry Multiple Regression for the

Twelve Predictive Models ........

XXXIX Backward Elimination Multiple Regression for

The Twelve Predictive Models . . . . . 133

XL Stepwise Selection Multiple Regression for the Twelve Predictive Models . . . . . . 134

XLI Summary of Statistics for Predictive Model \#2 135

XLII Predictive Model \#1: Summary of Significant Final Statistics...........

XLIII Predictive Model \#2: Summary of Significant Final Statistics............

XLIV Predictive Model \#3: Summary of Significant Final Statistics..........

XLV Predictive Model \#4: Summary of Significant Final Statistics........... . . $13 \varepsilon$

XLVI Predictive Model \#5: Summary of Significant Final Statistics...........

XLVII Predictive Model \#6: Summary of Significant Final Statistics............

XLVIII Predictive Model \#7: Summary of Significant Final Statistics...........

XLIX Predictive Model \#8; Summary of Significant Final Statistics............

L Predictive Model \#9: Summary of Significant Final Statistics . . . . . . . . . 
TABLE

PAGE

LI Predictive Model \#10: Summary of Significant

Final Statistics........... 140

LII Predictive Model \#12: Summary of Significant

Final Statistics.......... 140

LIII Casewise Plot of Standardized Residual . . . 142 


\section{LIST OF FIGURES}

FIGURE

PAGE

1. The Widening Gap ............. . 7

2. MIS in the Organization ......... 22

3. Hardware/Software Cost Trends ......... 41

4. Information Systems in Context ........ 44

5. An Information System Framework ........ 45

6. A General Management Information System Mode1 . . $4 \epsilon$

7. Basic Components of a Computer-Based Information system ............... . . 47

8. The Systems Development Methodology and Its

Relationship to the Information Systems Building Blocks ............. . . $4 \varepsilon$

9. The Structural Components of the Proposed CBMIS . 52

10. The Acquisition Phase of the Proposed CBMIS . . 54

11. The Design Phase of the Proposed CBMIS . . . . . 65

12. The Systems Development Life Cycle Showing Five Major Phases and the Major Activities Associated With Each ............. 66

13. The Most Relevant Environment for a CBMIS in a Developing Country............. 68

14. The Implementation Phase of the Proposed CBMIS . . 75

15. The Operational Phase of the Proposed CBMIS . . 79 
16. Normal Probability Plot of Studentized

Residuals ............. 14 . .

17. Standardized Scatter Plot of Predicted Values vs Residuals ............. 145 
CHAPTER I

STATEMENT OF THE PROBI.EM

The economic disparity between developed and developing countries is on the increase, and experts generally believe that the advent of the computer age in developed countries has been instrumental in widening an already significant economic gap between the two. Most developing countries have recognized the magnitude of the problem and have responded to it by attempting to acquire and utilize computer technology. Their efforts to date have not, however, ameliorated the problem. A careful study of computer status in these countries shows the reason: most have encountered problems in the acquisition and utilization of Computer-Based Management Information Systems (CBMIS's) which have considerably reduced their efficiency and effectiveness. A majority of these problems have been caused by the lack of a systematic approach for the acquisition, design, and implementation of a CBMIS.

To help assure that developing countries can indeed benefit from the acquisition of computer technology, this study has been undertaken. Expert opinions presented in international conferences on information technology throughout the world have been studied, books and journals in the computer field have been carefully examined, and the problems encountered by users in several 
developing nations have been scrutinized. Based upon the results of this research, various measures of CBMIS success have been established; and the design, acquisition, and implementation factors * associated with these measures of success have been identified. Because several different success measures were used, each with a separate set of associated desigi, acquisition, and implementation factors, twelve predictive regression equations were developed. These equations were tested using data collected in Spring 1983 from 79 Iranian governmental computer installations (which includes relatively successful as well as not-so-successfur users). A variety of multiple regression procedures were run on the data, including forced entry, forward entry, backward elimination, and stepwise selection techniques.

The end product of this project is a series of guidelines for the CBMIS decisionmaker which have been derived from statistically significant regression equations. The guidelines are clustered into two parts: (1) whether or not a country should automate; and (2) if automation is advisable, how to improve the chances of success in various phases of design, acquisition, and implementation of the CBMIS.

The study shows that there are seven types of situations for which computer automation may not be advisable. For the remaining types of situations where computer automation seems to be advisable, the study has provided answers to the following questions:

Throughout this study, "factor" and "variable" have been used interchangeably; "predictive equation" and "predictive model" have also been used interchangeably. 
- What are the most important variables for the optimum utilization of the existing computers? (Success in utilization)

- What are the most important variatles for the timely and efficient implementation of a CBMIS (Success in implementation)

- Should a developing country employ standardization in data collection? In data transmission? In hardware selection? In software selection? (Success in data migration)

- How should a developing country choose the manufacturer of computer technology? (Success in obtaining satisfactory manufacturer performance)

- How can experience-sharing among installations be improved? (Success in experience-sharing)

- How can the reliability of the provided information be improved? The usefulness? Responsiveness of the CBMIS? Utilization of the provided information? Adaptability of the existing CBMIS to the growing technology? (Success in reliability, usefulness, responsiveness, utilization, and adaptability to changing technology). 
The magnitude of the challenge facing developing nations cannot be fully appresiated without an understanding of at least three related areas: (1) the role of computer technology in the economic and social development of Third World countries; (2) the ever-increasing economic gap between developed and developing countries; and (3) the status of computers in developing countries. The first portion of this study will be devoted to an examination of these three areas.

COMPUTER TECHNOLOGY IN DEVELOPING COUNTRIES:

SOME BACKGROUND INFORMATION

The Role of Computer Technology in Economic and Social Development

This topic has been succinctly covered by Ralph Simmons in his report, Guidelines for the Use of Computer Technology in Developing

Countries. He states:

The computer is unique within the fields of science and technology in terms of its potential support to economic and social development. It serves as an important tool in numerous functional activities that are at the core of the developmental process. Within service areas such as transportation or communications, the computer is used to support daily operations as well as long range planning. The uses range from support to engineering design and construction to operational control to business and fiscal activities. The support to the planning function frequently includes economic analysis, facility expansion, and operational modeling. In the area of public administration and government operations, the computer has proved to be valuable through its capabilities to assist in information processing. When properly used, it can provide information that is more comprehensive, more timely, more accurate, more detailed and more relevant. It is especially significant to development as it can support the national planning process itself.

(Simmons, 1972: 2) 
Others see the role of the computer slightly differently. Donald Sexton, for exariple, in an article in Technos expresses the role in the following way:

Developing countries do have a great need for computers. While they desire sound, rapid states of economic growth, their plans are severely constrained by scarce resources. In such environments, planning is paramount. The computer, with its immense data processing, statistical, and operations research capabilities, can immeasurably aid such planning.

(Sexton, 1972: 9)

Yet another perspective is offered by the United Nations in its two comprehensive reports $(1971,1973)$ on the Application of Computer Technology for Development. These reports emphasize the role of the computer in national development.

Every government requires systematic maintenance of records if it is to function effectively. Examples of statistics which are basic to governments are:

--population and demographic records

--taxation records

--production statistics in various industry groupings, for example, agriculture, manufacturing, mining, construction

--economic indices, foreign reserves and trade balances, national income, private and public debt, consumer spending, average prices and earnings, and the like

--educational statistics, including number and types of schools, teacher training, educational level attained within the population, etc.

(United Nations, 1971: 85)

Simmons also considers the importance of computers to economic planning and national development. 
Computers and computer technology have played a central role in the growth of modern economics by providing an essential bridge between the accumulated body of formal theory on the one hand, and the growing availability of large data bases on the other. The result of this crucial bridging function has been the growth of modern econometrics and, more recently, an increasing application of economics to the formulation and testing of alternative policies and programs for dealing with social and economic problems.

(Simmons, 1972: 49)

Computer capabilities have been used extensively by a few developing countries in solving mathematical models. One such country is Israel, which has used computers in Kibbutz agriculture for more than a decade (Goldschmidt, 1974: 77-90). India has also employed computers in commercial, educational, and research activities (Chandrasekkar, 1972: $844-852)$.

Since the cost of labor in developing countries is much cheaper than in developed countries, many people initially felt that the application of computers in service areas of developing countries may not be cost justified. However, several studies have proven that this is an incorrect assumption. As Joseph Papa points out,

A recentiy conducted feasibility study for the Ministry of Communication in Korea found that large benefits could be gained by automating telephone billings, central postal savings, national life insurance accounting, and inventory control. Although clerks receive only the equivalent of $\$ 50$ per month working for the ministry, personnel savings which would be achieved by automating these applications nationwide would yield a benefit/cost ratio of approximately two. 
The Economic Gap Between Developing Countries and the Industrialized World

The number of computers used in industrialized countries is increasing. In 1974, there were 162,000 computers in operation in the United States alone; by 1980 , that number had climbed to more than a million (Couger, 1981: 1).

Figure 1 demonstrates the huge economic gap that exists between developing and industrialized countries. Many people believe that computer technology has been instrumental in widening this gap.

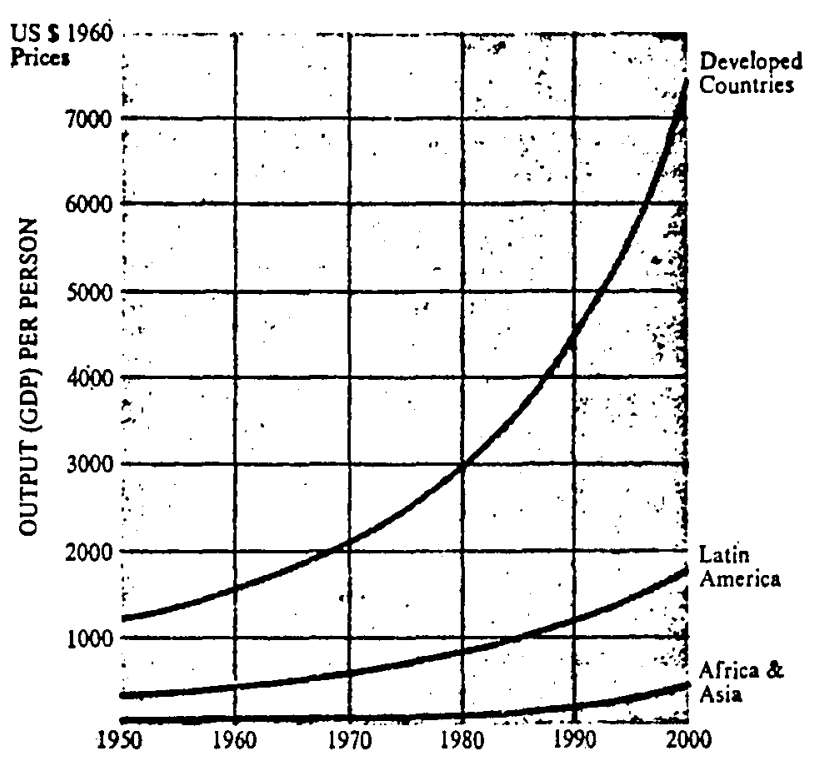

Figure 1. The Widening Gap

Source: (Ward, 1971: xii)

An effective computer utilization program, one which considers all the important variables involved in computer utilization, may help developing countries to narrow this gap.

The Status of Computers in Developing Countries

Most of the developing countries have realized that computer 
technology may well be the key to increasing their economic status. One series of surveys which has proven convincing to them was done by the United Nations. These studies show clearly that developing countries with a relatively high GNP have employed more computers than have countries with a relaiively low GNP.

Table I shows the number of computers and computer usage in several of the developing countries. As the tabie indicates, developing countries have used computers for administrative purposes more than for any other. Table II shows the growth in the numbers of computers in selected countries, and Table III indicates the United Nation's classification (under four general headings) of the level of computerization in all developing countries. Taken together, these three tables provide an accurate and concise picture of the status of computers in developing countries.

As Table I (and many other studies) shows, most of the applications of the computer in developing countries have been business related. A comprehensive study conducted by the US Dept of Commerce to determine the market for computers in Iran showed that $94 \%$ of sma $11-, 89 \%$ of medium-, and $74 \%$ of large-scale computer time has been utilized in business-oriented applications* (US Dept of Commerce, 19\%: 20). Since the cost of labor in developing countries is relatively cheap, it appears they might better direct their computer utilization toward scientific and other applications which are less labor-intensive than business applications are.

At that time, the US Dept of Commerce classified as small computers up to $32 \mathrm{~K}$ of $\mathrm{CPU}$, medium between $33-99 \mathrm{~K}$, and large as $100+\mathrm{K}$. 
TABLE I

COMPUTER STATISTICS: BREAKDOWN BY NUMBER AND USAGE

\begin{tabular}{|c|c|c|c|c|c|}
\hline \multirow[b]{2}{*}{ Country } & \multirow[b]{2}{*}{$\begin{array}{c}\text { Total } \\
\text { of } \\
\text { Computers } \\
\end{array}$} & \multicolumn{4}{|c|}{ Usage } \\
\hline & & $\begin{array}{l}\text { Education } \\
\text { and } \\
\text { Iraining } \\
\end{array}$ & $\begin{array}{c}\text { Inventory Distr } \\
\text { and } \\
\text { Manufacturing }\end{array}$ & $\begin{array}{l}\text { Business } \\
\text { Admin }\end{array}$ & $\begin{array}{c}\text { Public Admin } \\
\text { and } \\
\text { Statistics } \\
\end{array}$ \\
\hline Bolivia & 6 & 1 & 3 & 1 & 2 \\
\hline Brazil & 1,219 & 110 & 475 & 445 & 189 \\
\hline Central African & & & & & \\
\hline Republic & 3 & - & - & - & 3 \\
\hline Colombia & 82 & 7 & 40 & 20 & 15 \\
\hline Cyprus & 5 & - & 1 & 3 & 1 \\
\hline Fiji & 6 & - & - & 2 & 4 \\
\hline Greece & 175 & 7 & 38 & 75 & 55 \\
\hline Hungary & 161 & 26 & 38 & 26 & 10 \\
\hline Iceland & 17 & 1 & 4 & 10 & 1 \\
\hline Iraq & 7 & $j$ & $i$ & 3 & 2 \\
\hline Jamaica & 34 & 3 & 8 & 20 & 3 \\
\hline Kuwait & 17 & 1 & 8 & 7 & 1 \\
\hline Lebanon & 29 & - & 4 & 14 & 11 \\
\hline Madagascar & 24 & 1 & 3 & 15 & 5 \\
\hline Malaysia & 28 & $i$ & 7 & 7 & 13 \\
\hline Morocco & 52 & 3 & - & 29 & 20 \\
\hline Nicaragua & 14 & - & - & 8 & 6 \\
\hline Pakistan & 19 & 2 & 2 & 9 & 6 \\
\hline Poland & 245 & 70 & 109 & 34 & 24 \\
\hline Singapore & 34 & 3 & 5 & 18 & 8 \\
\hline Sudan & 4 & 1 & 1 & - & 2 \\
\hline Thailand & 27 & 4 & 6 & 2 & 15 \\
\hline Turkey & 82 & 8 & 43 & 20 & 11 \\
\hline Upper Volta & 1 & - & - & - & $i$ \\
\hline Yugoslavia & 147 & 20 & $\ldots \ldots-\ldots$ & ......... & 45 \\
\hline Zaire & 19 & 4 & - & 15 & - \\
\hline
\end{tabular}

Source: (United Nations, 1973: 28) 
TABLE II

GROWTH IN NUMBERS OF COMPUTERS

IN SELECTED COUNTRIES

\begin{tabular}{|c|c|c|c|c|c|c|c|}
\hline Country & Item & 1960 & 1963 & $\underline{1965}$ & 1967 & 1968 & 1969 \\
\hline Australia & $\begin{array}{l}1 \\
2 \\
3\end{array}$ & $\begin{array}{r}30 \\
16.4 \\
1.8\end{array}$ & $\begin{array}{r}137 \\
20.0 \\
6.8\end{array}$ & $\begin{array}{r}348 \\
23.0 \\
15.1\end{array}$ & $\begin{array}{r}608 \\
27.7 \\
22.4\end{array}$ & $\begin{array}{r}718 \\
30.2 \\
23.8\end{array}$ & $\begin{array}{r}869 \\
33.3 \\
26.1\end{array}$ \\
\hline Chile & $\begin{array}{l}1 \\
2 \\
3\end{array}$ & $\begin{array}{l}-- \\
-- \\
--\end{array}$ & $\begin{array}{r}9 \\
2.7 \\
0.3\end{array}$ & $\begin{array}{r}14 \\
4.0 \\
3.0\end{array}$ & $\begin{array}{r}26 \\
5.6 \\
4.6\end{array}$ & $\begin{array}{r}32 \\
5.5 \\
5.8\end{array}$ & $\begin{array}{r}36 \\
6.0 \\
6.0\end{array}$ \\
\hline Iran & $\begin{array}{l}1 \\
2 \\
3\end{array}$ & $\begin{array}{l}-- \\
-- \\
--\end{array}$ & $\begin{array}{l}-- \\
-- \\
--\end{array}$ & $\begin{array}{r}2 \\
6.6 \\
0.3\end{array}$ & $\begin{array}{r}9 \\
8.0 \\
1.1\end{array}$ & $\begin{array}{r}18 \\
8.9 \\
2.0\end{array}$ & $\begin{array}{r}32 \\
10.2 \\
3.1\end{array}$ \\
\hline Israel & $\begin{array}{l}1 \\
2 \\
3\end{array}$ & $\begin{array}{r}2 \\
2.0 \\
1.0\end{array}$ & $\begin{array}{r}12 \\
2.5 \\
4.8\end{array}$ & $\begin{array}{r}35 \\
3.5 \\
10.0\end{array}$ & $\begin{array}{r}80 \\
3.9 \\
20.2\end{array}$ & $\begin{array}{r}100 \\
4.0 \\
24.7\end{array}$ & $\begin{array}{r}160 \\
4.6 \\
34.8\end{array}$ \\
\hline Japan & $\begin{array}{l}1 \\
2 \\
3\end{array}$ & $\begin{array}{l}-- \\
-- \\
--\end{array}$ & $\begin{array}{l}-- \\
--\end{array}$ & $\begin{array}{r}1,683 \\
88.6 \\
19.0\end{array}$ & $\begin{array}{r}3,035 \\
120.0 \\
25.3\end{array}$ & $\begin{array}{r}4,132 \\
142.3 \\
29.0\end{array}$ & $\begin{array}{r}5,601 \\
166.9 \\
33.6\end{array}$ \\
\hline Philippines & $\begin{array}{l}1 \\
2 \\
3\end{array}$ & $\begin{array}{l}-- \\
-- \\
--\end{array}$ & $\begin{array}{l}6 \\
8.1 \\
0.7\end{array}$ & $\begin{array}{r}19 \\
9.1 \\
2.1\end{array}$ & $\begin{array}{r}30 \\
10.5 \\
2.9\end{array}$ & $\begin{array}{r}45 \\
11.4 \\
3.9\end{array}$ & $\begin{array}{r}67 \\
12.9 \\
5.2\end{array}$ \\
\hline USA & $\begin{array}{l}1 \\
2 \\
3\end{array}$ & $\begin{array}{r}4,528 \\
509.0 \\
8.9\end{array}$ & $\begin{array}{r}5,867 \\
596.3 \\
26.6\end{array}$ & $\begin{array}{r}29,142 \\
692.1 \\
42.1\end{array}$ & $\begin{array}{r}55,785 \\
803.6 \\
66.9\end{array}$ & $\begin{array}{r}55,606 \\
863.6 \\
64.4\end{array}$ & $\begin{array}{r}67,977 \\
929.5 \\
66.7\end{array}$ \\
\hline
\end{tabular}

Item $1=$ number of computers

2 = gross domestic product in billions of dollars

3 number of computers per billion dollars GDP

Source: (United Nations, 1973: 32) 
TABLE III

GENERAL CLASSIFICATION OF COMPUTER UTILIZATION

IN DEVELOPING COUNTRIES

Leve1

Initial

Basic

Operational

Advanced

\section{Characteristics}

There are no operational computers in the country. A few nationals have had contact with computing. The snly local sources of information are computer salesmen.

Triere is some understanding of computers in government (and private) decision centers. A few computer installations are to be folind. There are some nationals involved in computer operations. There is some education and training in computer technology in the country. Computers are used in basic government operations.

There is extensive understanding of computers in government (and private) decision centers. Among the numerous computer installations there are some very large machines. There are centers for education and training in computer technology, and some are of excellent quality. They ciffer degree programs in computer or information science. There is design and production of software and some manufacture of hardware. Computers are affecting many disciplines, particularly science, engineering and medicine.

Most government and administrative work is carried out by computers. There are well established professional activities and national meetings on computers. There is a complete range of quality education and training programs. The number of computers, of all sizes, is increasing rapidly. Time-sharing, teleprocessing and reniste job entry are common. There is design and production of both hardware and software. Many technologies have been changed or are in the course of being changed. New applications of computers are found regularly. There is a strong participation in and contribution to international activities. 
With regard to the issue of computer application, Simmons has classified use as one of five types: (1) business-oriented (accounting, payrol1, inventory), (2) scientific and engineering (highway design, meteorology, economic analysis), (3) information management (data storage and retrieval systems, library automation), (4) industrial (process control, quality control), and (5) education (computer-aided instruction, specific educational programs). He clearly indicates that of the five types, only classification (1) is generally used by developing countries (Simnons, 1972: 43).

Management information systems supported by computers offer a means of major improvement to the fundamental functions of management; i.e., planning, organizing, directing, controlling, and evaluating, but they have not been widely used in the developing countries.

(Simmons, 1972: 12)

\section{PROBLEMS ENCOUNTERED IN COMPUTER UTILIZATION IN DEVELOPING COUNTRIES}

Several studies have shown that developing countries have encountered a series of problems in the utilization of computers. The nature and degree of seriousness of the problems vary from country to country, but some examples are human, economic, technical, managerial, political, and social problems. A comprehensive study conducted by Ralph Simmons over nine selected countries highlights some of these problems:

Ethiopia: Underutilization of existing hardware, shortages of qualified personnel and discrepancies in the salaries of government employees and people in industry and quasi-governmental positions are the most serious problems. (p 66)

Turkey: Unreliable voltage levels in power supplies and unreliable communication systems, shortage of qualified data processing personnel, and under 
utilization of existing computers are the major concerns. (pp 79, 83, 85)

Brazil: Because of the shortage of qualified personnel, salaries are very high. This has created serious problems in terms of friction between employees, which, in turn, stimulates a high turnover rate. ( $p$ 96)

Colombia: The major problem here is the lack of available foreign exchange, the high tax rates, etc, associated with bringing a computer into Colombia. Duties, transportation, etc, total $84 \%$ of the purchase price. It is also difficult to arrange financing. ( $p$ 101)

Korea: Some computers were acquired for the prostige factor with no analysis made as to their actual application. ( $p$ 108) Under utilization of existing computers and shortage of foreign exchange are other serious problems. ( $p$ 108) Perhaps the most serious of all is the lack of systemization in traditional manual methods of data handling. Changes are thus difficult because they involve not only the procedure itself but also changes in the basic system of operations and in patterns of human behavior in work performance. (p 109)

(Simmons, 1972: 57-124)

Nigeria, Uganda, the Republic of China, and Thailand, the other four countries detailed in the simmons study, experienced problems similar to those outlined above.

A detailed examination of the documents published by the Plan and Budget Organization (PBO) of the Iranian government, indicates that Iran, like the other developing countries discussed above, has encountered many problems in attempting to become a computerized society. These problems may be summarized as follows: underutilization of computer capacity; delays in computer installation and utilization; lack of an information center (prices, applications, new developments, etc); lack of cooperation and coordination among the installed computer 
centers; severe shortage in computer personnel (managers, systems analysts, technical advisors, programers, and operators); discrepancies in salaries of foreign ind domestic consultants; and problems of unskilied labor (displaced personnel) (PiBO, 1977).

Another important problem in computer utilization has been pointed out by the US Department of Commerce (1976: 7). Due to the lack of reliable communications systems in Iran, more than $70 \%$ of all applications have been batch processed. For this country of 33 milition people, there were, for example, only 500,000 telephone numbers! (US Dept of Commerce, 1976: 12)

\section{OBJECTIVES OF THE STUDY}

After a careful examination of the status of computers in several developing countries, the following can readily be concluded:

- Most of the developing countries do not have a significant number of operational computers;

- There is no single study done to show whether any of these countries have used a systematic approach for the employment of computers in their operations; i.e., a guide to organize a Tisting of the key variables involved in this transformation;

- By ignoring the mosi crucial variables involved in computer utilization, existing computers have not been efficiently and effectively used. Misutilization and under utilization have created several undesirable results.

The major objective of this research project is to improve the technology transfer process by an identification of the most 
critical variables involved in this process and an incorporation of those variables into a descriptive model. The variables span a broad range, all the way from acquisition to implementation of a CBMIS. A statement made by the United Nations about the use of computers in developing countries neatly states the underlying philosophy of this study:

The computer is not a panacea for administrative and development problems. Possession of a computer may at first create at least as many problems as it solves. Its use requires highly trained systems designers, analysts, programmers and operators. Without such trained personnel, the computer cannot be used effectively. It also requires reliable data which have to be collected and transcribed suitably. The computer demands a considerable infrastructure or else it cannot function. There can be no question of the unjustified advocacy of computers, and the Secretary General concurs with the conviction that it is better not to get a computer at all than to get one and not be prepared or able to use it effectively.

(United Nations, 1973: 9)

\section{RESEARCH QUESTIONS}

This study seeks answers to many questions relating to the transfer of computer technology from developed to underdeveloped countries. Of the two groups of questions used, the first deals with preliminary considerations and includes the following:

- What are the important variables to include in a model of transferring CBMIS technology to a developing country such as Iran?

- Which variables are the most crucial?

- Based on the proposed model, under what conditions might a country choose to continue to operate manually? 
The second group of questions is concerned with the transformation process after the decision to automate has been made. Questions in this category include:

- What should the acquisition criteria be?

- How important is the role of the user and of top management in the utilization of the existing computers?

- How important is the existence of a master system plan?

- What are some of the most importani variables for the optimum utilization of the existing computers?

- How should a developing country choose the manufacturer of computer technology?

- What are some of the most important variables for the timely and efficient implementation of a CBMIS?

- How can the level of experience sharing among the installations be improved?

- Should a developing country employ standardization in data collection? in data transmission? in hardware selection? in software selection?

- How can the level of data migration be improved?

- How can the reliability of the provided information be improved?

- How can the usefulness of the provided information be improved?

- How can the responsiveness of the CBMIS be improved?

- How can the utilization of the provided information be improved? 
- How can the adaptability of the existing CBMIS to the growing technology be improved?

- How can the economic difficulties encountered in the acquisition of a CBMIS be improved?

- How important is the role of project management in the implementation of a CBMIS?

- What are some of the most important social issues for the employment of a CBMIS in a developing country?

- How important is the role of economic feasibility for timely implementation of a CBMIS?

- How important is the role of data base in the migration of data?

\section{EXPECTED CONTRIBUTIONS OF THE STUDY}

The end product of this study is a series of guidelines for decisionmakers which have been derived from statistically significant regression equations. The guidelines are clustered into two parts: (1) whether or not a developing country such as Iran should automate; and (2) if automation is advisable, how to improve the chances of success in various phases of the acquisition, design, and implementation of the CBMIS.

\section{SOURCES}

Both primary and secondary sources of information are used in this study. Secondary material, which provides the building blocks of the model set forth in this study, includes the following: 
technical journals, books, articles and materials generated at international conferences and seminars, United Nations materials, information disseminated by the government of Iran, and personal experiences and observations.

The primary source of information for this study is a detailed questionnaire which was completed by responsible authorities at all the significant computer installations in Iran (see Appendix A).

Chapter II, following, deals expressiy with the crucial background material obtained through secondary sources of information. 
CHAPTER II

\section{LITERATURE REVIEW}

The overall aim of this chapter is to provide a brief look at other secondary sources which have a bearing on the subject study and to provide a definition of terms which will be central to later discussions. This material necessarily focuses on management information systems--what they are, what their role has been in the past, and what it is likely to be in the future, relative to developing countries.

\section{A GENERAL DEFINITION OF INFORMATION TECHNOLOGY}

Information technology is a relatively new field of science which includes several interrelated subfields of which hardware, software, and telecommunicatioris are probably the most important.

The Conference Bsoard (1972: v) defines information technology as

$$
\begin{aligned}
& \text { and use of information. It is not confined to hardware } \\
& \text { or software but acknowledges the importance of man and } \\
& \text { the goal he sets for information technology, the values } \\
& \text { employed in making these choices, the assessment cri- } \\
& \text { teria used to decide whether he is controlling this } \\
& \text { technology and is being enriched by it. }
\end{aligned}
$$

The Conference Board also says that the components of information technology include: mass and individual communications, combuter technology, audio technology, and imaqe technoloqy (1972: 23). 
ELECTRONIC DATA PROCESSING (EDP), MANAGEMENT INFORMATION SYSTEMS (MIS), AND DECISION SUPPORT SYSTEMS (DSS)

Computer scientists have traditionally treated electronic data processing, management information systems, and decision support systems as though they were one and the same. Because there has been no agreement on a working definition for each of these terms, the distinctions have blurred; the three terms have been used interchangeably in much of the data processing literature. Walter Kennevan, for example, defines MIS as and an organized method of providing past, present,
tions and external intelligence. It supports the planning,
control, and operational functions of an organization by
furnishing uniform information in the proper time frame to
assist the decision-making process.

(Kennevan in McLeod, 1979: 14)

As this definition indicates, the author uses MIS as a decision support system. However, he does not clarify whether MIS is to be used for a particular level of organization (e.g., strategic planning, management control, operations management). His failure to make such a clarification confuses MIS with EDP and DSS in the minds of many readers.

More recently, some authors have attempted to make the distinction between EDP/MIS and DSS clear. One such author is Steven Alter. Alter uses EDP mostly for clerical activities. He believes that EDP focuses mostiy on the past, while DSS, which is involved largely with management activities, places its emphasis on the present and the future (1980: 2). Throughout his book, Alter describes a broad 
range of successful and not-so-successful decision support systems. Peter Keen and Michael Scott Morton are two other authors who address the distinction between EDP/MIS and DSS. They describe DSS as the use of the computer to:

- assist the manager in his decisionmaking process for semistructured tasks;

- support, rather than replace, managerial judgment;

- improve the effectiveness of decisionmaking rather than its efficiency.

(Keen, 1978: 1)

They describe the main characteristics of MIS somewhat differently:

The main impact has been on structured tasks where standard operating procedures, decision rules, and information flows can be reliably predefined... . The main payoff has been in improving efficiency by reducing costs, turnaround time, and so on, and by replacing clerical personnel ... The relevance for managers' decisionmaking has mainly been indirect, for example, by providing reports and access to data.

$$
\text { (Keen, 1978: 1-2) }
$$

Ralph Sprague and Eric Carlson (1982) have gone one step further. Throughout their book, Building Effective Decision Support Systems, these authors discuss the differences between EDP and MIS/ DSS. They also present a variety of guidelines for the design and implementation of effective decision support systems.

The above-mentioned authors have all demonstrated amply how a computer can support a manager in his decisionmaking activities. One is aware, from a synthesis of these different definitions, that the computer can be used in all three levels of organization. If, 
however, it is used at the bottom, it is referred to as MIS; and if it is used at the middle and upper levels, it is called DSS. The following diagram clarifies this notion.
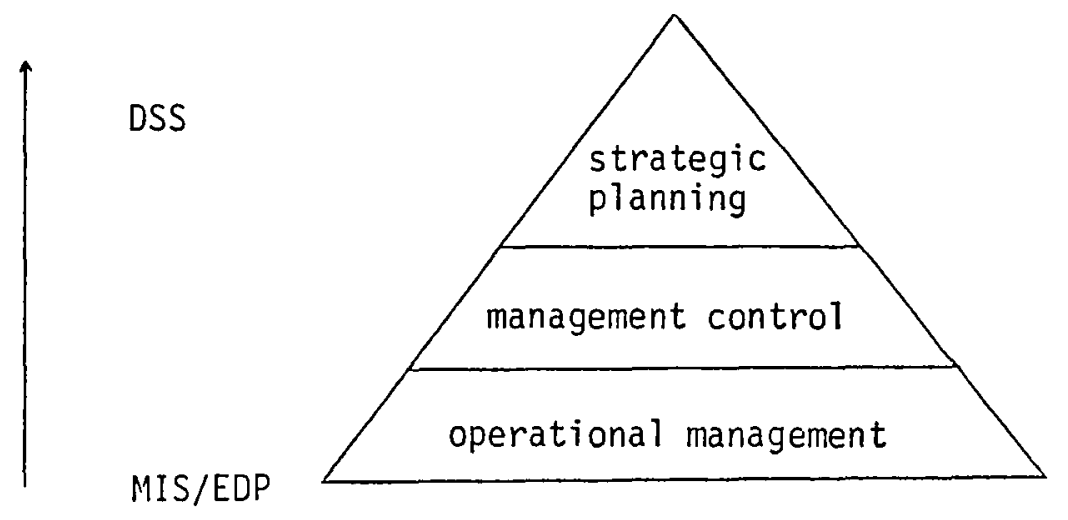

Figure 2. MIS in the Organization

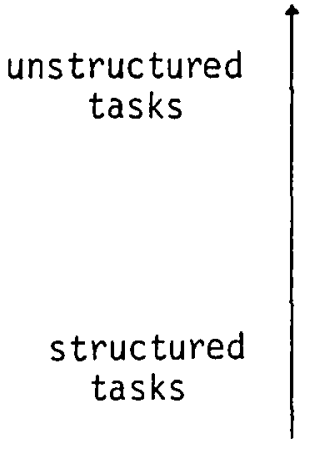

MANAGEMENT INFORMATION SYSTEMS

Definition

Throughout this study, Management Information Systems may be taken to mean the following:
- a well organized integration of men, machines, facilities, and procedures designed to assist a decisionmaker in making decisions--or better decisions-- at all levels in an organization.

This definition highlights six important elements in a management information system:

1. It is well organized and integrated (in terms of the elements which comprise it);

2. The human element is a key factor (i.e., the user, the designer, the implementer, and the maintainer); 
3. "Machine" refers to the computer and other related technologies, i.e., telecommunications, telex, ...

4. "Facilities" refers to other supporting technologies, such as the building, the air conditioning system . . .

5. "Procedure" is the way a process must be done. It is important, even in a manual system;

6. The last element is the necessity for a goal in MIS. The goal must always be the production of an accurate, timely, relevant, integrated body of information to support a decisionmaker in his decisionmaking activities.

One needs to keep in mind that the existence of a computer is not a requirement in MIS design; a manual MIS can provide meaningful information as well. However, this study will be concerned with computer based management information systems (CBMIS) exclusively.

\section{Components of a CBMIS}

Many authors have discussed this topic. Although each author has stressed the fact that there are many variables, one can find a striking number of similarities among the descriptions of the various writers. For example, Gordon Davis (1974: 192) lists the physical components of a management information system in the following manner:

-- hardware (CPU, I/O units, . . .)

-- software (computer programs, operating systems .....)

-. files (data base) (tapes, disk packs, . . . .)

-- procedures (user instructions, instructions for preparation of input, . . . .) 
-- operating personnel (computer operators, system analysts, .....)

However, as Davis mentions, the above are just the physical components of a MIS. Robert Good's (1979) definition emphasizes the user impact of MIS:

- data

-- storage and retrieval

-- analysis

-- communication and data transmission

-- presentation

-- manager

William Taggert's description (1980: 30-31), like that of Davis, places the emphasis on the physical components of a MIS:

-- input

-- processing units

-- transmission units

- output

The summary notion from the descriptions of these different authors is that the MIS definition presented earlier in this chapter should include the following elements:

- Data: the raw facts which come to the system from its environment. The environment of an MIS depends upon the particular context in which the system has been designed. (The section of this study which deals with the descriptive 
model for a CBMIS will provide an opportunity for a fuller discussion of the "environment" of the system.)

- Storage: the location of the data (in its original or "disaggregated" form--or in any other form) filed for future usage. The storage device can be a simple cabinet, or a modern data base with multiple access, or anything in between.

- Analysis: the process of putting the data into a form which is more meaningful for a decisionmaker. In this stage, many different options exist for the transforming of data into information.

- Information: the output of a MIS. The designer must consider a broad range of options available to the user. He certainly should take into account the user's personal organizational style.

- The Human Factor: includes operating personnel, the user, and the top management of the organization. A close communication among these people is crucial for a successful MIS design.

Centralization and Decentralization in MIS Organization

Centralization/decentralization is an issue which is prevalent in much of the literature. William Taggart, for instance, discusses it in terms of several factors such as: applications, decisionmaking, coordination and control, and economics. He summarizes the advantages and disadvantages of each issue in Table IV on the following page. 
TABLE IV

COMPARATIVE ADVANTAGES OF CENTRALIZATION VS DECENTRALIZATION

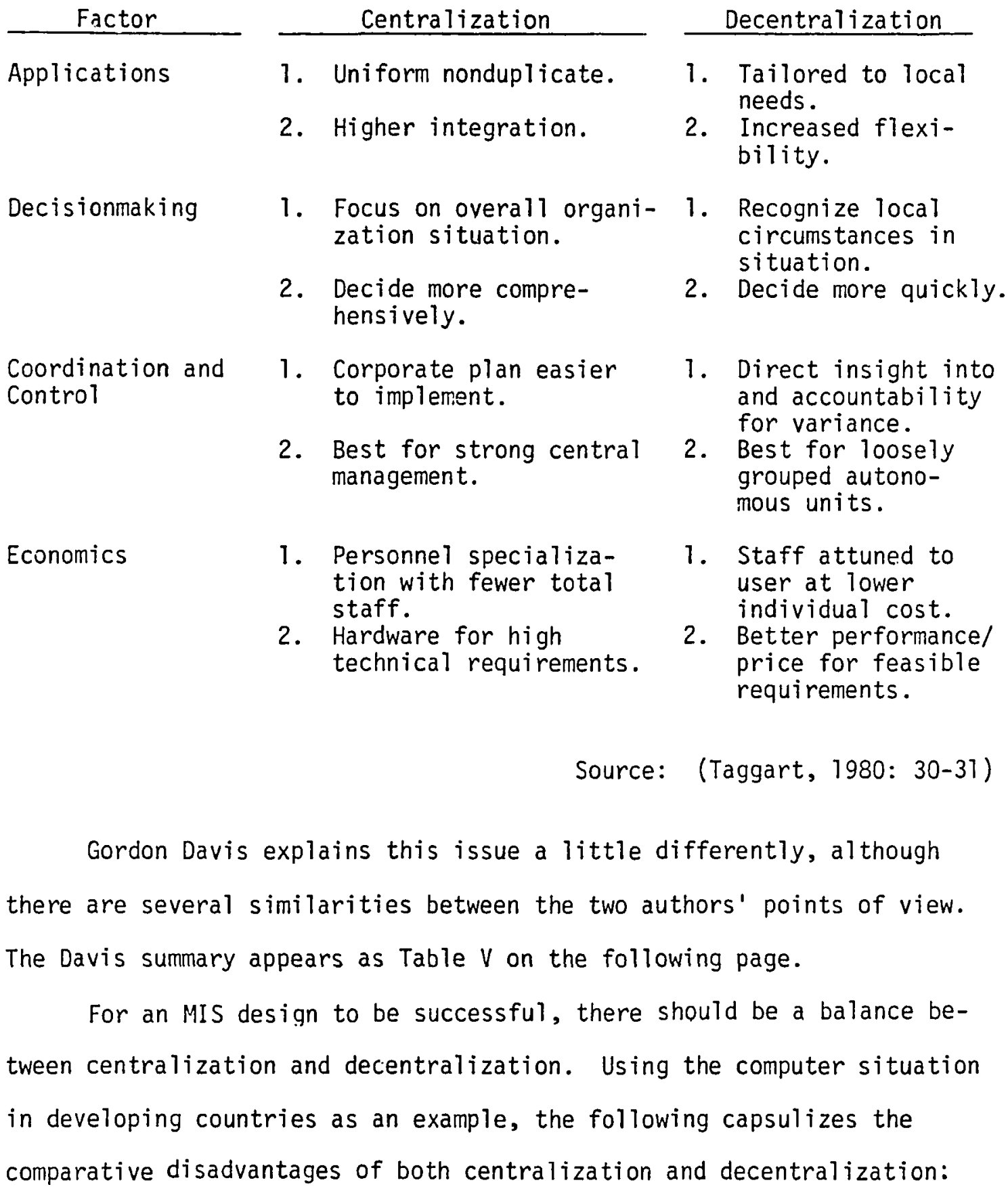


TABLE V

CENTRALIZATION VS DECENTRAL IZATION

Supportive of Centralization

1. Economies of scale, especially hardware but also personnel

2. Savings from elimination of duplicate system development

3. Advantages from standarization

4. Advantages from uniform system output

Disadvantages of Centralization

-- scheduling problems

-- poor responsiveness

-- administrative problems

-- limited national training

-- limited applications (fewer applications being user-oriented)

-- high risks in decisionmaking (larger scale decisions)

-- highly trained people are required

- high installation costs

-- high unused capacity

Disadvantages of Decentralization

-- lack of economy of scales (personnel, hardware, applications)

-- lack of centralized control

-- lack of unique decisionmaking

-- possible redundancy
1. Improved service through responsiveness to location conditions (or lack of responsiveness by centralized system)

2. Company policy of decentralization in management

3. Lack of commonality among organizational units makes standard systems infeasible

Source: (Davis, 1974: 376) 
The Human Factor in MIS Design and Implementation

In reviewing the literature, one can readily see that this subject has been thoroughly treated for MIS design in the United States. However, due to the high unemployment rate, relatively low user awareness, and traditional environments of developing countries, this issue becomes more complicated, and thus has more implications for the MIS designer, when applied to them. (See the following for indepth discussions of the human factor in US MIS design: Dock,(1981: 379-380), Wi1loughby (1981: 31-42), Dickson (1970: 59-71), A1ter (1380: 23-32), Carper (1977: 48-50), Testa (1974: 13-17), Plintzberq, (1978: 1-23), Bariff (1977: 820-828), and Berkeley (1975:6).

The human factor has always been and likely will always be a key element in all stages of computer acquisition, design, and implementation in developing countries, as well as in developed ones. However, the most serious problem in connection with computer utilization in developing countries involves the human element. For example, in the acquisition phase of computer technology, highly informed managers are required in order to justify an acquisition. In the design and implementation phases of computer utilization, highly informed managerial and technical personnel are required to carry out the project. Still the process is not over; on the part of the user, this issue takes on even more importance. The number of computer users in developing countries who consider the computer to be a status symbol is high. However, there are many cases in which computer systems have not been used at all, or at best, have been used only at the very lowest levels of their capacities. 
As mentioned earlier, many authors have treated the human issue. Mintzberg (1978: 1-23) studies this important issue under the following three headings: "The Formal Information at Fault," "The Organization at Fault," and "The Brain at Fault." In the case of formal information, he argues that the formal information system is too limited, that formal information systems tend to aggregate data (and, as a result, much of the information produced is too general for the manager), that much formal information is received too late, and, finally, that some formal information is unreliable.

In the case of the organization, he levels what are probably his most serious criticisms:

-- organizational objectives are often rigid and dynfunctional and encourage the manager to use inappropriate information;

-- the power and political situations within the organization may cause the manager to ignore or distort information related to overall effectiveness;

-- the nature of his work drives the manager to favor verbal channels and neglect documented sources of information. And finally, about the brain, Mintzberg makes these comments:

-- the manager suffers from cognitive limitations that restrict the amount of information he can consider in complex decision processes;

-- the brain systematically filters information in line with predetermined patterns of experience (and this filtering may be significantly different in different cultures!); 
-- psychological failures and threats further impede the brain's openness to information.

These points which have been made by Mintzberg have widespread implications for the purposes of the present research and will therefore be explored in greater detail in another part of this study.

Dickson and Simmons (1970: 59-71) discuss this issue under the heading "Consequences of Change." They conclude that people resist the new in favor of the old. Change has always been a threat to economic security, status, and interrelationships among people at work. They also state that the resulting behavior may be one of aggression, projection, and/or avoidance. These types of behavior may/may not occur, depending upon the particular position of the affected person in his organization, his own temperament, etc.

Carper (1977: 48-50) treats the human issue similarly to Dickson and Simmons. He points out that people believe the new MIS causes job or role ambiguity, job rigidity, and time pressures.

Most of the authors listed above have come up with solutions to the problem. The consensus seems to be that an MIS design which gets the user involved in all stages of the design and implementation has a good change of overcoming most of the aforementioned problem areas. In each case, the solutions proposed by these authors have something to do with the user. They have all, directly or indirectly, emphasized that a successful MIS must be as responsive as possible to the user's needs. The user's personal and organizational styles must be considered, 
and, more importantly, the user's cognitive map must be emphasized in the MIS design.

Computer-Based Management Information Systems as a Transferred Technology

Technology transfer has a lot to do with the model which is designed in this study. The major element of the model, computer technology, is being transferred from developed countries to developing ones. The particular methods by which this transfer can take place have been studied by authors such as Kathie Priebe (1978: 109-113). While these methods provided an essential body of background information for this study, they are not the project's focus. Rather, this project will be interested in identifying the important variables to be considered in the transferrence.

In reference to the successful transfer of computer technology, Harry Huskey (1978: 256) makes the following points:

- there must be a need;

- technical leadership is required;

- managerial leadership is essential; and

- the necessary resources must be available.

To emphasize the importance of established infrastructure in support of the transferred technology in the recipient country, foley points out:

the problem with technology transfer iies not with the technology itself but within the replication of the environment in which it operates.

(Foley, 1978: 119)

He continues: 
The successfui transfer of technology from one site to multiple locations depends on certain prerequisites being fulfilled. The major prerequisites are:

-- that the administrative environment in the remote sites has evolved to a sufficient degree to where it can raise its performance by accepting centrally developed technology;

-- that the development, maintenance and change to the technology can be managed centrally with a sufficient degree of responsiveness to meet remote site needs;

-- that each remote site has the skill to accurately define requirements of $100 \%$ quality, assure the imported product, and manage the technology;

-- that remote sites have the administrative and technological skills to achieve and maintain commonality in methods, data, information, architecture, and use of technology;

-- that the total administrative needs and their solutions are clearly articulated in an end-point plan and that resources can be directed towards achieving the end point.

(Foley, 1978: 124)

D A Golden (1978: 1-2) mentions still other points involved

in the technology transfer situations:

While the objective of technology transfer is easily defined, the process as a whole is complex and almost defies description. However, some of the basic characteristics of a true transfer should be mentioned:

-- It is a people-oriented phenomenon, and its success depends upon close interrelationships between the donor and the recipient.

-- It demands the existence of a high degree of motivation on the parts of both the donor and the recipient.

-- It is a continuing activity, since technology does not stand still.

-- It is a multifaceted, diversified, and constantly 
changing process with great variations from one industry to another.

-- It requires that the technology gap between the donor and the recipient be of manageable proportions.

-- It is a very costly operation, and, what is worse, most of the cost is hidden.

-- It has little similarity with the dissemination of knowledge or pure science.

-- Buying technology can either be the most useless outlay, or the best possible bargain, depending upon both the ability of the donor to transmit it and the recipient to turn it into a successful enterprise.

Clearly, then, there are many key variables involved in this transferrence. Taking these variables into consideration will greatly enhance the chances of success of the CBMIS.

Project Management as a Tool for Design and Implementation of a CBMIS

Development of a CBMIS involves many people and many activities. It requires an interdisciplinary and interorganizational team that often includes new types of relationships and responsibilities. Project management can smooth this process if it is effectively used.

Thomas Gildersleeve, in his book, Data Processing Project Management (1974), lists several activities involved in the design and implementation of an MIS project. The relationship between the plan, the budget, and the schedule is, he feels, the key element in designing a satisfactory MIS project. He further states that communication and coordination among the people involved is an essential factor; this cooperative spirit can best be achieved by using project management techniques. 
There are some specific techniques which have been used as planning and controlling tools more frequently than other tools in project management. The responsibility matrix, the Gantt chart, and PERT are three such tools.

The Responsibility Matrix. Since, in the development of a CBMIS, many activities are involved, a responsibility matrix can be used to clarify relationships and performance responsibilities. A responsibility matrix shows the participants of the MIS project and documents their degree of involvement in each decision activity.

The Gantt Chart. The Gantt chart is a planning and scheduling tool which graphically shows the different activities involved in a project and the time period anticipated for completing each of them. It is helpful in showing the status of each activity and in identifying those activities which are behind or ahead of schedule.

PERT. (Program Evaluation and Review Technique) is another planning and controlling technique; it uses a network instead of the bar graph (which the Gantt chart employs). PERT focuses on interrelationships among activities and shows those activities which are critical in terms of finishing the project on time.

Many of the problems in the implementation of a CBMIS in developing countries are the result of not using the project management tools. Iran is a case in point. However, the responsible authorities in Iran are becoming aware of this important fact. As Ali Nowtash has stated:

EDP managers in developing countries should make extensive use of project control packages such as PERT and CPM. The use of these systems 
indicates the bottlenecks and red tape in the various government departments.

(Nowtash, 1971: 87)

To emphasize the importance of project management in the implementation of a CBMIS, Henry Lucas points out:

The history of the development of computer software shows many failures. Projects either do not meet their initial design objectives or are implemented weeks or months behind schedule.

(Lucas, 1973: 173-183)

An effective project management must define the goals and objectives of MIS design and the available resources. These will aid in the designing of a satisfactory MIS which will respond to the users' needs on a timely basis.

Cost/Benefit Analysis in the Design and Implementation of a CBMIS

Cost/benefit analysis has always been a difficult task in CBMIS due to the difficulty of estimating the benefit generated by the CBMIS. Most of the benefits produced by computerized systems are intangible. As Leslie King and Edward Schrems conclude, "Costbenefit analysis applies where benefits are quantifiable and cost effectiveness is otherwise" (1978: 20).

However, cost/benefit analysis is one of the tools which enables a decisionmaker to operate manually or to automate his operations. Since the CBMIS is an expensive investment, several considerations should be explored before its acquisition. Computer investment is like any other investment. Consequently, capital budgeting 
such as net present value, pay back period, internal rate of return, and other capital budgeting techniques are applicable. One should consider modifying these techniques where intangible benefits are evident. A computer-based management information system produces (or is supposed to produce) many intangible benefits; these, of course, are difficult to express in monetary terms. But one can attach some monetary value to them, following a cost/benefit procedure. For any investment, the net present cash inflow should be equal to or greater than the present cash outflow. If this is the case, it is an appropriate investment from the cost/benefit point of view.

King and Schrems have a detailed documented list of the costs and benefits of computerized information systems. Two of their lists have been incorporated into this study and appear as Tables VI and VII. There is one significant omission in that material, however: opportunity cost should also be a consideration. Since most of the developing countries have serious problems with foreign currencies, this factor should be weighed heavily. Although an accurate evaluation of opportunity cost is almost impossible, even a rough estimation will provide the decisionmaker with a better view about the automation of his operations. 


\section{TABLE VI}

\section{POSSIBLE INFORMATION SYSTEM BENEFITS}

Benefits from contributions of calculating and printing tasks

Reduction in per-unit costs of calculating and printing (CR)

Improved accuracy in calculating tasks (ER)

Ability to quickly change variables and values in calculation programs (IF)

Greatly increased speed in calculating and printing (IS)

Benefits from contributions to record-keeping tasks

Ability to "automatically" collect and store data for records (CR, IS, ER)

More complete and systematic keeping of records (CR, ER)

Increased capacity for recordkeeping in terms of space and $\cos t(C R)$

Standardization of recordkeeping (CR, IS)

Increase in amount of data that can be stored per record (CR, IS)

Improved security in records storage (ER, CR, MC)

Improved portability of records (IF, CR, IS)

Benefits from contributions to record searching tasks

Faster retrieval of records (IS)

Improved ability to access records from large databases (IF)

Improved ability to change records in databases (IF, CR)

Ability to link sites that need search capability through telecommunications (IF, IS)

Improved ability to create records of records accessed and by whom (ER, MC)

Ability to audit and analyze record searching activity (MC, ER)

Benefits from contributions to system restructuring capability

Ability to simultaneously change entire classes of records (IS, IF, CR)

Ability to move large files of data about (IS, IF)

Ability to create new files by merging aspects of other files (IS, IF)

Benefits from contributions of analysis and simulation capability

Ability to perform complex, simultaneous calculations quickly (IS, IF, ER)

Ability to create simulations of complex phenomena in order to answer "what if?" questions (MC, IF)

Ability to aggregate large amounts of data in various ways useful for planning and decisionmaking (MC, IF)

Benefits from contributions to process and resource control

Reduction of need for manpower in process and resource control (CR)

Improved ability to "fine tune" processes such as assembly lines (CRM, MC, IS, ER)

Improved ability to ma intain continuous monitoring of processes and available resources (MC, ER, IF)

* $C R=$ Cost reduction or avoidance; ER - Error reduction; IF = Increased speed of activiity; $M C=$ Improvement in management
planning or control 
TABLE VII

POSSIBLE INFORMATION SYSTEMS COSTS

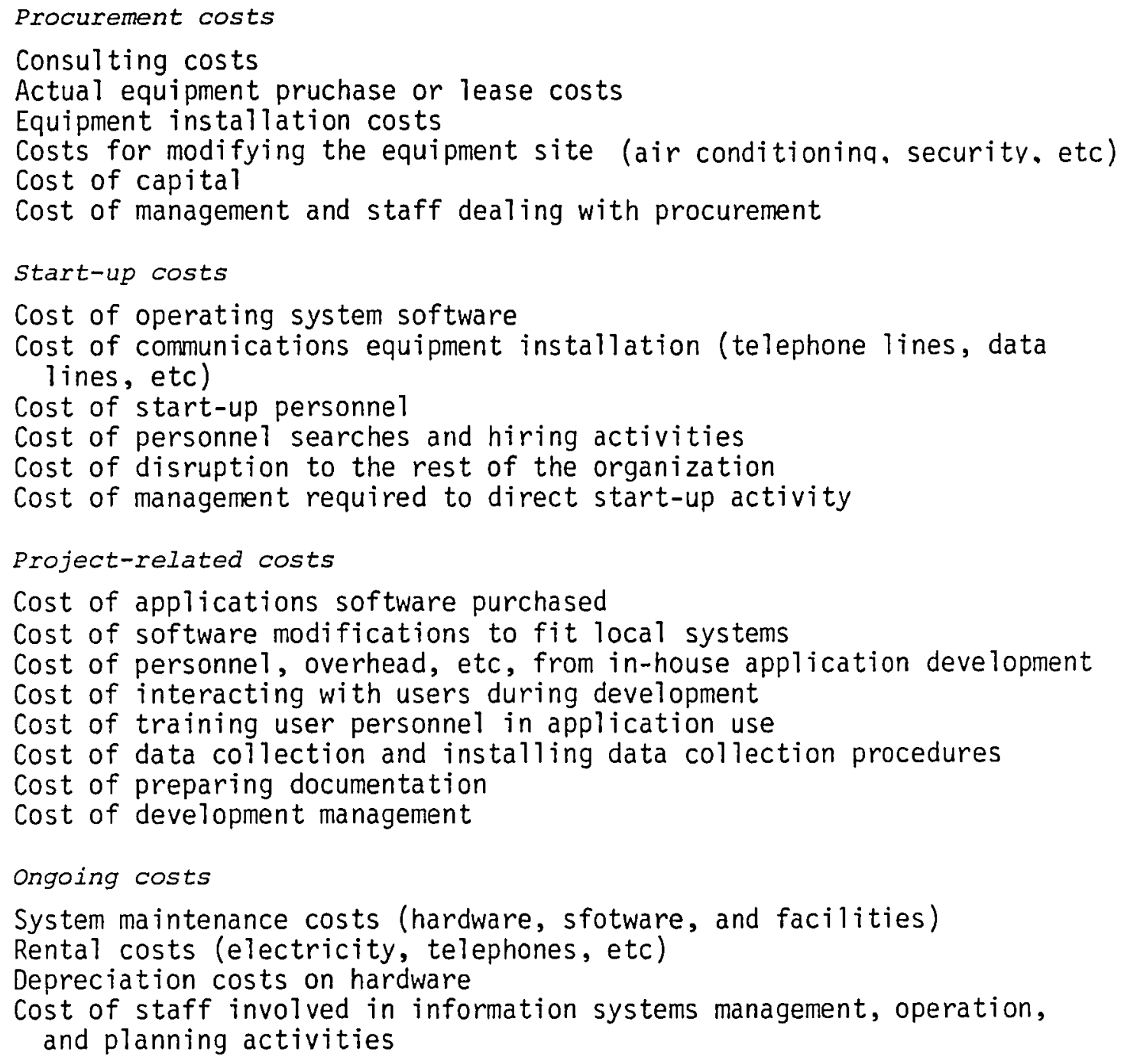

Source: (King, 1973: 24) 
The Future of the CBMIS and Its Implications for Developing Countries

The following contain discussions of the future of the CBMIS in developing countries: (Davis, 1974: 468-470), (Huskey, 1978: 258), (Frienteib, 1978: 557-559), (A1ter, 1980: 183-193), (Lucas, 1973: 252261), (Dock, 1981: 453-456), (Spencer, 1978: 376-386), (Edwards, 1979: 341-353), and (She 11y, 1380: 134-138).

Although different authors have emphasized different issues with regard to the future of the CBMIS, nearly all of them agree on the following points:

1. The cost of labor will continue to increase. This means that computers will likely play even more important roles in future societies than they do in today's.

2. Hardware technology will continue to improve. Furthermore, the price of storage and retrieval of information will continue to decrease. Table VIII demonstrates the overall development of hardware technology.

3. Software technology will continue to improve. In comparing the development of hardware and software technologies, one can see that hardware technology has improved at a much faster rate than software technology. Figure 3 shows the hardware/software cost trends. A comparison of today's COBOL language with that of 15 years ago does not produce much of 
a difference; therefore, in software technology, there is room for improvement. Data base management systems (DBMS), structured programing, and word processing will continue to improve, and their usage will become more common.

TABLE VIII

OVERALL DEVELOPMENT OF HARDWARE TECHNOLOGY

TUAE FRAMEWORK

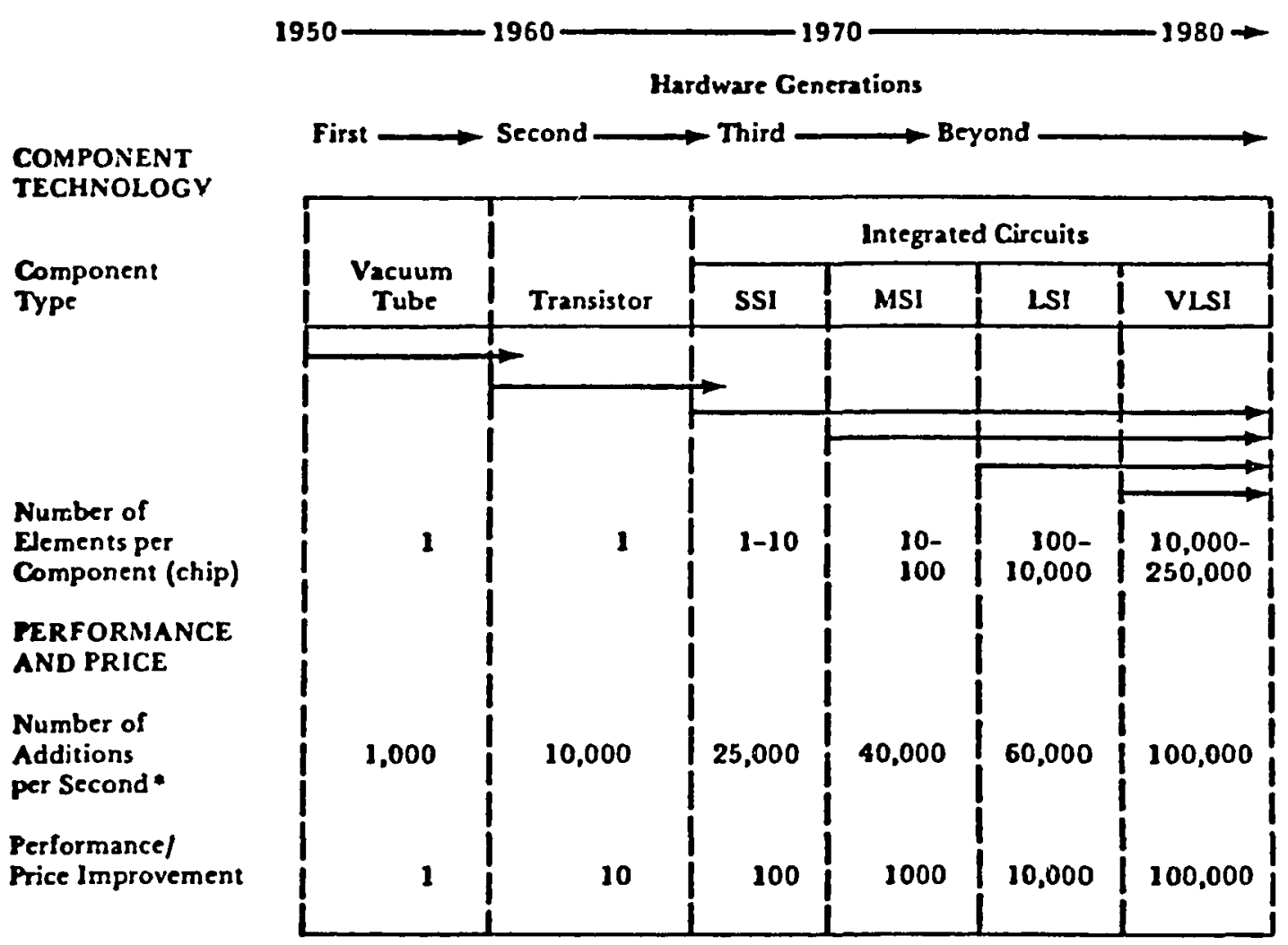

- Five digit decimal mumber addition. 


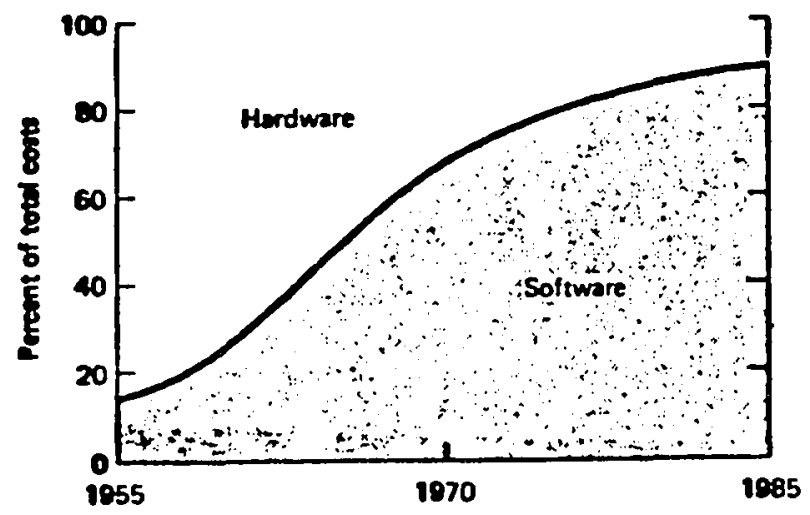

Figure 3. Hardware/Software Cost Trends

Source: (Boehm, 1974: 75)

4. Improvement in telecomunication. In the future there will likely be inc d data base sharing with more reliability and probably more security. Electronic mail and electronic newspapers will become common.

5. New applications of the computer will become viable due to the decreasing costs of purchasing and maintaining them.

6. People worldwide will become more aware of computers. As Couger and McFadden point out, "over $50 \%$ of the US labor force is now involved in information occupations-jobs that create, manipulate or use information or work with technologies which do these things" (1981: 3). 
SUMMARY

So, what does all this mean to developing countries? According to Harry Huskey (1978: 256),

for developing countries this means that initial computer activity should be in the education area so that they can stay abreast in a quickly changing environment.

Boehm and Dexter indicate that

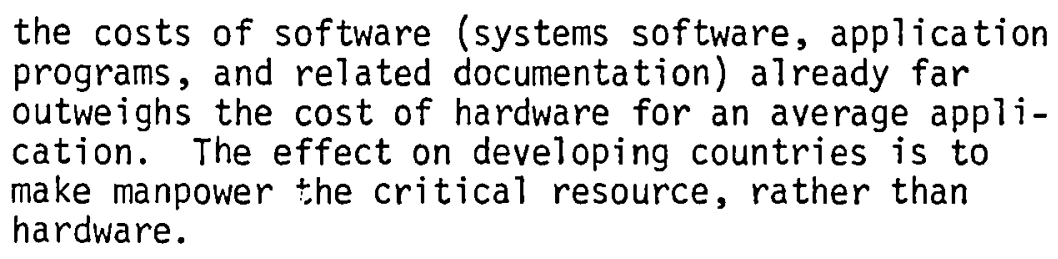

(1974: 75)

A careful study of the trends of growth in computer technology leads one to the following conclusions:

First, the ever-decreasing cost of hardware technology will make the computer a more affordable commodity for developing countries. These countries will, therefore, be in a better position to take advantage of this opportunity.

Secondly, developing countries, in their computer utilization, should consider this growth in order to be more adaptable to further development. Modular design is one technique which will likely help preserve adaptability.

Thirdly, to take full advantage of computer technology, developing countries should define their requirements for computer acquisition. This definition will be the major objective of the present research project. 


\section{CHAPTER III}

\section{DEVELOPMENT OF A DESCRIPTIVE MODEL FOR A COMPUTER-BASED MANAGEMENT INFORMATION SYSTEM (CBMIS) FOR DEVELOPING COUNTRIES}

This chapter presents and develops the descriptive model which is the focal point of the current research project. As background material, alternative models by different authors are presented as well. Finally, the building blocks of the proposed model are examined; these blocks include the stage development of the CBMIS, different phases in the model, and the essential variables involved in each phase.

GENERAL MODELS FOR A COMPUTER-BASED MANAGEMENT INFORMATION SYSTEM

Henry Lucas has devised a general model for an information system (shown on the following page as Figure 4). As this figure demonstrates, Lucas identifies two types of information systems in an organization: the formal and the informal. He maintains that:

a formal system has a prescribed set of rules and procedures for gathering, analyzing, and disseminating data. An informal system is more concerned with highly variable information that is not collected as a matter of routine; such systems tend to develop naturally within the organization.

$$
\text { (Lucas, 1973: 5) }
$$

As Figure 4 shows (see page 44), computer technology has heen applied mainly to processing data in a formal information sustem. Based upon this figure, one can conclude that Lucas recognizes 


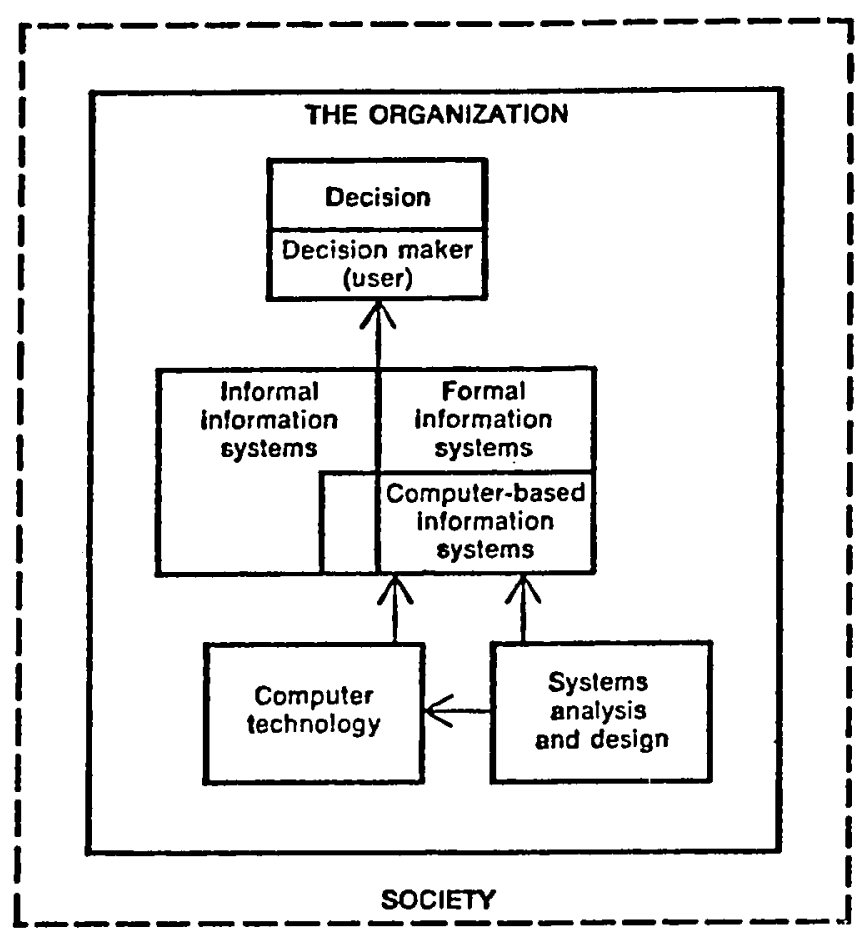

\section{Figure 4. Information Systems in Context}

Source: (Lucas, 1973: 4)

computer technology, systems analysis and design, and the user as

the major components of an information system. In Figure 5 (presented

on $\mathrm{p} 45$ ), Lucas distinguishes the characteristics of information for

each level of the organization, and he defines the role of an information system to be the collection and interpretation of data.

Elias Awad presents a somewhat different model from Lucas's (although there are also striking similarities). The Awad model is presented on page 46 as Figure 6. As this figure shows, Awad defines 


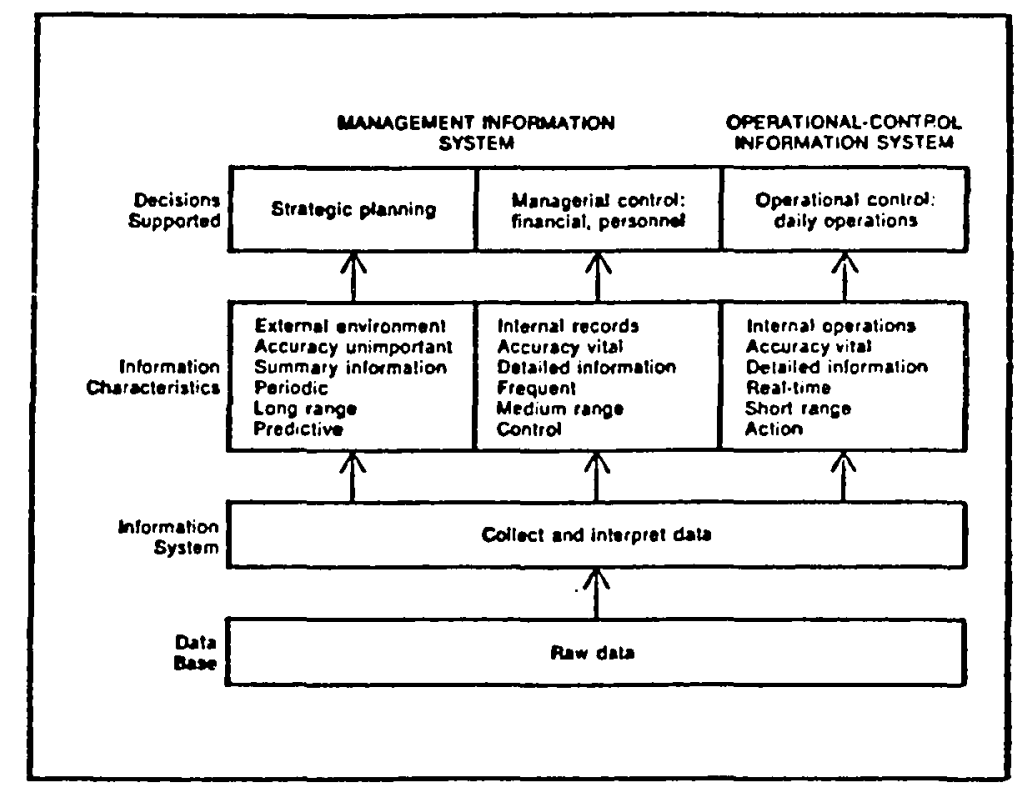

Figure 5. An Information System Framework

Source: (Lucas, 1973: 15)

the output of an information system as management information. His model demonstrates a continuous interaction between the MIS and the manager's functions (e.g., planning, organizing, etc). Figure 6 also shows that Awad includes the data base as an inherent part of an MIS. John Burch et al present still a different model for a CBMIS. Their model is represented in Figure 7 on page 47 . The major components of this CBMIS are human, software, hardware, and data base. These authors present a more detailed discussion than most on information processing operations. They are convinced that a well organized integration of the major components of a CBMIS will provide managers with all the necessary information for decisionmaking activities. A 


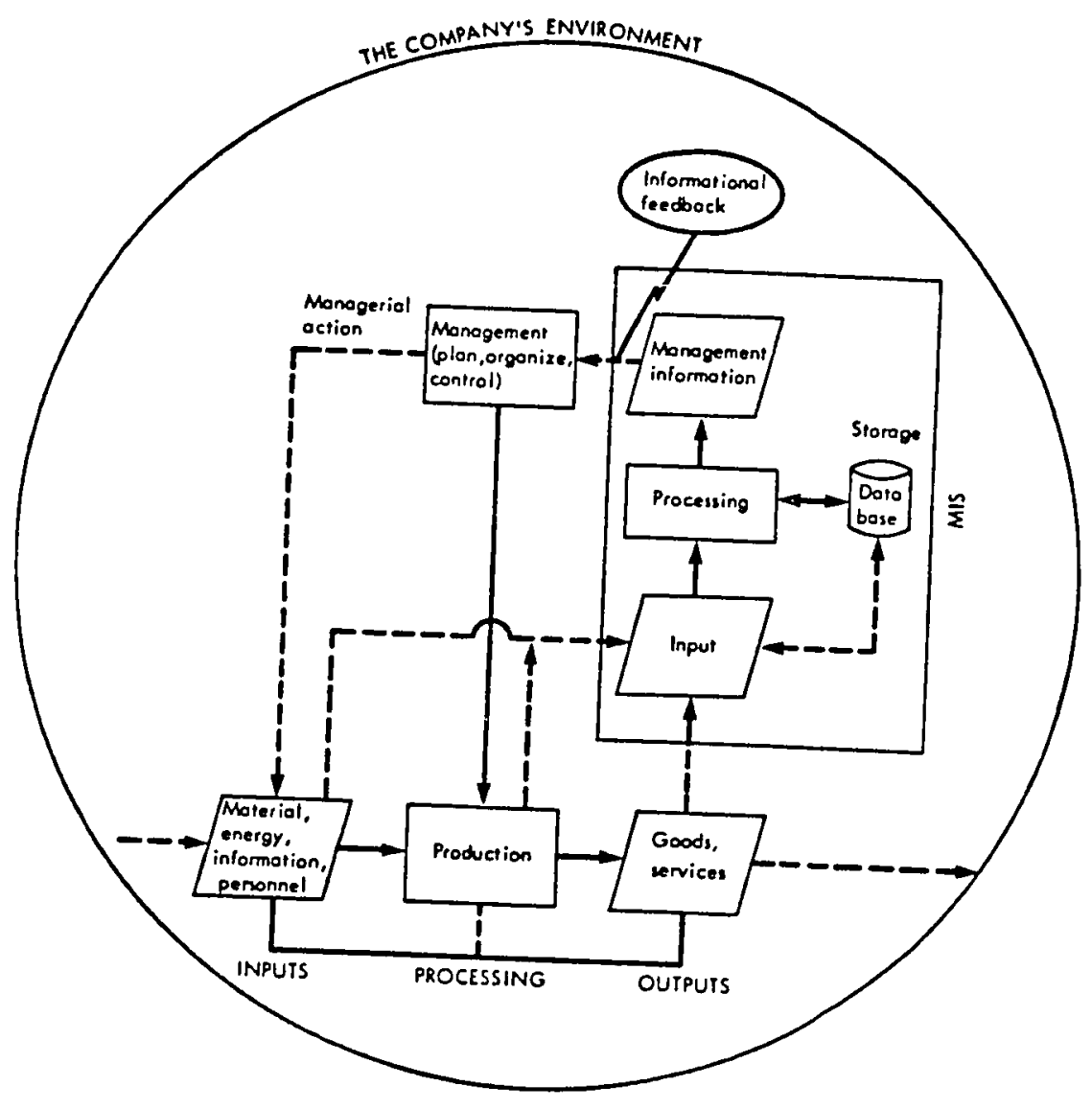

Figure 6. A General Management Information System Mode1

Source: (Awad, 1979: 21)

close look at this figure indicates that information processing activities must include a variety of tasks, of which capturing the raw data is only one.

Ultimately, these authors present a comprehensive chart which shows clearly the relationship between the system design methodology 


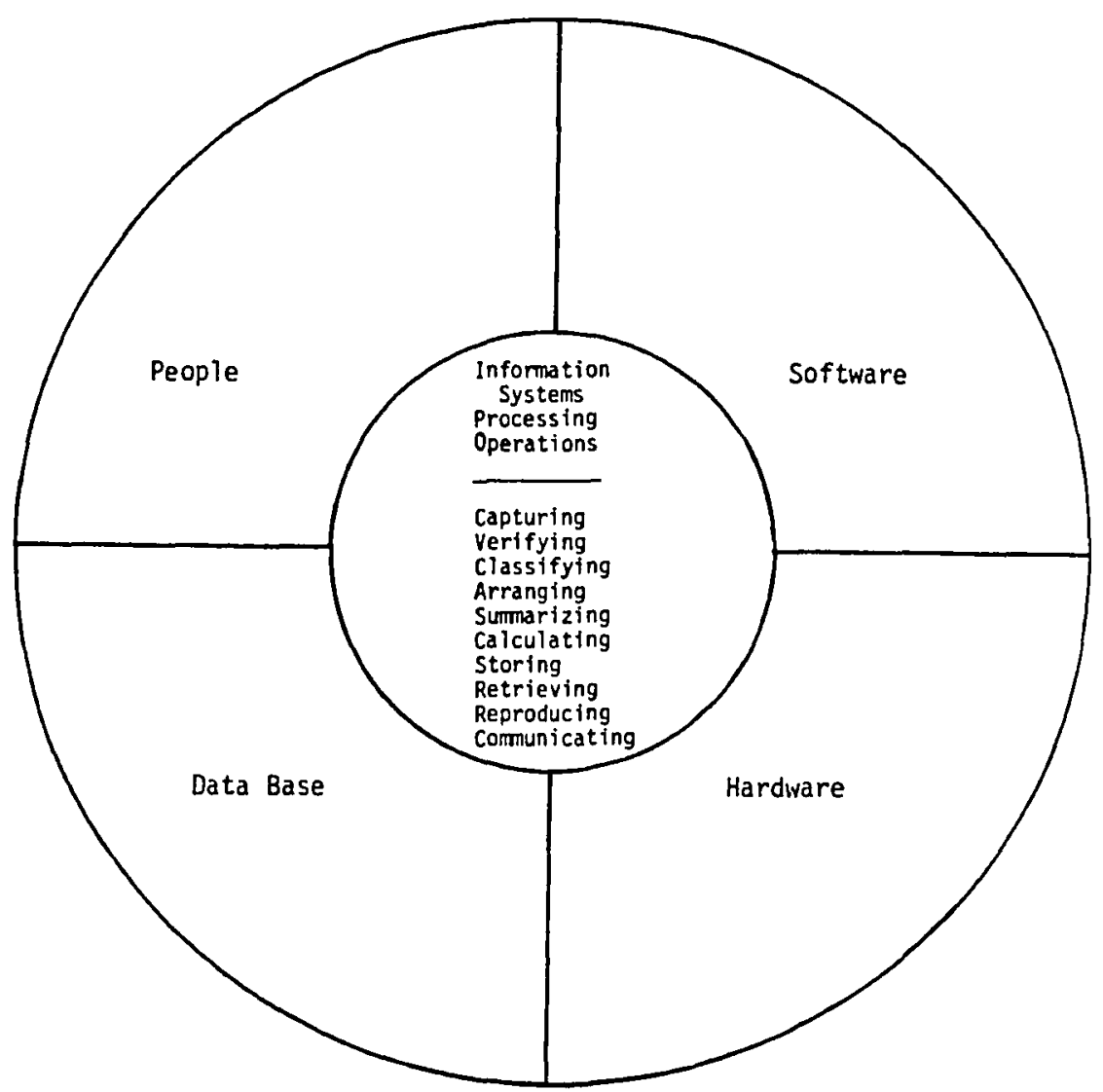

Figure 7. Basic Components of a Computer-Based Information System Source: (Burch et a 1, 1979: 75)

and their general model for a CBMIS. This chart is represented on page 48 as Figure 8 . This chart overviews all the phases these authors beTieve to be involved in systems analysis and design.

While these models provided a rich theoretical background for the development of the model to be used in this study, they were not entirely relevant, either singularly or by composite, to the study at hand. As will be seen later, all these models exclude several very important variables which are crucial to a CBMIS for developing countries. 


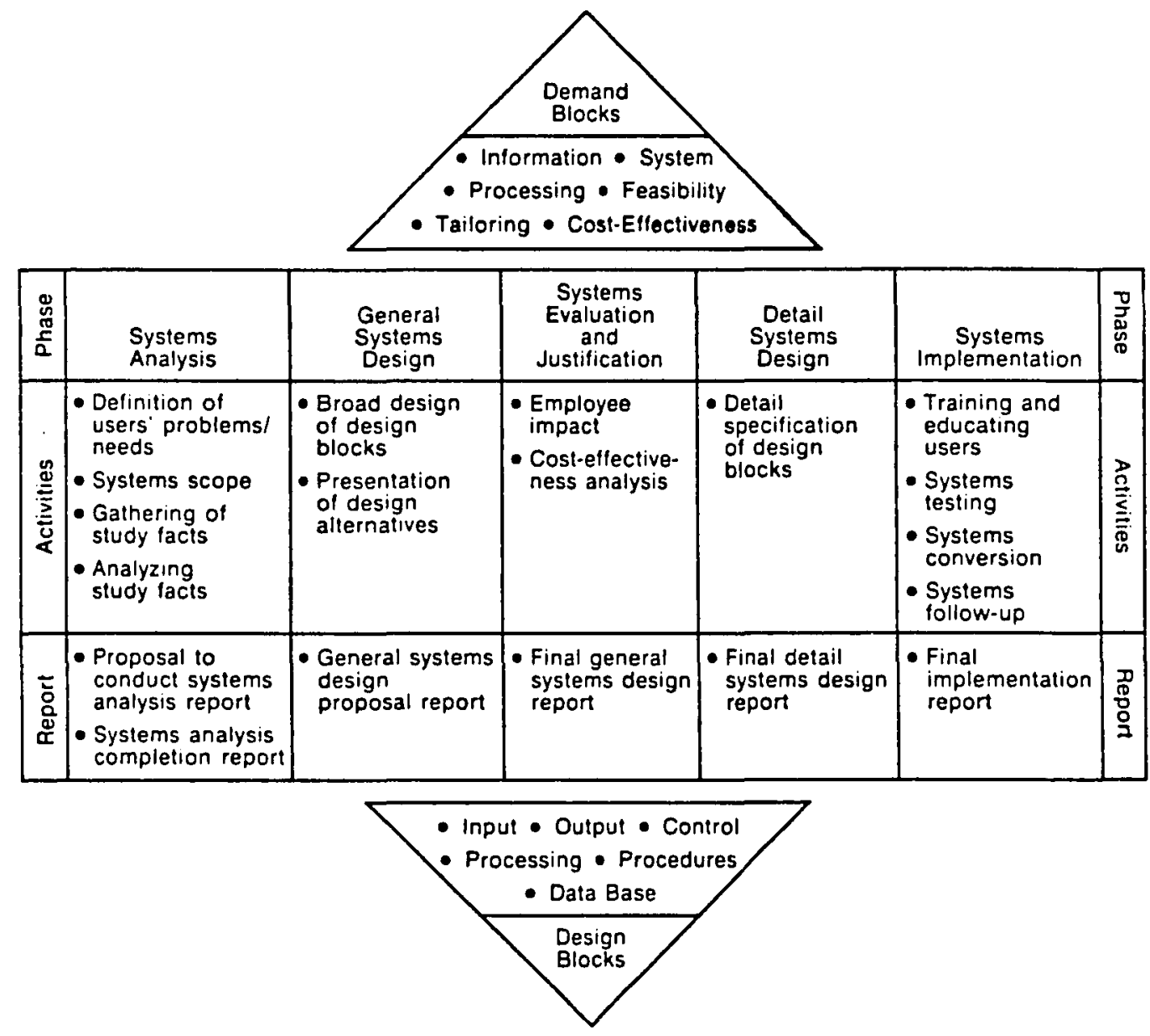

Figure 8. The Systems Development Methodology and Its Relationship to the Information Systems Building Blocks

Source: (Burch et al, 1979:248)

OTHER WORK RELATIIG TO THE PROPOSED CBMIS

The closest work done relating to the present study is that of A M M Kheir (1979), which is a doctoral dissertation completed at 
George Washington University. Kheir made an extensive study, guided by Reinl's normative reference model, with the result being the development of an acceptable framework for a CBMIS for developing countries. He incorporated the experience of the Bureau of Census into his model and had the model verified and revised by a panel of experts to suit the environment of a developing country such as the Sudan. Tables IX and $X$ on the following pages show the results of both the Riehl and the Kheir models.

Unhappily, the Kheir model focuses almost exclusively on variables which relate onlv to the desian and implementation of a CBMIS. thereby omitting several others of equal or even greater importance. As was shown in Chapter I, many other factors have a direct bearing on the success or failure of a CBMIS in a developing country, and these factors simply cannot be ignored.

The model proposed in this study incorporates those additional variables--indeed, it attempts to cover the whole scope of relevant variables--and additionally presents a series of predictive equations which can be utilized to predetermine the likelihood of success in various phases of the acquisition, design, and implementation of a CBMIS .

Despite its weaknesses, the Kheir model served as a useful starting point for the work accomplished in this study. 
TABLE IX

SUMMARY OF RIEHL'S NORMATIVE-REFERENCE MODEL

STRATEGIC PLANNING PRINCIPLES

Master Systems Planning

Management Involvement

Master Systems Plan

Planning Coordination

Provision for Change

PROJECT PLANNING PRINCIPLES

System Development Life Cycle

Project Proposal

Feasibility Study

Economic Analysis

Project Management

Project Plan

Project Control Reporting

Estimation Process

Change Control

System Development Standards

Cost Allocation

PROJECT CONTROL PRINCIPLES

User-Management Control

Information Requirements Definition

Functiona? Specifications

Performance Criteria

Detailed Design Specifications

System Implementation

System Testing

Conversion

Post Implementation Audit

ORGANIZATIONAL BEHAVIOR CONSIDERATION PRINCIPLE

User Acceptance

Source: (Kheir, 1979: 33) 
TABLE $X$

A CONCEPTUAL MODEL FOR THE COMPUTER-BASED INFORMATION SYSTEM FOR THE DEPT OF STATISTICS, SUDAN

I. Strategic Planning
A. Master System Planning
B. Master System Plan
C. Provision for Change
D. Management Involvement
E. Planning Coordination

II. Project Mangement, Planning and Coordination
A. Feasibility Study/Project Proposal
B. Functional Specifications
C. Performance Criteria
D. System Development Life Cycle
E. Project Management and Control
F. Estimation Resources (all resources including cost allocation)
G. Systems Development Standards
H. System Testing and Conversion
I. Post Implementation Audit

III. Behavioral Considerations
A. Management Involvement
B. Motivation Factors
C. User Participation
D. Awareness of User Attitudes
E. Flow of Communications

Source: (Kheir, 1979: 145) 
DEVELOPMENTAL PHASES OF THE PROPOSED CBMIS

For the effective and efficient utilization of a CBMIS in a developing country, three phases must be carefully studied: the acquisition phase, the design phase, and the implementation phase. In this mode1, a fourth phase--the operational phase--has been added; its purpose is to demonstrate how carefully the other three have been examined. Figure 9 , below, represents these relationships schematically.

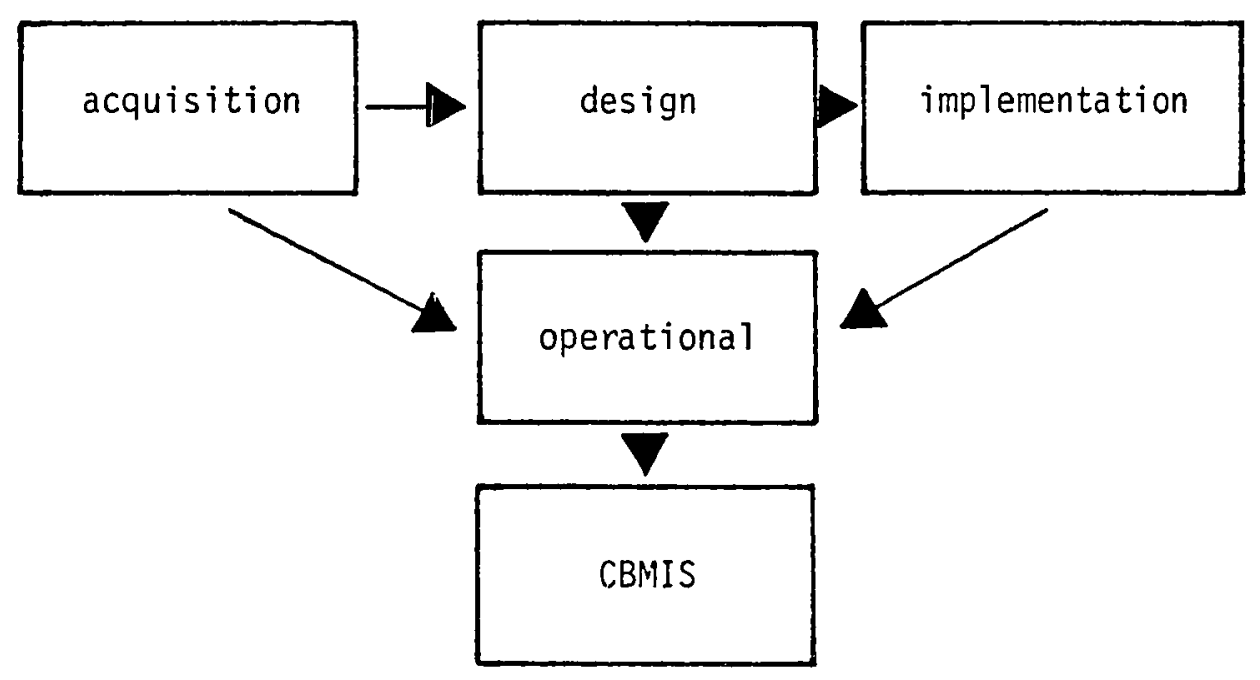

Figure 9. The Structural Components of the Proposed CEMIS

The acquisition phase incorporates the most important variables which have either a direct or an indirect impact on the future success of the CBMIS in a developing country. This phase can be considered the most important on in that its proper employment, coupled with an 
accurate identification of the significant variables, will help a developing country to identify the basic requirements and at the same time see the consequences of a particular acquisition. Careful consideration of the appropriate variables in this phase may additionally assist a particular country in deciding whether or not employment of computer technology is suitable.

In the design phase, another series of variables which have either direct or indirect impact on the effectiveness and efficiency of the design and utilization of a CBMIS will be introduced. In this phase, the assumption is that a particular developing nation has carefully monitored the variables in the first phase and there are only minimal problems in the acquisition of computer technology. During the implementation phase, the project is physically implemented. Here, ideas are transferred from paper to the actual situation.

The operational phase of the proposed model simply describes the performance of the CBMIS. This phase demonstrates the degree to which the variables in the first three phases have been considered.

It cannot be emphasized too strongly that the key to successful employment of this model can be found in a close, critical examination of the variables involved. Such carefur scrutiny not only increases the chances of success for the CBMIS, but minimizes existing problems which developing countries have indicated they are experiencing.

The following pages will overview the essential variables included in each model phase. 
The Acquisition Phase

As mentioned earlier, this phase is the starting point for the employment of the CBMIS. This phase highlights the basic requirements for the technology transfer and indicates the consequences of the utilization of computers in developing nations. Figure 10 illustrates the basic variables incorporated in this phase.

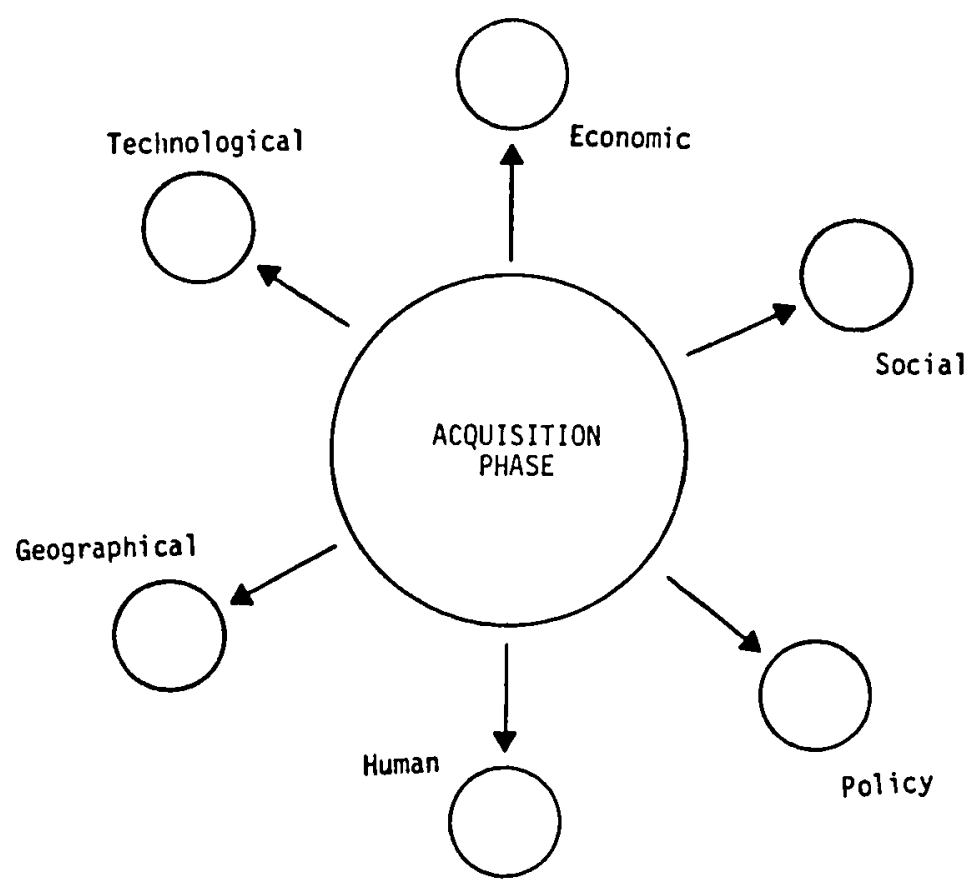

Figure 10. The Acquisition Phase of the Proposed CBMIS

The Economic Dimension. The economic dimension of this model identifies all the costs and benefits involved in the employment of the CBMIS. As mentioned in Chapter II, probably the most comprehensive list of costs and benefits has been presented by $\mathrm{J}$ King-Leslie and $E \mathrm{~L}$ Schrems. The following list of economic considerations used in this 
model is based on their work. It should be remembered, however, that the single greatest benefit to developing nations resulting from automation is the creation of a new set of decisionmaking tools for the enhancement of their economic and social development (Simmons, 1972: 2; Sexton, 1972: 9). Such a benefit is, of course, long-term and one which does not lend itself readily to quantification.

The economic considerations, then, are the following:

-- consulting costs

-- equipment purchase or lease costs

-- equipment installation costs

-- physical planning costs (air conditioning, remodeling, etc)

-- cost of capital

-- cost of software

-- cost of communication devices

-- personnel costs

-- training costs

-- research and development costs

-- documentation costs

-- maintenance costs

-- depreciation costs

-- opportunity costs

-- availability of foreign exchange

A detailed cost/benefit analysis of computer utilization will enable a particular developing nation to justify this technology transfer 
from an economic point of view. Opportunity costs in particular are difficult to estimate; however, an accurate determination of these costs is very significant in terms of the ultimate decision a country makes regarding whether or not to automate.

The Social Dimension. Since developing countries are the importers of computer technology, the social dimension of the CBMIS will be rather different than it would be for developed countries. This topic has been written about extensively (see, for example, Giannoni (1972: 300-302), Danet (1971: 31-33), Elizur (1971: 34-35) and Mumford (1978: 239-244)), and the major authors tend to be in agreement about the elements comprising this dimension. The following list takes into account the writings mentioned immediately above:

-- unemployment for unskilled labor

-- the privacy problem

-- possible creation of unnecessary complexities

- computer fraud

-- creation of a new working class (which may cause turnover in the organization)

-- conflict between foreign and domestic consultants (higher pay for foreign consultants)

-- social cost of retraining (what to do with traditional bookkeepers)

-- reduction of employee's communication at work

-- possible effect on population geographical distribution (moving from one place to another)

-- possible effect on human communication outside work (i.e., 
conditioning people to prefer playing computer games rather than interacting socialiy)

A careful investigation of the social issues involved in the employment of computer technology will assist the decisionmakers in finding remedies for these problems. Although some of these social issues are an inherent part of the automation process, still, with careful planning, the negative aspects can be minimized.

The Policy Dimension. This dimension includes a variety of variables. Aspects of it may interface with several other national policies in a particular developing nation. The major considerations of this dimension are as follows:

-- acquisition criteria

-- employment of standardization

-- acquisition constraints

-- existence of information centers

-- existence of a system master plan

-- centralization/decentralization issues

-- number of training centers

These variables are important enough and diversified enough so that a brief statement must be made about each individually:

Acquisition Criteria: Computers have been acquired by different countries for different reasons. Some of the reasons are: complexity of organizational activities, decisions made by other organizations, economic factors, improvement over the control of operations and future planning, increased accuracy of information, capacity for future 
expansion, prestige, etc. Chapter IV of this study discusses these different reasons in detail.

Employment of Standardization: There are both advantages and disadvantages to the employment of standardization in hardware and software selection, in data collection, and in data transmission for developing countries. Bonn (1971: 278-296) and Brandon (1953) have both treated this subject in depth, as have others. The Brandon work in particular points out problems associated with standardization. And aithough his cautions are valid, this study chooses to treat standardization as a benefit, if it is effectively employed, in the case of developing nations. Some of the unique advantages of standardization include: an increase in experience sharing among various installations, an improvement in data migration from installation to installation, an improvement in the level of cooperation and coordination among the centers, an improvement in the adaptability of the present CBMIS to the growing body of technology, and, finally, a belief that standardization may make future computer acquisition an easier task.

Acquisition Constraints: Some of the developing countries studied in this research project have expressed difficulties in the physical acquisition of computer technology (India and Colombia are prime examples). These difficulties include high taxes, tariffs, and import duties and inefficient transportation. Clearly, these kinds of restrictions make the computer a much less affordable comodity; they also may delay the utilization of the CBMIS. Creation of a central office for coordination among the computer installations and central 
government agencies may help to minimize the above-mentioned problems.

\section{Existence of Information Centers: An examination of} the computer status in several developing countries does not show clearly that information centers exist for advising users. The possible lack of such centers may result in buyers' making inappropriate investments. Such centers are invaluable for disseminating information about prices, new developments, new types of applications, characteristics of different systems, etc. They might also garner information from books, articles, professional societies, trade publications, conferences, and the like for users' benefit. Certainly, they would be of utmost importance in eliminating or reducing the duplication of mistakes among users. So it is critical to know whether such centers exist in a particular country, and if so, how effective the centers are in assisting in the above-mentioned ways.

\section{Existence of a Master Systems Plan: This aspect of the} policy dimension is essential in terms of helping a particular nation assess $i t s$ needs and set up its priorities. As E M Shay has pointed out:

The Master Systems Plan (MSP) first and foremost is a plan: it is not a specification for a system design. Its purpose is twofold. First, it tells the systems manager (indeed all management) which system should be worked on next. Second, it describes the relationship of that system to all other systems which are currently operational, being implemented, or have been planned for possible development.

(Shay, 1975: 514)

In the particular case of developing nations, the Master System Plan should go beyond Shay's definition. It would be better for developing 
nations to first define their priorities, goals, and objectives. Only after a careful definition of each of these factors should the computer be brought in. Bringing in the computer first and deciding what to do with it next is a great mistake which many developing countries have made in the past.

The MSP for developing countries should include the following: factors:

-- annual requirements of computer technology

-- future requirements of computer technology

- cost estimation

-- staffing projections

-- a detailed statement of system development standards

All phases involved in the proposed model will interact together through the Master System Plan. Careful preparation of the MSP will likely raise the interesting question of "Is the computer really needed?"

Centralization vs Decentralization Issues: The issue of whether the CBMIS should be centralized or decentralized has been debated widely in the literature. Une particularly cogent discussion is presented by A G Mollegaard (1972: 494-497). Traditionally, most developing countries have chosen to operate on a centralized basis. Probably the economy of scale in hardware acquisition has been a determining factor in this method of operation. In other cases, political motivations have had a great deal to do with the decision. A detailed analysis of the motivations behind these choices is beyond the scope of this project; suffice it to say that developing countries 
should carefully examine the centralization/decentralization issue (relative advantages/disadvantages of each was presented in Chapter II). Decentralized operations with centralized control may be the most appropriate policy for developing nations.

Number of Training Centers. Lack of qualified data processing personnel and a dearth of training centers have been a universal problem in most (if not all) of the developing countries. The significance of this issue has been discussed by several authors, notably Mead. (1978: 665-671), Sexton (1972: 10), Thomson (1972: 947949), Lucena (1974: 376-383), Blaxter (1971: 89-100), and Finerman (1971: 112-123). The majority of these countries have had severe problems in staffing their computer installations. Figures on Iran, for example, show that computer utilization has grown at a much faster rate than has the number of trained data processing personnel. The lack of qualified personnel has forced many of these countries (for examnle, Ethiopia, Brazil, and Turkey) either to hire foreign consultants (at very high salary rates) or to run the computer installations at less than optimum capacity. Additionally, the employment of foreign consultants has caused turnover problems in many of these countries. Higher salaries and better working conditions are the two major factors involved in the turnover problem. To avoid such problems, the MSP should be re-examined, and requirements and existing resources should be re-evaluated.

The Human Dimension. As mentioned above, the shortage of qualified data processing personnel is a universal problem in developing countries. However, it is not only the number of qualified people 
which is at issue; it is also the level of their training, their awareness, and their willingness to cooperate.

For the efficient and effective utilization of a CBMIS, the expertise of the following staff members is required:

-- decisionmaker managers

-- user manager

-- analyst programmer

-- systems designer

-- data collection expert

-- hardware engineer

-- software engineer

-- systems programmer

-- regular programmer

-- technician

-- input/output coordinator

-- peripheral equipment operator

-- key punch operator

A few of the developing countries have had some success in the training of the last three groups. However, in general, the shortage of qualified personnel remains a serious problem. Before bringing in the computer, these needs should be evaluated and appropriate actions taken for meeting the needs.

The human dimension of the proposed model does not limit itself to the number of data processing personnel required. User and top management involvement in all phases of the acquisition, design, and implementation of the computer is an equally important consideration. 
Involvement of these categories of staff members greatly increases the chances of success of the CBMIS.

The Geographical Dimension. The geographical dimension identifies the variables which should be considered in choosing a particular manufacturer or developed country as the exporter of the computer technology. This dimension encompasses a variety of variables such as the following:

-- availability of the maintenance personnel

-- availability of the replacement parts

-- availability of a backup for the exporter

-- the magnitude of the technological gap between the exporter and the recipient country

Consideration of the first three factors in this dimension is a straightforward process. However, the fourth factor raises a knotty issue: some studies have shown that the smaller the technological gap between the donor and the recipient, the higher the chances of success will be. One such study was performed by A K M Haq (1979). D A Golden, in his general guidelines for technology transfer from developed to developing countries (1978:2), comes to a similar conclusion: "It \{the successful transfer of technology\} requires that the technological gap between the donor and the recipient be of manageable proportions." These considerations become even more complicated if the choice of manufacturer has been made on a strictly or largely political basis. While a detailed discussion of these elements is outside the aims of this study, it is essential that the decisionmaker look carefully at these issues for they may provide some interesting 
a)ternatives in terms of the choice of an exporter for the computer technology.

The Technological Dimension. This dimension identifies the basic technological requirements for the utilization of the CBMIS. Most of the developing countries studied in this project have had severe problems with the technological requirements of the CBMIS. The technological dimension may be summarized as follows:

-- existence of communication technology

-- existence of air conditioning technology

-- existence of a specially adapted housing structure

-- existence of reliable voltage

A final consideration in terms of the technological dimension is the suitability of a particular information system for automation. Obviously, not all information systems have the same suitability. For example, accounting and production information systems are considerably easier to automate than marketing information systems. This factor is referred to as the "technical feasibility" factor and is of prime importance in the employment of a CBMIS.

The Design Phase

This phase of the model identifies a series of variables which have a direct bearing on the effectiveness and efficiency of a CBMIS. The general framework for this phase has been adapted from a model presented by Dr George Lendaris* in his SySc 573 course at Portland

Dr Lendaris includes context, environment, input, selector, data base, massager, output, and boundary in his model. 
State University, Portland, Oregon. His model has been modified for the purposes of this study to increase its suitability for the particular environment of developing nations. Variables which have been incorporated into the proposed model are shown in Figure 11. They are briefly discussed below.

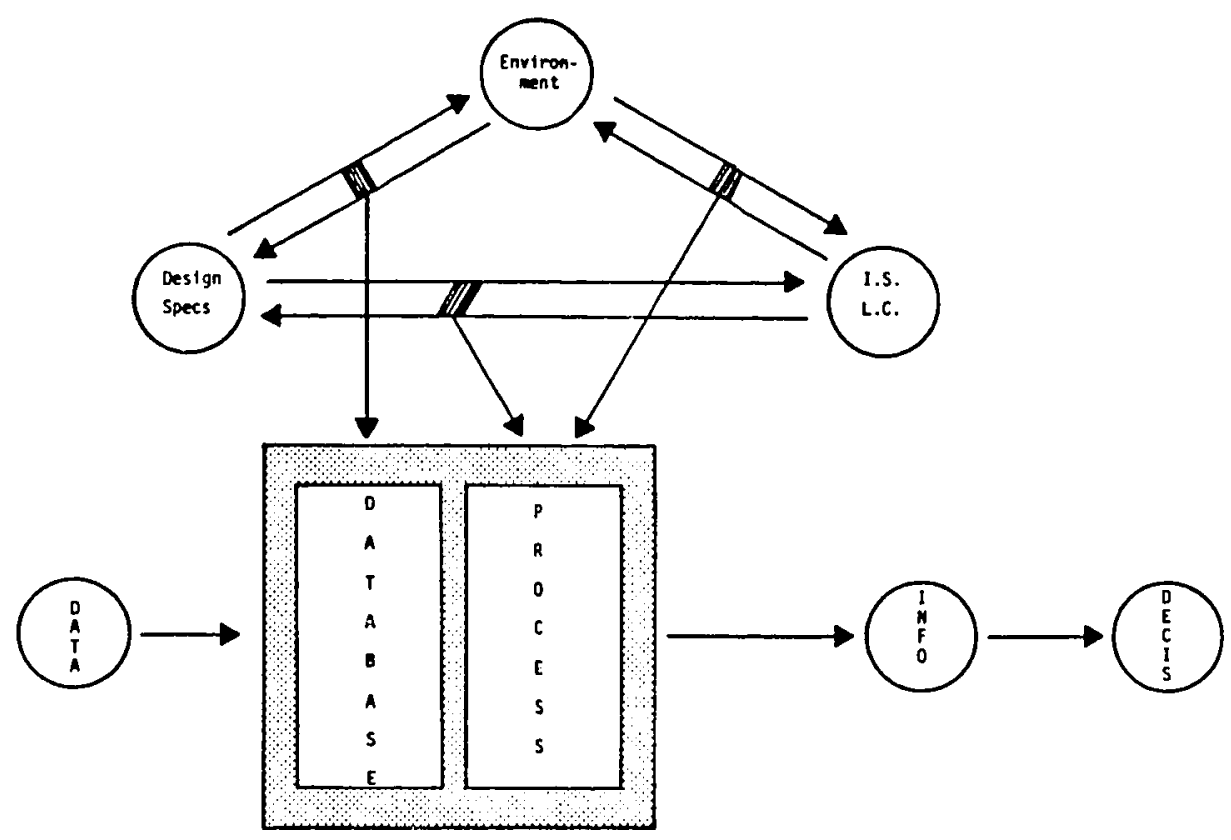

Figure 11. The Design Phase of the Proposed CBMIS

The Information System Life Cycle (ISLC). The information system

life cycle has been fully discussed by many authors (see, for instance, (Grad, 1979: 16-27), (Davis, 1974: 413-419), Eurch, 1979: 26-35), and (Lucas, 1978: 219-232)). Berch et al have neatly summarized the information system life cycle in Figure 12 on the following page. As it appears there, it consists of five major phases, with the major related activities from problem definition to systems followup detajled in the appropriate phase. 


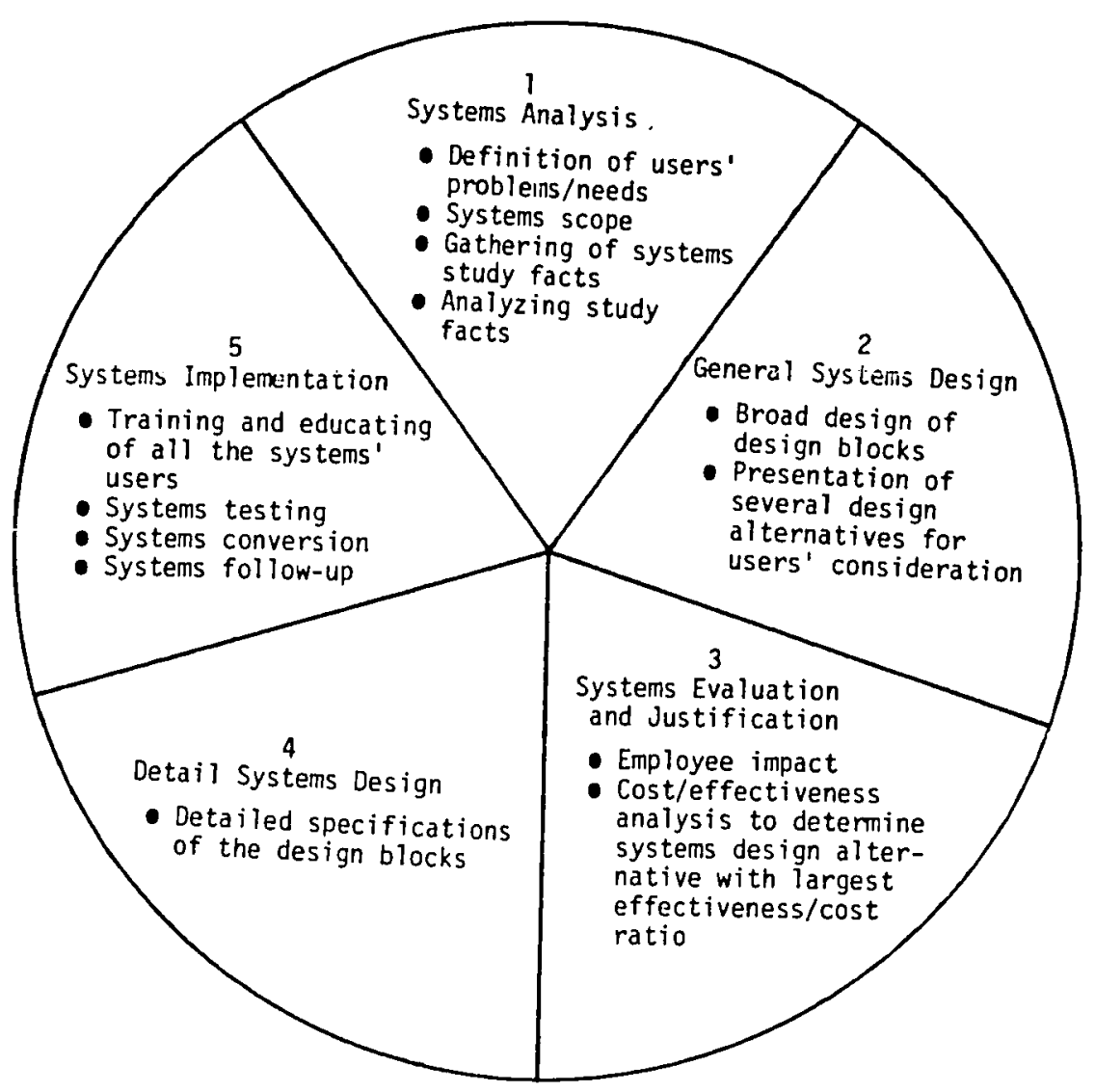

Figure 12. The Systems Development Life Cycle Showing Five Major Phases and the Major Activities Associated With Each

Source: (Burch, 1979: 32)

Lucas has expressed his view about the systems life cycle somewhat differently (albeit with many similarities). His view appears as Table XI on the following page. Taking both these views into account (as well as others mentioned briefly above), it appears that the well-defined information systems life cycle should include the following: 


\section{TABLE XI}

\section{THE SYSTEMS LIFE CYCLE}

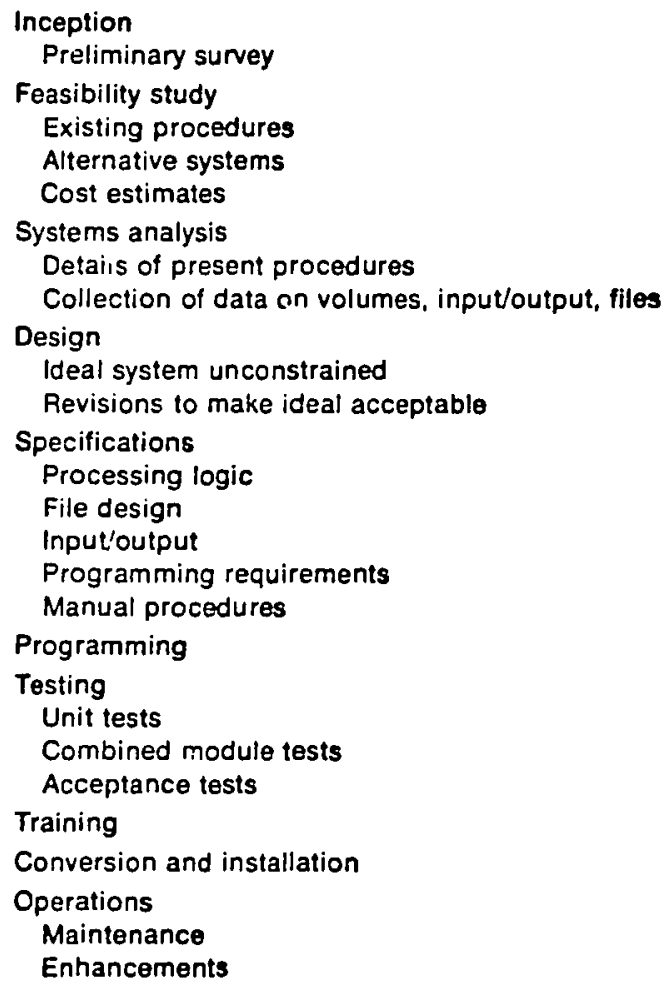

Source: (Lucas, 1978: 220)

-- problem definition: is the objective of automation quite clear?

-- manual system considerations: is there a debugged manual system for automation?

-- user needs: are the user needs well defined?

-- types and characteristics of the particular information to be automated 
-- system scope (boundary considerations): are the desired operating characteristics of the system defined?

In short, the information system life cycle is a macro view of the problem and the system which intends to solve it.

Environment. The environment of the CBMIS includes all the variables and factors which have something to do with the present and future success of the computerized system. A CBMIS could have many different environments, the most relevant of which (for this particular study) is shown below as Figure 13. Of course, other environments are possible, depending upon the particular situation for which a CBMIS is being designed.

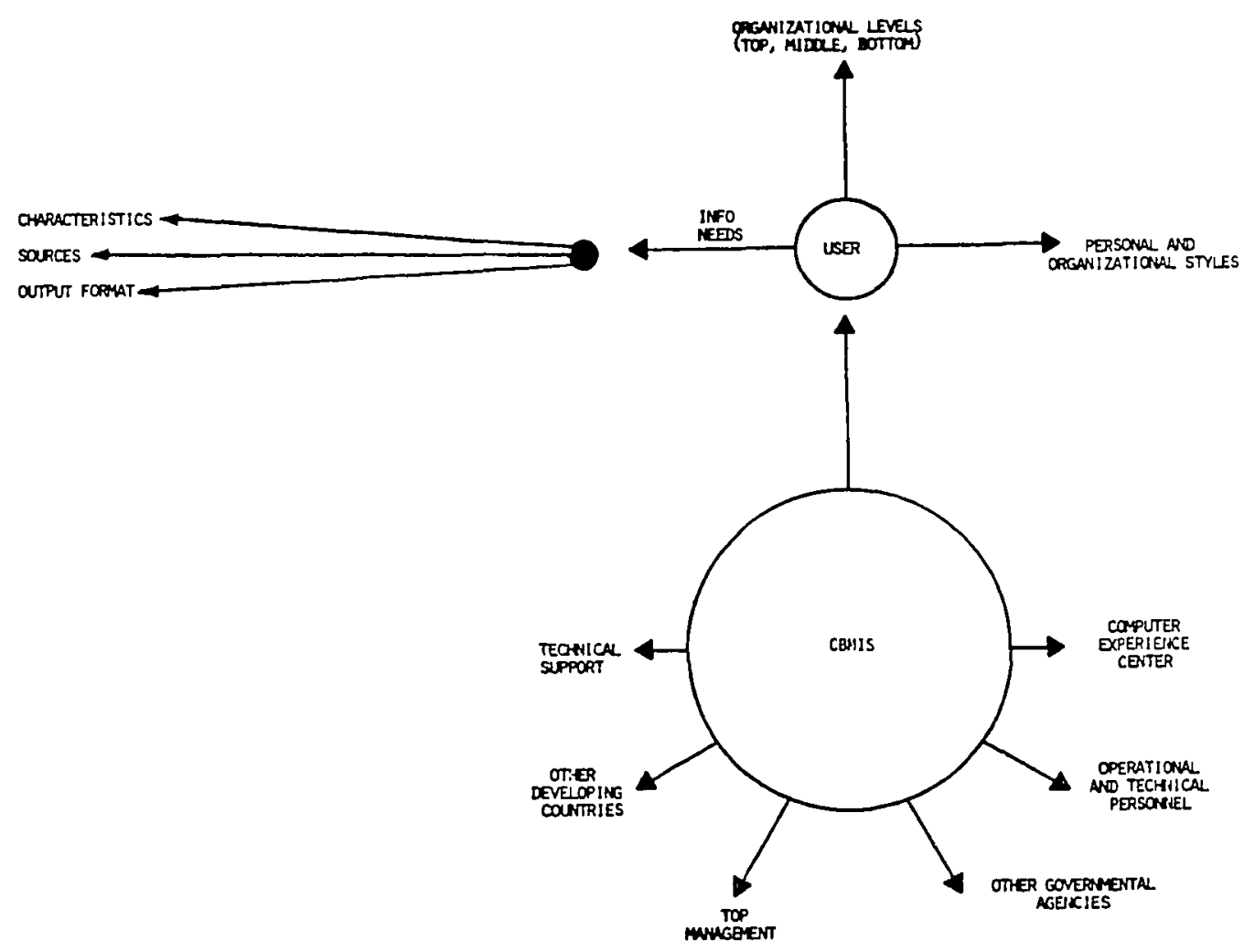

Figure 33. The Most Relevant Environment for a CBMIS in a Developing Country. 
Design Specifications. After a careful review of the information system's life cycle and a precise definition of the environment of a particular CBMIS, the design specifications should be elaborated. Comprehensive design specifications play a crucial role in the CBMIS by creating consistency in computer utilization, by increasing the adaptability of the existing CBMIS to growing technology, by increasing the chances of acceptance by the users, and finally by serving as a guideline for CBMIS utilization. The following four factors are the most important design specification variables for the special case of developing countries: types of design (task force vs individual), provision for change (modularity in design), functional specifications and performance criteria, and system documentation. These four design specification variables are briefly discussed immediately below.

Types of Design (task force vs individual): Traditionally, a CBMIS has been designed largely by data processing personnel. As a result, the designs have not always had the full support of the users. The emerging issue of task force design emphasizes the participation of all impacted personnel in the design of the CBMIS. This particular method could increase the commitment of users and at the same time give them a chance to express their views regarding the utilization of the CBMIS.

Provision for Change (modularity in design): Acquisition and utilization of computer technology should not be a one-shot operation in developing nations; rather, it should be a continuous process. Design specifications of the proposed model should consider the ways 
and methods by which a particular developing nation might adapt to the growing technology. Modularity in design could provide such an opportunity. Modularity should be considered in relation to: hardware acquisition, software acquisition, systems design principles, and, most importantly, software development.

Functional Specifications and Performance Criteria: In order to stay within the range of the predefined objectives for the CBMIS, the designer should articulate the functional specifications of a particular system. These specifications serve as a centralizing mechanism. A continuous comparison of these specifications with the actual operation of the system will point up the deviations between predefined goals and actual performance. The smaller the deviation, the higher the achievement of goals. Functional specification include the following:

-- time/cost and other resource estimations (roughly, how much time and money are needed to design and implement a particular (BMIS?)

-- specific objectives of the CBMIS

-- input/output specifications

-- a description of system functions and characteristics

-- accuracy of reports

-- reliability of reports

-- degree of acceptance and utilization of the CBMIS by users

System Documentation: A comprehensive written document which describes the details and step-by-step operation of the CBMIS 
can be very helpful for its effective and efficient utilization. This document may also aid in improving the performance of existing systems.

Input (Data). Inputs are facts which are incomina to the CBMIS from its environment. The sources of these inputs depend upon the situation for which a particular CBMIS has been designed, but at least the following elements should be considered:

-- external vs internal data

-- past/present/future data

- recency of data

-- disaggregated vs aggregated data

-- numerical as well as conceptual data

In order to send data to the CBMIS, a sophisticated system should also include on-line, batch, and even voice input devices. However, due to the severe shortage of communication lines, on-line data entry in most developing countries is in its infancy.

Data Base. Data base is a series of computer files which attempts to eliminate or at least minimize duplication within the CBMIS. This study does not concern itself with the various types of data bases (e.g., relational, hiererchical, network); they have been fully discussed by others, notably Date (1981: 63-79). For amplification of the advantages and disadvantages of data base and Data Base Management Systems (DBMS) over the so-called flat files, see authors such as Chvalovsky (1976: 54-55), Curtice (1976: 46-49), Sobczak (1977: 139-150), Wiorkowski (1977: 109-114), Tsichritzis, 1978: 147-151), Holland (1980: 141-144), and McFadden (1978: 131-138). The central issue involved in this study is the existence of a data base 
(of any kind). Since different governmental agencies use the same data for different applications, the existence of a data base in the proposed model is an absolute requirement.

The advantages of a data base in the special case of developing countries is as follows:

-- data interchange or data migration improvement

-- enforcement of standards

-- reduction of redundancy: different governmental agencies could specialize in the gathering and maintenance of particular data

-- avoidance of inconsistency

-- improvement of security

As I Padunchwit and B Tamthai have pointed out:

Another area that shows governments' great need is the use of data bank systems where, as the government draws on resources of information from mass storage devices, various vital pieces of information can be more readily correlated to assist the government to plan, forecast, develop, and control projects that previously had to be based upon accounting history sheets.

(1972: 546-547)

Process. With the existence of a well-defined data base in a CBMIS, a variety of analyses can be performed. Different mathematical models can be employed in order to convert raw data to the most acceptable and usable form of information. Statistical and financial analysis can become a very easy task. For this project, the following mathematical models may be included: 
-- econometric models

-- optimization models

-- simulation and forecasting models

-- simple and multiple regression models

-- budgeting and financial models

-- cluster analysis models

Therefore, this part of the proposed model emphasizes two factors: availability of the appropriate modeis and types of analysis (e.g., simple vs complex, historical vs futuristic, etc)

Output (Information). The ultimate objective of designing and implementing any CBMIS should be the production of timely, integrated, useful information. Utilization of the provided information can be drastically improved if the output format and methods of reporting match the particular needs and styles of the various users. A sophisticated CBMIS should include at least the following output formats:

-- hard vs soft copies

-- graphic vs tabular format

-- details vs summaries

-- exceptional vs full reporting

In the case of reporting methods and utilization of a CBMIS, Steven Alter (1980: 110-112) has suggested the following methods:

-- subscription method (information is reported on a regular basis)

-- clerk method (there is one person between the CBMIS and the user) 
-- direct method (information can be requested directly from the CBMIS)

-- intermediary methods (the user receives technical advice about the provided information)

In summary, this part of the proposed model should consider the following factors:

-- the screening process (conceptual filtering to avoid bombarding the decisionmaker with masses of information)

-- timeliness (lacking this factor, decisionmakers may use an informal system)

-- variety (internal vs external, comparison between different years or agencies, etc; wide variety is desirable)

-- convenience of access (may include Alter's systems utilization methods)

-- types of presentation and output (described in detail above)

A combination of these factors can have a dramatic impact on the success of the CBMIS.

The Implementation Phase

In the implementation phase of the proposed model, the project is transferred from paper to an actual physical situation. Variables in this phase identify the factors which are critical for the smooth and efficient implementation of the CBMIS. Figure 14 on the following page shows the most important factors involved in this phase. 


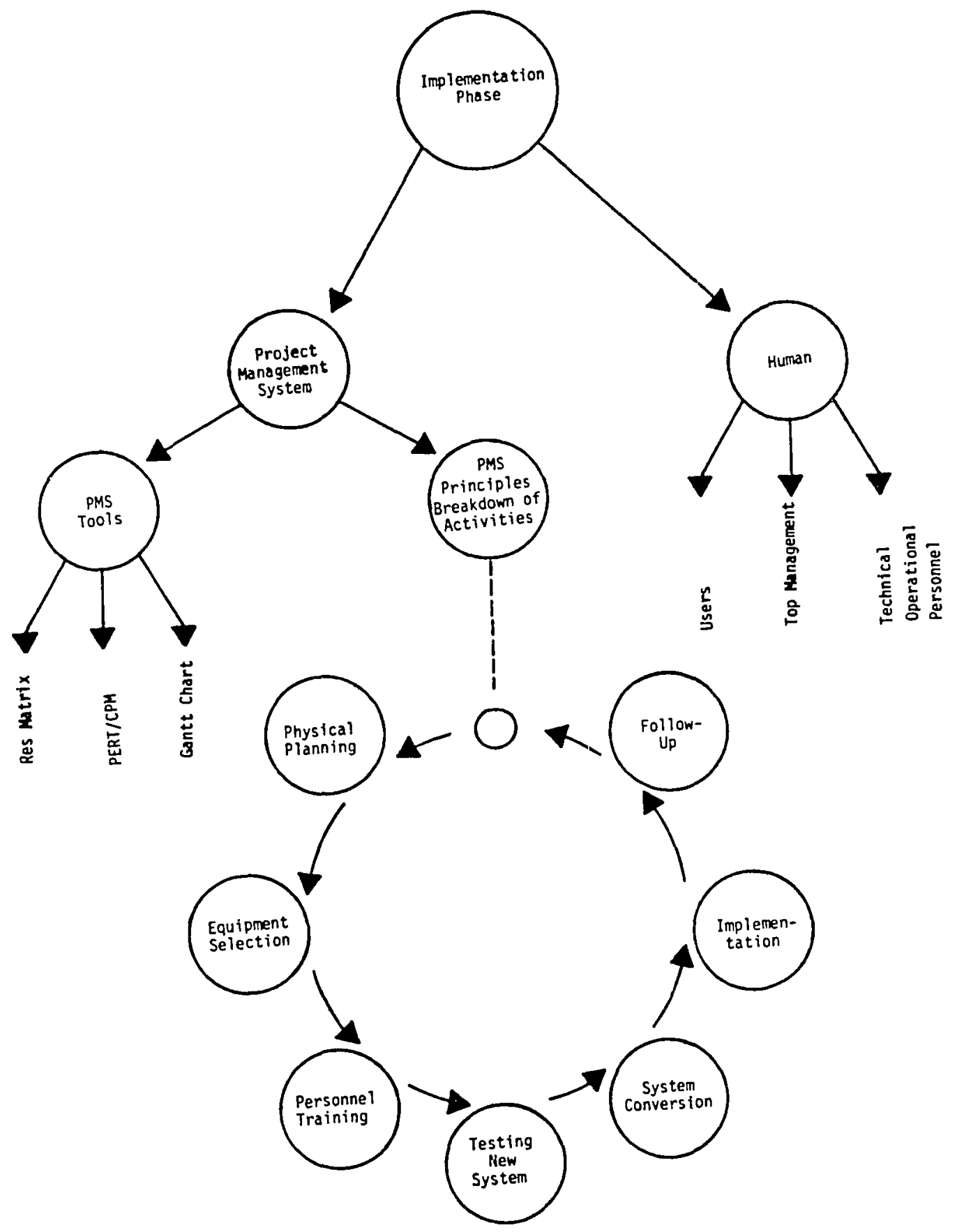

Figure 14. The Implementation Phase of the Proposed CBMIS 
Human. Timely and smooth implementation of a CBMIS is heavily dependent on availability of adequate numbers of trained technical and operational personnel. Obviousiy, this factor must have been considered in the acquisition phase of the proposed model.

User and top management involvement in the implementation phase of the CBMIS can also be quite important to its success. This may be the final opportunity for top management and the users to commit their views to the operation and utilization of the CBMIS.

Project Management. For the special purposes of this study, two major issues will be addressed in terms of project management as a tool for planning, scheduling, and coordination of all the activities involved in implementation of the CBMIS:

-- project management principles

-- utilization of tools and techniques of project management

Project management principles indicate the breakdown of all the activities involved in the implementation of a CBMIS into measurable tasks. As $J$ G Burch has pointed out,

A project management system (PMS) is a system that supports the tasks of planning, scheduling, and controlling projects. The essential feature of a PMS is a mechanism for delineating a project into measurable work units.

(1979: 457)

The activities involved in the project management phase of the CBMIS have been shown in Figure 14. They are briefly explained below:

-- physical planning: designers should consider the most 
appropriate physical layout for the installation of

a CBMIS. This includes wiring, air conditioning, remodeling, etc.

-- equipment selection: includes such considerations as CPU capacity, peripheral equipment, secondary storage, etc.

-- personnel training: includes both on- and off-the-job training.

-- testing the new system: the new system snould be tested with sample data in order to increase the chances for future success.

-- system conversion: should be accomplished after careful testing has been carried out. There are several different conversion methods: direct, parallel, modular, and phase-in conversion (for full explanations, see Bercher, 1979: 436-437), for example. The appropriate method should be selected depending upon the particular circumstances of a specific CBMIS.

-- implementation: during this stage, the CBMIS is fully installed. The overall operation of the system starts after this phase.

-- follow-up: After the system is fully implemented, the designers should continue to monitor it in order to be certain that the predefined objectives have been met and the users find the system workable. Adjustments should be made, as necessary. 
To assure the most successful implementation of the CBMIS, several project management tools may be utilized: responsibility matrices, PERT/CPM, and Gantt charts, to name a few. These tools, which have been discussed to some extent in Chapter II of this research project, make a significant contribution to ensuring that the implementation phase of the CBMIS reaches its full potential.

\section{The Operational Phase}

This is the last phase of the proposed model. This phase demonstrates the performance of the CBMIS; it also indicates how carefully and fully the first three phases have been considered. The operational phase can be studied through several different dimensions, which are illustrated graphically in Figure 15 on page 79. This figure is derived from the study made of the computer status in ten developing countries (elaborated in Chapter I), and most of the variables included in Figure 15 come directly from that specific study. The remainder have been compiled by a careful analysis of related literature from both developed and developing countries.

The following list of variables also highlights significant questions which should be investigated in each case:

-- Efficiency and Effectiveness of the Organization

1. Has efficiency and effectiveness of the organization been improved as a result of the acquisition of computer technology?

2. What are some of the most decisive variables which have either a direct or an indirect impact on this 


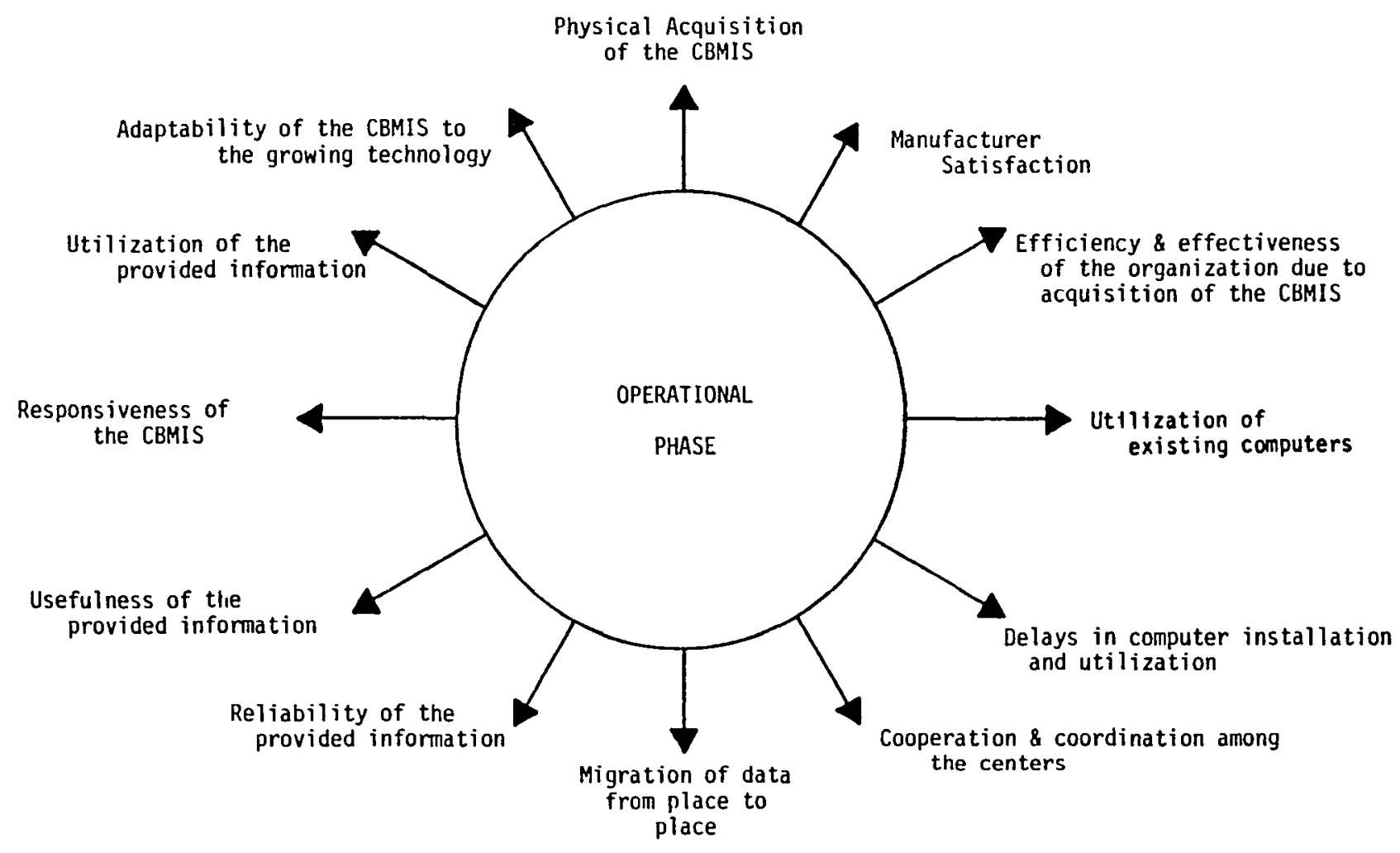

Figure 15. The Operational Phase of the Proposed CBMIS 
improvement?

-- Utilization of Existing Computers

1. Have the existing computers been efficientiy used?

2. What are some of the most decisive variables which have either a direct or an indirect impact on this issue?

-- Delays in Computer Installation and Utilization

1. Has the computer installation and utilization been timely?

2. What are the key variables?

-- Cooperation and Coordination Among the Installations

1. Have the different installations been able to share experiences?

2. What are the key variables?

-- Migration of Data From Place to Place

1. Have the different installations been able to use each others data?

2. What are the key variables?

- Reliability of the Provided Information

1. Has the information provided by the CBMIS been reliable?

2. What are the key variables?

-- Usefulness of the Provided Information

1. How usefur has the provided information been to users?

2. What are the key variables? 
-- Responsiveness of the CBMIS

1. Has the CBMIS been responsive to the views and needs of the users?

2. What are the key variables?

-- Utilization of the Provided Information

1. Has the provided information actually been utilized?

2. What are the key variables?

-- Adaptability of the Present CBMIS to the Growing Technology

1. How adaptable is the present CBMIS?

2. What are the key variables?

-- Physical Acquisition of Computer Technology

1. Has the physical acquisition of computer technology been relatively easy to accomplish and timely?

2. What are the key variables?

-- User Satisfication with the Manufacturer

1. Has the user been satisfied with a particular manufacturer?

2. What are the key variables?

\section{SUMMARY}

This chapter developed the descriptive model for a CBMIS. It discussed three different phases included in this model. It also introduced the fourth phase. This phase includes all the predictive equations for the successful employment of a CBMIS. Chapter IV will identify the most decisive elements from the four phases and will further the analysis. 


\section{CHAPTER VI}

\section{ANALYSIS}

INTRODUCTION

A primary function of this chapter is to show the relationships which exist between various individual dependent variables and a respective series of independent variables. These relationships are demonstrated by use of forced entry multiple regression.

Secondly, tests of the experimental null hypotheses are presented; they consist of the global $F$ test for a particular model and the test of an individual parameter coefficient in the multiple regression moder.

A third purpose is to present the different runs accomplished for each predictive model in order to show the rationale for selecting one over the others as the best predictive model.

Finally, this chapter examines the residuals and explains the issue of multicolinearity. This examination helps locate areas where the assumptions of multiple regression may have been violated.

\section{RELATIONSHIPS BETWEEN DEPENDENT AND INDEPENDENT VARIABLES}

This section introduces each of the predictive models, determines mean and standard deviation for all the variables, and discusses pairwise correlations between any dependent variable and respective independent variables. 
hereinafter referred to as "independent variables" or "measure of success factors," describe the first three phases of the proposed model. They are measurable and have a significant impact on the success of the CBMIS, both singularly and collectively (although some are more crucial than others). The issue of degree of impact will be dealt with more fully in Chapter VI of this project.

The Acquisition phase of this model will be described in terms of six major factors: Policy (P), Human (H), Social (S), Geographical (g), Economic $(E)$, and Technical $(T)$. These six elements can be further elaborated as follows:

Policy:

AV ${ }_{1} P$ - acquisition criteria: complexity of the organization's activities

AV ${ }_{2} P$ - acquisition criteria: other organizations' decisions

AV ${ }_{3} P$ - acquisition criteria: economic considerations

AV ${ }_{4} P$ - acquisition criteria: improve control of the operations

AV ${ }_{5} P$ - acquisition criteria: capability to plan for the future

AV ${ }_{6} P$ - acquisition criteria: more accurate information

AV ${ }_{7} \mathrm{P}$ - acquisition criteria: more current information

AV ${ }_{8}{ }^{P}$ - existence of consulting firms and/or vendors for prices, applications, new developments, etc

AV ${ }_{9} P$ - centralization/decentralization issues

${ }^{A V} V_{10} P$ - existence of master system plan (goals, objectives, needs)

$A V_{11} P$ - employment of standardization--in data collection

${ }^{A V}{ }_{12} P$ - employment of standardization--in data transmission 
$\mathrm{AV}_{13} \mathrm{P}$ - employment of standardization--in hardware selection $\mathrm{AV}_{14} \mathrm{P}$ - employment of standardization--in software selection $\mathrm{AV}_{15} \mathrm{P}$ - acquisition constraint: duties/tariffs

$\mathrm{AV}_{16} \mathrm{P}$ - acquisition constraint: transportation

$\mathrm{AV}_{17} \mathrm{P}$ - acquisition constraint: taxes

$A V_{18} P$ - number of training centers

Human:

$\mathrm{AV}_{19} \mathrm{H}$ - user involvement (awareness, motivation, attitude, communication)

$\mathrm{AV}_{20} \mathrm{H}$ - top management involvement

$A V_{27} \mathrm{H}$ - existence of appropriate numbers of data processing personnel

Social:

$\mathrm{AV}_{22} \mathrm{~S}$ - unemployment of unskilled labor - what to do

$\mathrm{AV}_{23} \mathrm{~S}$ - privacy problem (have any measures been taken?)

$\mathrm{AV}_{24} \mathrm{~S}$ - computer fraud (have any measures been taken?)

$A V_{25} \mathrm{~S}$ - existence of foreign consultants

$\mathrm{AV}_{26} \mathrm{~S}$ - conflict among foreign and native consultants (salary differences, working conditions differences, etc)

Geographical :

$A V_{27} G$ - availability of maintenance personnel for the manufacturer $\mathrm{AV}_{28} \mathrm{G}$ - availability of replacement parts for the manufacturer $A V_{29} G$ - availability of backup for the manufacturer $\mathrm{AV}_{30} \mathrm{G}$ - political considerations for the selection of the manufacturer 
Ecconomic:

$A V_{37} E$ - economic feasibility (cost/benefit analysis)

$\mathrm{AV}_{32} \mathrm{E}$ - availability of foreign exchange

Technical:

$\mathrm{AV}_{33^{T}} \mathrm{~T}$ - existence of communication technology

$\mathrm{AV}_{34} \mathrm{~T}^{\mathrm{T}}$ - existence of air conditioning technology

$\mathrm{AV}_{35} \mathrm{~T}$ - existence of specially-designed building

$A V_{36}{ }^{T}$ - existence of reliable voltage

The Design phase of this model includes seven major elements:

Life Cycle considerations (LC), ENvironmental considerations (EN), design SPecifications (SP), INput considerations (IN), Data Base considerations (DB), PRocess considerations (PR), and OUtput considerations (OU).

Life Cycle:

DV 37 LC - technical feasibility (suitability of different information systems for automation)

$D_{38} L C$ - problem definition (goals and objectives--specific problem to be solved)

$D V_{39} L C$ - scope of the system (desired operating characteristics of the system)

$D V_{40} L C$ - existence of debugged manual system

ENvironment:

$\overline{\mathrm{V}} \mathrm{V}_{41} \mathrm{EN}$ - existence of information centers (experience sharing, 
minimize duplication of mistakes) (computer experience center)

$D V_{42} E N$ - user invoivement (information needs and styles)

$\mathrm{DV}_{43} \mathrm{EN}$ - top management involvement

SPecifications:

$D V_{44} S P$ - types of design (task force vs individual)

$\mathrm{DV}_{45} \mathrm{SP}$ - provision for change (modularity in design)

$D_{46} S P$ - functional specifications and performance criteria

$D V_{47} S P$ - systems documentation

INput (Data):

$D V_{48} I N$ - internal vs external data

$\mathrm{DV}_{49}$ IN - recency of data

$D_{50}$ IN - disaggregated vs aggregated data

Data Base:

$D V_{51} D B$ - existence of data base

PRocess:

$D V_{52} P R$ - availability of models (types of analysis, appropriateness of models)

Output:

$\mathrm{DV}_{53} \mathrm{OU}$ - output considerations (screening process, timeliness, variety, convenience of access, types of presentation)

The Implementation phase of this model has been described in terms of two major factors: HUman (HU) and Project Management Systems 
(PMS).

HUman:

$$
\begin{aligned}
& \mathrm{IV}_{54} \mathrm{HU} \text { - user involvement } \\
& \mathrm{IV}_{55} \mathrm{HU} \text { - top management involvement }
\end{aligned}
$$

Project Management Systems:

$$
\begin{aligned}
& \text { IV }{ }_{56} \text { PMS - project management principles (breakdown of the project } \\
& \mathrm{IV}_{57} \text { PMS - usage of project management tools, e.g., PERT/CPM, }
\end{aligned}
$$

\section{THE PREDICTIVE MODELS}

Twelve predictive models are utilized in this research project. They were carefully constructed based upon information obtained on the status of computers in 10 developing countries (see Chapter I) and upon the Titerature search discussed in Chapters II and III. These models and their functional relationships form the foundation for the development of the predictive statistical equations formed in Chapter $V$. Their major function is to describe the performance of the CBMIS and to demonstrate how fully the first 58 variables have been considered. They have been employed, as Chapter $V$ will detail more fully, for the following reasons: 
- they will be used to test the significance of each variable included in the descriptive model;

- they will be used to support one or a series of policy decisions;

- they will be used as predictive models to improve the chances of success for the employment of a CBMIS.

Throughout the remainder of this study, these variables will be categorized as Operational phase (0), DePendent (DP) variables:

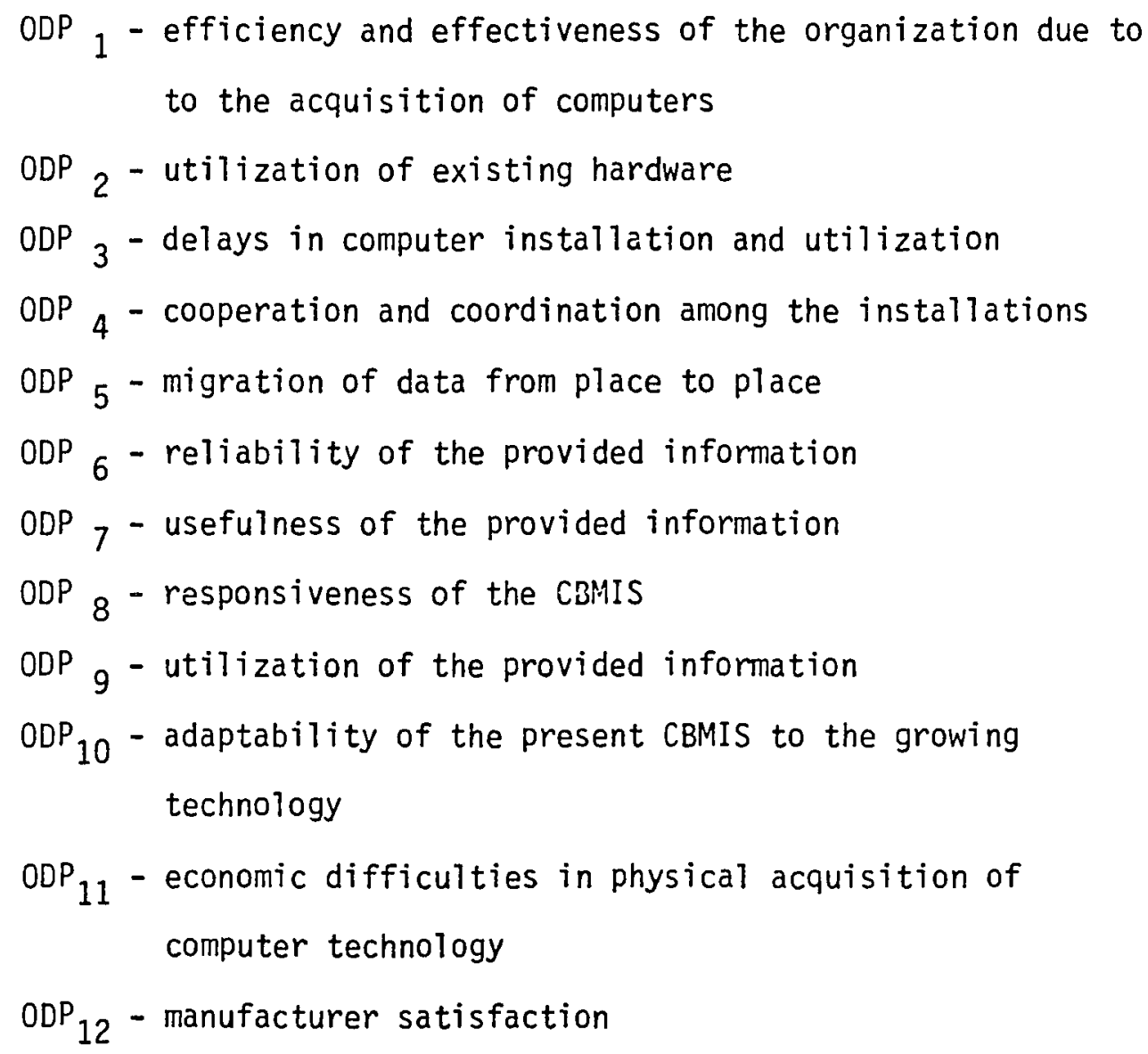


RELATIONSHIP BETWEEN THE DESCRIPTIVE AND PREDICTIVE MODELS

Table XII on the following page presents the overall relationships between the dependent and independent variables. Uitimately, a series of multiple linear regressions will be employed to provide a picture, through a set of products, of the extent to which a single dependent variable $(Y)$ is dependent upon a series of independent variables ( $x^{\prime} s$ ). The assumptions, the products, and the statistical significance of these relationships will be elaborated on in Chapters $V$ and $V I$ of this research project.

\section{BACKGROUND FOR THE PREDICTIVE MODELS}

This section presents all twelve of the predictive models, as well as the justification of their relationships with the independent variables from the descriptive model.

\section{Predictive Mode1 \# 1: Efficiency and Effectiveness of the Organization} Due to the Acquisition of Computer Technology

Generally, organizations elect to adopt computer technology in the first place in order to improve some aspect(s) of the efficiency and effectiveness of their operations. (Although there are documented cases of developing countries having adopted computer technology for other reasons, for example for perceived elevation in status, such cases are extremely rare.) Thus, it is reasonable to expect to find some correlation between computer acquisition criteria and an improvement in the efficiency and effectiveness of an organization.

The specific reasons developing countries usually decide to 


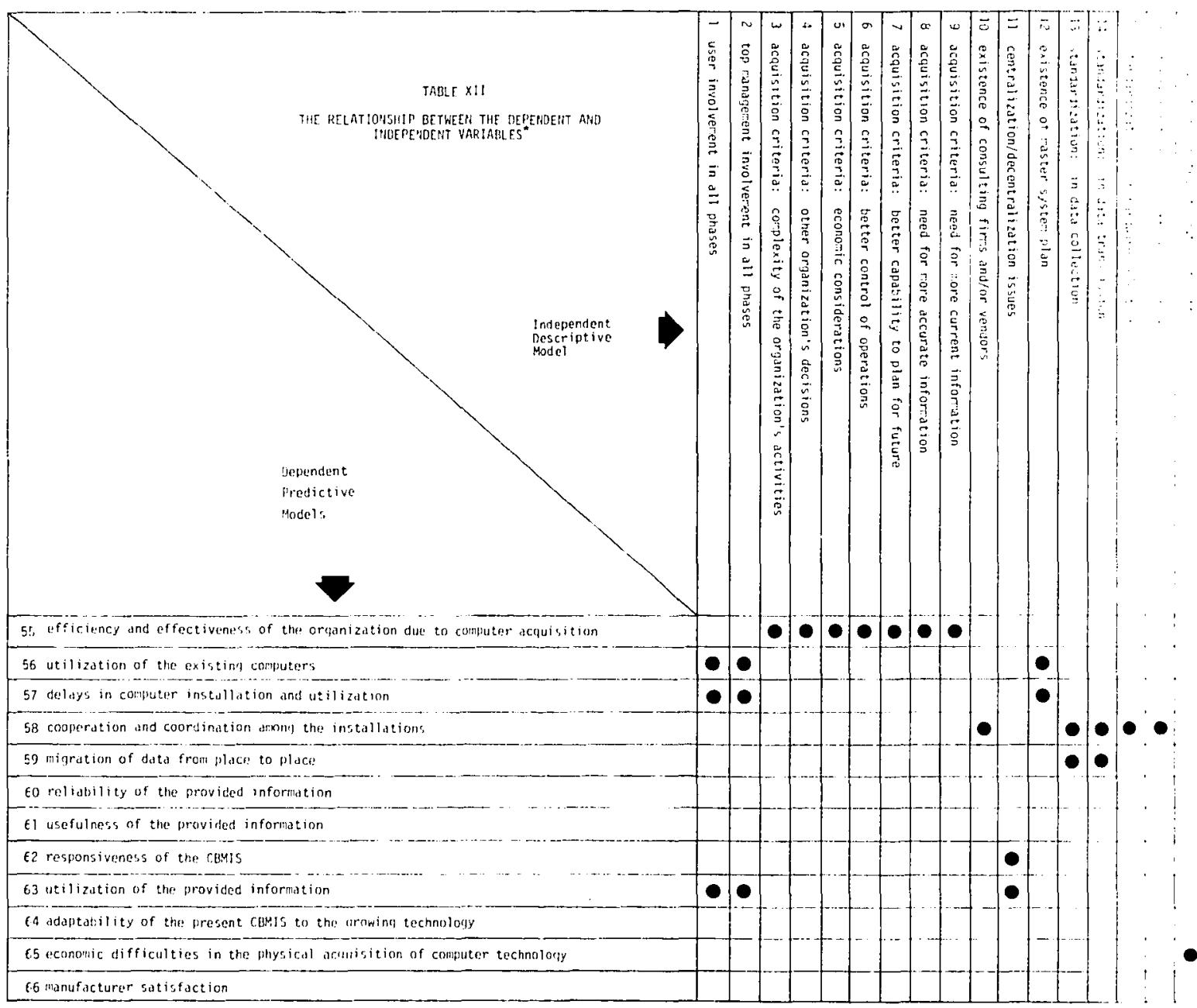

This 1 isting is stightly different from the detailed description presented in Chapter $1 \mathrm{~W}$, for simplicity purposes, the followina varintilu, ......... 


computerize their operations include the following:

- increased complexity of the organization's activiites

- other organizations have done so (equivalent to adoption for status purposes)

- economic considerations (possibly THE major factor)

- anticipated improvement over control of the operations

- anticipated improvement in capability to plan for the future

- anticipated improvement in accuracy of information

- anticipated improvement in recency of information

\section{Predictive Model \#2: Utilization of Existing Computers}

Nearly all the countries studied in this research project have had the common problem of underutilization of existing computers (see, for example, Simmons, 1972 and Plan and Budget Organization, 1977). For developing countries, which generally have a shortage of resources and a severe need to accelerate their economic and social development, this problem has a particularly high significance. Computer underutilization may result from a variety of sources, the more significant of which are the following:

- lack of user invovlement in all phases of the acquisition, design, and implementation of the CBMIS (resulting in a lack of commitment)

- lack of top management involvement

- lack of a master plan for defining needs and priorities

- shortage of data processing personnel 
- conflicts between foreign and native consultants*

- inefficiency of supporting technologies (e.g., communication, air conditioning, specially-designed buildings, reliable voltage, etc)

- technical infeasibility of a system for automation

- problem not well defined before bringing in computer

\section{Predictive Model \#3: Delays in Computer Installation and Utilization}

Another common problem among developing countries is the delays in computer installation and utilization, which means simply that project utilization does not meet the deadlines (see Plan and Budget Organization, 1977). This problem is of concern in developed countries, too, but is much greater for underdeveloped ones. Several factors may contribute to the existence of this problem. The first five factors listed under Predictive Model \#2 also apply to Model \#3. In addition, the following are important contributors:

- economic infeasibility

- unavailability of foreign exchange

- 1ack of a debugged manual system

- lack of usage of project management principles and tools

Predictive Model \#4: Cooperation and Coordination Among the Installations

Experience sharing among computer installations in a developing country could significantly reduce duplication of mistakes, thereby

These problems originate due to the fact that foreign consultants generally receive higher salaries and more favorable working conditions. 
assisting users in acquiring and installing the most appropriate systems. The creation of a harmonious pattern among the various installations is expected to set the stage for future cooperation to fluorish.

Following are some of the most important factors which could enhance cooperation and coordination among the various installations:

- existence of information centers for prices, applications, new developments, etc

- employment of standardization in data collection

- employment of standardization in data transmission

- employment of standardization in hardware selection

- employment of standardization in software selection

- existence of computer experience centers.

Predictive Model \#5: Migration of Data from Place to Place

Because, on many occasions, different governmental agencies use the same data for different applications, migration of this data is very important, both in terms of saving money and of saving time. It would additionally have the benefit of allowing different agencies to specialize in accumulating and maintaining different types of data.

Following are some of the most important factors in assisting the migration of data from one agency to another:

- standardization in data collection

- standardization in data transmission

- existence of an operational data base

- existence of a computer experience center (or centers) 
Predictive Model \#6: Reliability of the Provided Information

The reliability of information has a high correlation with the success of the CBMIS. Reliability, for purposes of this study, refers to the nature of the data and the types of analysis which have been performed in order to provide information for decisionmaking.

Two general factors are probably the most crucial in terms of ensuring reliability:

- data considerations (e.g., internal vs external; past, present, and future data; recency; aggregated vs disaggregated)

- availability of appropriate mathematical models

Mathematical models, it should be noted, should be used with caution. While they are extremely important in converting data to information, the right data used in conjunction with an inappropriate model will not yield reliable information.

Predictive Model \#7: Usefulness of the Provided Information

Obviously, the provided information should be reliable in order to be useful to a user. However, there are many instances in which reliable information has been provided which was simply not helpful for a particular decisionmaking process; i.e., the information was either superfluous or extraneous. Usefulness, therefore, is particularly important to the efficiency of a CBMIS.

Data considerations and the availability of mathematical models are imnortant to usefulness as they were to reliability. In addition, the following two factors are important: 
- scope of the system (desired operating characteristics)

- output considerations

\section{Predictive Model \#8: Responsiveness of the CBMIS}

Reliability and usefulness of the data play an important role in the responsiveness of the CBMIS, but they, in and of themselves, do not ensure it. In addition, the information should be user and application oriented in order to be thoroughly responsive. The following three characteristics, then, are added to those listed for Models \#6 and \#7:

- centralization/decentralization issues

- types of design (task force vs individual)

- post-implementation audit (monitor to ensure goals have been met)

Predictive Model \#9: Utilization of the Provided Information

Generally, users will not employ information which is not reliable, helpful, and/or responsive. However, some provided information can possess all these characteristics and still not be utilized.

Two important factors can rectify this situation: top management involvement and careful attention to the social issues involved in acquisition of computer technology. The specific issues are listed below (in addition to those mentioned for Models \#6, \#7, and \#8):

- top management involvement (for detailed study, see Sexton)

- consideration of what to do with unemployed unskilled laborers

- computer fraud and privacy problems 
Predictive Model \#10: Adaptability of the Present CBMIS to the Growing Technology

If developing nations intend to benefit fully from computer technology, their utilization should be a continuous one. Following are some of the most important considerations:

- number of data processing training centers

- provision for change (modularity in design)

- functional specifications and performance criteria (to serve as control mechanisms for defining future characteristics of a CBMIS)

- systems documentation

Predictive Model \#11: Physical Arquisition of Computer Technology

A study done by Simmons has indicated that some of the developing countries have had various constraints placed upon them in terms of the physical acquisition of computer technology. While the degree and severity of these constraints differs somewhat from country to country, they can be generally classified as the following:

- heavy duties

- high taxes

- inefficient transportation systems

Certainly, a lessening of any of these problems would make the computer a more affordable comodity for developing countries.

Predictive Mode] \#12: Manufacturer Satisfaction

Because developing nations must import computer technology from 
developed nations, the manufacturers or exporters could be extremely important factors in the success (or failure) of a CBMIS. The following considerations could be important in selecting a manufacturer:

- availability of maintenance personnel

- availability of replacement parts

- availability of a back-up (hardware and software)

- political considerations (If this is the only criterion for selecting a given exporter, chances for success will be questionable, at best.)

\section{SUMMARY}

This chapter described the elements which make up both the descriptive model and the predictive models of the CBMIS. With these models firmly in mind, Chapter $V$ will move on to the multiple linear regression modeling which will be used to interpret the significance of the included variables. 
CHAPTER $V$

RESEARCH METHODOLOGY, PHASE II

INTRODUCTION

This chapter carries the research methodology one step further. The rationale behind the employment of multiple linear regressions as a theory building technique is explained, the predictive models are fully elaborated, and the research questions are presented.

RATIONALE FOR THE EMPLOYMENT OF MULTIPLE LINEAR REGRESSIONS

In order to measure the significance of the variables involved in the proposed model, a series of hypotheses were tested. The test consisted of 12 multiple linear regressions, run using four different methods: stepwise, forward entry, forced entry, and backward elimination. This system of multiple linear regressions assists in answering the first group of research questions, as follows:

- What are the important variables to include in a model of transferring CBMIS technology to a developing country such as Iran?

This question is answered by the variables contained in the descriptive model outlined in Chapter IV of this study. All of these variables have been included in the system of multiple linear regressions for further analysis. 
- Which variables are the most crucial?

The answer to this question is based upon the statistical significance of a particular variable employed in one of the twelve multiple regression models (e.g., standardized B coefficients).

- Based on the proposed model, under what conditions should a developing country such as Iran operate manually?

Based upon the answer provided for the above question, one can draw some conclusions about the choice between automated and manual systems. This should highlight the significance of a particular variable for the success of the CBMIS and the status of this particular variable in a developing country such as Iran.

In order to answer the second group of research questions (presented in Chapter I), each multiple regression model was analyzed for the following three purposes:

- to test the significance of each variable included in the mode1;

- to support one or a series of policy decisions;

- to serve as a predictive model to improve the chances of successful employment of the CBMIS.

A detailed questionnaire was designed. It was pilot tested by the doctoral committee members and by outside experts and then sent to 79 Iranian governmental installations as a means of obtaining the necessary data for the regression analysis (See Appendices $A$ and $B$ ). This questionnaire measures al1 the 66 variables included in the proposed models by use of a Likert scale of 1 to 7 . The regression analysis 
used is cross-sectional and analyzes these variables at a specific moment in time.

The classic assumptions of regression analysis, e.g., linearity independence of residuals, homoscedasticity, normality of residuals, and the relevancy of each to this particular study will be fully discussed in Chapter VI. However, one issue must be mentioned here: since the data are ranked, an assumption of equal intervals among the ranks has been made--the data are treated as interval data. This is an acceptable assumption which has been used many times in social science research (e.g., Kerlinger, 1973).

\section{MULTIPLE LINEAR REGRESSION AS A THEORY BUILDING TECHNIQUE}

In order to establish a quantitative measure of the relationship among the variables and to define the relative importance of each, as well as to find the most accurate predictive models (from among those possible), two sets of multiple linear regression models were run.

The first set was run to define the relative importance of each variable in both the predictive and descriptive models. For this reason, a forced entry multiple linear regression option was run. This option included all the variables for each model and determined the relative importance of each variable.

The second set was run to present the most precise predictive models. A combination for stepwise, forward entry, and backward elimination techniques were used. The most complex, the stepwise linear regression technique, will be explained here as an example of how these techniques operate. 
This technique computes, by steps, the least squares values for the coefficients of an equation of the form:

$$
Y=B_{0}+B_{1} X_{1}+B_{2} X_{2}+B_{3} X_{3}+\ldots B_{n} X_{n}
$$

$Y$ is the dependent variable, $X_{1}, X_{2} \ldots X_{n}$ are independent variables, and $B_{0}, B_{1}, B_{2} \cdots B_{n}$ are the coefficients to be determined. Any combination of one dependent variable and one or more independent variables may be selected for analysis. In the stepwise procedure, independent variables are added, one at a time to the regression, yielding the following intermediate equations:

$$
\begin{aligned}
& Y=B_{0}+B_{1} X_{1} \\
& Y=B_{0}^{\prime}+B_{1}^{\prime} X_{2}+B_{2}^{\prime} X_{2} \\
& Y=B_{0}^{\prime \prime}+B_{1}^{\prime \prime} X_{1}+B_{2}^{q} X_{2}+B_{3}^{4} X_{3}
\end{aligned}
$$

Therefore, it is possible to obtain valuable statistical information at each step of the calculation. In each step, those independent variables not included in the regression are inspected to find the one that will give the greatest reduction in the unexplained variation of Y. This variable is then tested for significance; i.e., the computed F-ratio of the variable is compared with the supplied critical F-value. If the computed value is greater than the critical value, the variable is considered significant and is added to the regression solution. Ater each new variable has been added, those variables already in the regression are inspected to see whether any of them can now be deleted because their contribution to the reduction in the variation of $Y$ is no longer significant. Those variables which have a computed 
F-ratio less than the critical value are considered insignificant and are deleted from the regression solution. This process is continued until no more variables can be added or deleted. Thus, the final regression solution contains only those variables that are statistically significant (except forced variables).

Under user control, it is possible to force one or more of the independent variables into the regression solution. * These variables are added to the fit before any other variables, with no regard for statistical significance. The remaining independent variables are then added to the fit in the normal stepwise procedure.

Before introducing the hypotheses involved in this study, another point should be made clear: two of the regressions involved in this model have relatively larger numbers of independent variables. In order to reduce the number of variables, at least two options are available. The first is an inherent part of stepwise regression, i.e., the process is started with the variables which best predict; after reaching a satisfactory level, the process can be stopped. (If, for example, $80 \%$ of the variation in $Y$ is defined by 7 independent variables, a satisfactory level has been reached.) of course, the background which supports each model is equally important. (This issue was discussed in Chapter IV of.this paper).

A second option is to run a factor analysis on the variables involved in the regressions and to choose the most significant

This particular study does not, however, attempt to force any variable into the model. 
variables on which to run a stepwise regression simultaneously.

In either case, the final models will include the most significant variables which have a direct impact on the success or failure of the CBMIS.

\section{TEST OF HYPOTHESES AND RESEARCH QUESTIONS}

In this section, all twelve predictive models are introduced, the experimental null hypothesis presented, and the decision applications addressed. In all twelve instances, the following two tests apply:

Test of the utility of a multiple regression model: the global F test*

$$
H_{0}: B_{1}=B_{2}=\ldots \cdot B_{k}=0
$$

$H_{a}$ : At least one of the $B$ parameters does not equal 0

Test of an individual parameter coefficient in the multiple regression model

$$
\begin{aligned}
& H_{0}: B_{i}=0 \\
& H_{a}: B_{i} \neq 0 \text { when } i=1,2 \ldots . k \quad \begin{array}{l}
(k=\text { the number of } \\
\text { independent variables })
\end{array}
\end{aligned}
$$

Predictive Model \#1: Efficiency and Effectiveness of the Organization Due to the Acquisition of Computer Technology

$$
V_{1}=B_{0}+B_{1} V_{3}+B_{2} V_{4}+B_{3} V_{5}+B_{4} V_{6}+B_{5} V_{7}+B_{6} V_{8}+B_{7} V_{9}
$$

Decision Application

- What should the acquisition criteria be?

--complexity of the organization's activities

--other organization's decisions

The second test is performed only if the first test has been passed. 
--economic considerations

--better control of operations

--better capability to plan for the future

--more accurate information

--more current information

Predictive Model \#2: Utilization of the Existing Computers

$$
\begin{aligned}
V_{2}= & B_{0}+B_{1} V_{1}+B_{2} V_{2}+B_{3} V_{12}+B_{4} V_{21}+B_{5} V_{25}+B_{6} V_{33}+ \\
& B_{7} V_{34}+B_{8} V_{35}+B_{9} V_{36}+B_{10} V_{37}+B_{17} V_{38}
\end{aligned}
$$

Decision Applications

- How important is the role of the user and of top management in the utilization of the existing computers?

- How important is the existence of a master system plan?

- What are some of the most important variables for the optimum utilization of the existing computers?

Predictive Model \#3: Delays in Computer Installation and Utilization

$$
\begin{aligned}
V_{3}= & B_{0}+B_{1} V_{1}+B_{2} V_{2}+B_{3} V_{12}+B_{4} V_{21}+B_{5} V_{26}+B_{6} V_{31}+ \\
& B_{7} V_{32}+B_{8} V_{40}+B_{9} V_{52}+B_{10} V_{53}
\end{aligned}
$$

Decision Applications:

- What are some of the most important variables for the timely and efficient implementation of a CBMIS?

- How important is the role of project management in the 
implementation of a CBMIS?

- How important is the role of economic feasibility for the timeiy implementation of a CBMIS?

Predictive Model \#4: Cooperation and Coordination Among the Installations.

$V_{4}=B_{0}+B_{7} V_{10}+B_{2} V_{13}+B_{3} V_{14}+B_{4} V_{15}+B_{5} V_{16}+B_{6} V_{41}$

Decision Applications:

- How can the level of experience sharing among the installations be improved?

- Should developing countries employ standardization in data collection? in data transmission? in hardware selection? in software selection?

Predictive Model \#5: Migration of the Data from Place to Place

$$
Y_{5}=B_{0}+B_{7} V_{13}+B_{2} V_{14}+B_{3} V_{41}+B_{4} V_{49}
$$

Decision Applications:

- How can the level of data migration be improved?

- How important is the role of data base in the migration of data?

Predictive Model \#6: Reliability of the Provided Information

$$
Y_{6}=B_{0}+B_{1} V_{46}+B_{2} V_{47}+B_{3} V_{48}+B_{4} V_{50}
$$


Decision Application:

- How can the reliability of the provided information be improved?

Predictive Model \#7: Usefulness of the Provided Information

$V_{7}=B_{0}+B_{1} V_{39}+B_{2} V_{46}+B_{3} V_{47}+B_{4} V_{48}+B_{5} V_{50}+B_{6} V_{51}$

Decision Application:

- How can the usefulness of the provided information be improved?

Predictive Model \#8: Responsiveness of the CBMIS

$$
\begin{aligned}
V_{8}= & B_{0}+B_{1} V_{11}+B_{2} V_{39}+B_{3} V_{42}+B_{4} V_{46}+B_{5} V_{47}+B_{6} V_{48}+ \\
& B_{7} V_{50}+B_{8} V_{51}+B_{9} V_{54}
\end{aligned}
$$

Decision Application:

- How can the responsiveness of the CBMIS be improved?

Predictive Model \#9: Utilization of the Provided Information

$$
\begin{aligned}
Y_{9}= & B_{0}+B_{1} V_{1}+B_{2} V_{2}+B_{3} V_{11}+B_{4} V_{22}+B_{5} V_{23}+B_{6} V_{24}+ \\
& B_{7} V_{39}+B_{8} V_{42}+B_{9} V_{46}+B_{10} V_{47}+B_{11} V_{48}+B_{12} V_{50}+ \\
& B_{13} V_{51}+B_{14} V_{54}
\end{aligned}
$$

Decision Applications:

- How can the utilization of the provided information be improved? 
- What are some of the most important social issues for the employment of a CBMIS in a developing country?

Predictive Model \#10: Adaptability of the Present CBMIS to the Growing Technology

$Y_{10}=B_{0}+B_{1} V_{20}+B_{2} V_{43}+B_{3} V_{44}+B_{4} V_{45}$

Decision Application:

- How can the adaptability of the existing CBMIS to the growing technology be improved?

Predictive Model \#11: Economic Difficulties in the Physical Acquisition of Computer Technology

$V_{11}=B_{0}+B_{1} V_{17}+B_{2} V_{18}+B_{3} V_{19}$

Decision Application:

- How can the economic difficulties encountered in the acquisition of a CBMIS be overcome?

Predictive Model \#12: Manufacturer Satisfaction

$Y_{12}=B_{0}+B_{1} V_{27}+B_{2} V_{28}+B_{3} V_{29}+B_{4} V_{30}$

Decision Application:

- How should a developing country choose the manufacturer of computer technology?

In all of the above models, the following test statistic (see McClave and Dietrich, 1979) is used: 
For testing the utility of a multiple regression model, the global $F$ test:

Test statistic: $F=\frac{R^{2} / K}{\left(1-R^{2}\right) /\{n-(k+1)\}}$

Rejection region: $\quad F>F_{\alpha, k},\{n-(k+1)\}$

$\mathrm{n}=$ number of data points

$k=$ number of $B$ parameters in the mode?

$R^{2}=$ coefficient of determination

For testing of an individual parameter coefficient in the multiple regression model (two-tailed test) (see McClave, p 537):

Test statistic: $\quad t=\frac{\hat{B}_{i}}{S \hat{B}_{i}}$

Rejection region: $t<-t_{\alpha / 2, n-(k+1)}$

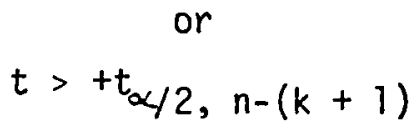

In this study, $\alpha$ has been set at 5 per cent.

SUMMARY

This chapter has presented all the research questions involyed in this study; it has also presented all the general hypotheses. In Chapter VI, the data will be analyzed. Various statistical analyses will be performed in order to show the significance of each variable. 
CHAPTER IV

RESEARCH METHODOLOGY, PHASE I

\section{INTRODUCTION}

This chapter first presents the most decisive elements of a descriptive model for the employment of computer-based management systems in developing countries. It secondly presents the twelve predictive equations which make up the predictive aspect of the proposed model.

Additionally, a cross-reference table is presented to show which of the 54 variables in the descriptive model are used in each of the 12 predictive equations. These relationships will be used in establishing the regression equations presented in Chapter $V$.

Finally, this chapter provides a brief background discussion which justifies the relationships between elements of the descriptive model and the predictive equations.

\section{ELEMENTS OF THE DESCRIPTIVE MODEL}

Fifty-eight variables were chosen to elaborate the descriptive part of the proposed model. For simplicity purposes, user involvement in all three phases $\left(V_{19}, V_{42}, V_{54}\right)$ has been combined and presented as $V_{7}$; top management involvement in all three phases $\left(V_{20}, V_{43}\right.$, and $\left.V_{55}\right)$ hereinafter is presented as $V_{2}$. For the remainder of this study, the names and numbers will be as appear in Table XII (p 90). These variables, 
Predictive Model \#1: Efficiency and Effectiveness of the Organization Due to the Acquisition of Computer Technology

Tables XIII and XIV show the most important statistical properties of this mode1. As Table XIII indicates, $V_{5}$ has the lowest mean, and $V_{g}$ has the highest. This indicates that, on the average, economic considerations have been the least important reason for computer acquisition; the need for more current information has been the most important one. This table also shows that, overall, the efficiency and effectiveness of operations have been improved by the employment of a CBMIS.

TABLE XIII

MEAN AND STANDARD DEVIATION

FOR PREDICTIVE MODEL \# 1

\begin{tabular}{|c|c|c|}
\hline Variable & Mean & Std Dev \\
\hline$v_{3}$ & 2.797 & 1.713 \\
\hline$v_{4}$ & 3.544 & 1.693 \\
\hline$v_{5}$ & 2.392 & 1.224 \\
\hline$v_{6}$ & 4.291 & 1.578 \\
\hline$v_{7}$ & 4.190 & 1.545 \\
\hline$v_{8}$ & 4.468 & 1.693 \\
\hline$v_{9}$ & 4.886 & 1.414 \\
\hline$v_{55}$ & 4.722 & 1.025 \\
\hline
\end{tabular}

Table XIV demonstrates the strength and direction of the relationship between the dependent variable (efficiency and effectiveness) and all the independent variables which describe this particular model. 
As this table indicates, $V_{3}$ (complexity of the organization's activities) has the strongest correlation with the dependent variable; conversely, $V_{5}$ (economic considerations) has the lowest correlation. Additionally, this table indicates the positive direction of the correlation. All, in fact, save one (other organizations' decisions) are positive.

\section{TABLE XIV}

\section{PAIRWISE CORRELATION FOR} DEPENDENT VARIABLE $V_{55}$

\begin{tabular}{ccc} 
Independent & Strength & Direction \\
\hline$v_{3}$ & 0.691 & positive \\
$v_{8}$ & 0.653 & positive \\
$v_{9}$ & 0.571 & positive \\
$v_{7}$ & 0.568 & positive \\
$v_{4}$ & 0.510 & negative \\
$v_{6}$ & 0.495 & positive \\
$v_{5}$ & 0.058 & positive
\end{tabular}

\section{Predictive Model \#2: Utilization of the Existing Computers}

Tables XV and XVI depict the most important statistical properties of this model. As Table XV indicates, $V_{35}$ has the highest mean, and $V_{25}$ has the lowest, which shows that existence of a specially-designed building is the most strongly considered variable in Model \#2. The mean of $V_{25}$ indicates that, on the average, a small percentage of the operations ( $\sim 20 \%$ ) has been managed 
by foreign consultants. It also shows that utilization of the existing computers is well under $100 \%$.

TABLE XV

MEAN AND STANDARD DEVIATION

FOR PREDICTIVE MODEL \#2

\begin{tabular}{cccc} 
Variable & Mean & Std Dev \\
\cline { 1 - 2 }$v_{1}$ & 2.481 & 1.663 \\
$v_{2}$ & 3.924 & 1.708 \\
$v_{12}$ & 4.329 & 1.685 \\
$V_{21}$ & 4.772 & 1.250 \\
$V_{25}$ & 1.544 & 0.829 \\
$V_{33}$ & 5.000 & 1.109 \\
$V_{34}$ & 5.051 & 0.999 \\
$V_{35}$ & 5.127 & 1.042 \\
$V_{36}$ & 4.329 & 1.095 \\
$V_{37}$ & 3.114 & 1.609 \\
$V_{38}$ & 4.291 & 1.923 \\
$V_{56}$ & 5.278 & 1.037
\end{tabular}

Table XVI shows the strength and direction of the relationship between the dependent variable (computer utilization) and all the independent variables which describe this particular model. As the table indicates, $V_{38}$ (problem definition) has the strongest correlation with computer utilization, and $V_{34}$ (existence of air conditioning) has the weakest, relatively speaking, although the 
absolute correlation is still high (.556). Furthermore, the direction of correlation is positive for each independent variable in this set, indicating that each of these variables has a positive impact on the utilization of existing computers.

TABLE XVI

$$
\begin{aligned}
& \text { PAIRWISE CORRELATION FOR } \\
& \text { DEPENDENT VARIABLE } V_{56}
\end{aligned}
$$

\begin{tabular}{ccc} 
Independent & Strength & Direction \\
\cline { 1 - 2 }$V_{38}$ & 0.814 & positive \\
$V_{12}$ & 0.805 & positive \\
$V_{21}$ & 0.801 & positive \\
$V_{37}$ & 0.734 & positive \\
$V_{1}$ & 0.672 & positive \\
$V_{2}$ & 0.627 & positive \\
$V_{25}$ & 0.627 & positive \\
$V_{33}$ & 0.591 & positive \\
$V_{36}$ & 0.585 & positive \\
$V_{35}$ & 0.560 & positive \\
$V_{34}$ & 0.556 & positive
\end{tabular}

Predictive Model \#3: Delays in Computer Installation and Utilization

Tables XIVV and XVIII present the most important statistical properties of this model. Table XVII indicates that $V_{26}$ has the lowest and $V_{27}$ has the highest mean, which indicates that either the proportion of foreign consultants has been very low or that there have not 
been major conflicts between native and foreign consultants. Also, $V_{21}$ (number of data processing personnel) has been the most important consideration in reducing delays in installation and utilization of a CBMIS. It is also clear that delays have occurred in several instances.

TABLE XVII

MEAN AND STANDARD DEVIATION

FOR PREDICTIVE MODEL \#3

\begin{tabular}{ccc} 
Variable & Mean & Std Dev \\
\cline { 3 - 3 }$v_{1}$ & 3.481 & 1.663 \\
$V_{2}$ & 3.924 & 1.708 \\
$V_{12}$ & 4.329 & 1.685 \\
$V_{21}$ & 4.772 & 1.250 \\
$V_{26}$ & 1.063 & 0.245 \\
$V_{31}$ & 3.354 & 1.121 \\
$V_{32}$ & 1.127 & 0.335 \\
$V_{40}$ & 4.747 & 0.912 \\
$v_{52}$ & 4.532 & 1.608 \\
$V_{53}$ & 1.899 & 1.582 \\
$V_{57}$ & 2.481 & 1.249
\end{tabular}

Table XVIII indicates the strength and direction of the relationship between the dependent variable (delays in CBMIS installation and utilization) and all the independent variables which describe the model. $V_{52}$ (project management principles) has the strongest correlation, and $V_{26}$ (conflict among foreign and native 
consultants) has the weakest correlation with the dependent variable. Direction of correlation, as Table XVIII shows, is all negative, with the exception of $v_{26}$ (conflict between foreign and native consultants).

TABLE XVIII

PAIRWISE CORRELATION FOR

DEPENDENT VARIABLE V57

\begin{tabular}{|c|c|c|}
\hline Independent & Strength & Direction \\
\hline$v_{52}$ & 0.818 & negative \\
\hline$v_{40}$ & 0.679 & negative \\
\hline$v_{12}$ & 0.606 & negative \\
\hline$v_{21}$ & 0.561 & negative \\
\hline$v_{31}$ & 0.499 & negati \\
\hline$v_{53}$ & 0.384 & negati \\
\hline$v_{1}$ & 0.304 & negati \\
\hline$v_{32}$ & 0.240 & negati \\
\hline$v_{2}$ & 0.223 & negati \\
\hline$v_{26}$ & 0.025 & positi \\
\hline
\end{tabular}

Predictive Model \#4: Cooperation and Coordination Among Installations

The most significant statistical properties of this model are contained in Tables XIX and XX. The lowest mean is shown to be $V_{41}$ (existence of information centers), and the highest mean is $V_{15}$ (standardization in hardware selection). This table indicates that lack of information centers for advising users is still a significant problem. It also indicates that standardization is becoming more 
common. The statistics additionally show that, on the average, the level of cooperation among users has been slightly above $50 \%$.

TABLE XIX

MEAN AND STANDARD DEVIATION

FOR PREDICTIVE MODEL \#4

\begin{tabular}{cccc} 
Variable & Mean & Std Dev \\
\cline { 1 - 2 }$V_{10}$ & 5.304 & 1.113 \\
$V_{13}$ & & 4.000 & 1.528 \\
$V_{14}$ & 2.962 & 1.870 \\
$V_{15}$ & 5.316 & 1.225 \\
$V_{16}$ & 5.139 & 1.288 \\
$V_{41}$ & 2.481 & 1.584 \\
$V_{58}$ & 3.886 & 1.527
\end{tabular}

Table $X X$ depicts the strength and direction of the relationship which exists between $V_{58}$ and the relevant independent variables. As this table shows, $v_{13}$ (standardization of data collection) has the strongest relationship with the dependent variable. It also shows that $V_{10}$ (existence of consulting firms) has the weakest relationship. This table also demonstrates the fact that all the relationships are positive, i.e., all the independent variables have a positive impact on the level of cooperation and coordination among the installations. 
TABLE XX

\section{PAIRWISE CORRELATION FOR DEPENDENT VARIABLE $V_{58}$}

\begin{tabular}{|c|c|c|}
\hline Independent & Strength & Direction \\
\hline$v_{13}$ & 0.879 & positive \\
\hline$v_{16}$ & 0.816 & positive \\
\hline$v_{41}$ & 0.812 & positive \\
\hline$v_{15}$ & 0.787 & positive \\
\hline$v_{14}$ & 0.676 & positive \\
\hline$v_{10}$ & 0.669 & positive \\
\hline
\end{tabular}

Predictive Model \#5: Migration of the Data from Place to Place

Tables XXI and XXII show the most important statistical properties of this model. As Table XXI indicates, $V_{41}$ (existence of information centers) has the lowest and $V_{49}$ (existence of an operational data base) the highest mean. This table also indicates that the overall level of data migration has been slightly above average.

\section{TABLE XXI}

MEAN AND STANDARD DEVIATION

FOR PREDICTIVE MODEL \#5

\begin{tabular}{|c|c|c|}
\hline Variable & Mean & Std Dev \\
\hline$v_{13}$ & 4.000 & 1.528 \\
\hline$v_{14}$ & 2.962 & 1.870 \\
\hline$v_{41}$ & 2.481 & 1.584 \\
\hline$v_{49}$ & 4.975 & 1.368 \\
\hline$v_{59}$ & 4.316 & 1.455 \\
\hline
\end{tabular}


Table XXII demonstrates the strength and direction of the relationship which exists between $V_{59}$ and the independent variables. As this table shows, $V_{49}$ (existence of data base) has the strongest and $V_{14}$ (standardization in data transmission) has the weakest relationshid to the dependent variable. The direction of the relationships is positive for every variable.

TABLE XXII

PAIRWISE CORRELATION FOR DEPENDENT VARIABLE $V_{59}$

\begin{tabular}{ccc} 
Independent & Strength & Direction \\
\hline$v_{49}$ & 0.848 & positive \\
$v_{13}$ & 0.831 & positive \\
$v_{41}$ & 0.729 & positive \\
$v_{14}$ & 0.612 & positive
\end{tabular}

Predictive Model \#6: Reliability of the Provided Information

Tables XXIII and XXIV present the most important statistical properties of this model. As Table XXIII indicates, $V_{50}$ (availability of mathematical models) has the lowest mean, and $v_{47}$ (recency of data) has the highest. The table also shows that general users' beliefs about the reliability of the provided information has been above average.

Table XXIV shows the strength and direction of the relationshp which exists between $V_{60}$ and the independent variables. $V_{46}$ (internal vs external data) has the strongest and $V_{48}$ (disaggregated vs aggregated 
data) the weakest relationship with the dependent variable.

TABLE XXIII

MEAN AND STANDARD DEVIATION

FOR PREDICTIVE MODEL \#6

\begin{tabular}{ccc} 
Variable & Mean & Std Dev \\
\hline$V_{46}$ & 2.696 & 1.572 \\
$V_{47}$ & 4.557 & 1.913 \\
$V_{48}$ & 3.228 & 1.569 \\
$V_{50}$ & 1.975 & 1.552 \\
$V_{60}$ & 4.823 & 0.958
\end{tabular}

TABLE XXIV

PAIRWISE CORRELATION FOR

DEPENDENT VARIABLE $V_{60}$

\begin{tabular}{|c|c|c|}
\hline Independent & Strength & Direction \\
\hline$v_{46}$ & 0.807 & positive \\
\hline$v_{47}$ & 0.803 & positive \\
\hline$v_{50}$ & 0.756 & positive \\
\hline$V_{48}$ & 0.736 & positive \\
\hline
\end{tabular}

Predictive Model \#7: Usefulness of the Provided Information

Tables XXV and XXVI present the most important statistical properties of this model. Table XXV indicates that $V_{50}$ (availability of mathematical models) has the lowest mean, and $V_{47}$ recency of data) has the highest. It also indicates that, on the average, users 
believe the information provided by the CBMIS to have been about $60 \%$ useful for decisionmaking.

TABLE XXV

MEAN AND STANDARD DEVIATION

FOR PREDICTIVE MODEL \#7

$\begin{array}{cccc}\text { Variable } & & \text { Mean } & \text { Std Dev } \\ V_{39} & & 3.506 & 1.860 \\ V_{46} & & 2.696 & 1.572 \\ V_{47} & 4.557 & 1.913 \\ V_{48} & 3.228 & 1.569 \\ V_{50} & 1.975 & 1.552 \\ V_{51} & 2.203 & 1.324 \\ V_{61} & 4.620 & 1.090\end{array}$

Table XXVI shows the strength and direction of the relationship which exists between $v_{61}$ and the independent variables. $V_{39}$ (scope of the system) is shown to have the strongest relationship with usefulness of the provided information, and $V_{50}$ (availability of mathematical models) has the weakest. The direction of all the relationships is positive, which means that the existence of any of these variables has a positive impact on the usefulness of the provided information. 
TABLE XXVI

PAIRWISE CORRELATION FOR

DEPENDENT VARIABLE $V_{61}$

\begin{tabular}{ccc} 
Independent & Strength & Direction \\
\hline$V_{39}$ & 0.868 & positive \\
$V_{47}$ & 0.822 & positive \\
$V_{46}$ & 0.815 & positive \\
$V_{51}$ & 0.809 & positive \\
$V_{48}$ & 0.794 & positive \\
$V_{50}$ & 0.783 & positive
\end{tabular}

Predictive Mode1 \#8: Responsiveness of the CBMIS

The most significant properties of this model are shown in Tables XXVII and XXVIII. Table XXVII shows that $V_{11}$ (centralization vs decentralization) has the lowest mean. This clearly indicates that a centralized computer policy is much more common than a decentralized policy. This table also shows that $V_{54}$ (post-implementation audit) has the highest mean. Furthermore, users generally believe that about $70 \%$ of the time, the CBMIS has been responsive to the needs of the users.

Table XXVIII shows the strength and the direction of the relationship which exists between $V_{62}$ and the independent variables. $V_{42}$ (types of design: task force vs individual) has been shown to have the strongest and $v_{11}$ (centralization/decentralization) the weakest relationship with the responsiveness of the CBMIS. 
TABLE XXVII

MEAN AND STANDARD DEVIATION

FOR PREDICTIVE MODEL \#8

\section{$\underline{\text { Variable }}$}

$v_{11}$

$v_{39}$

$v_{42}$

$v_{46}$

$v_{47}$

$v_{48}$

$v_{50}$

$v_{51}$

$v_{54}$

$v_{62}$

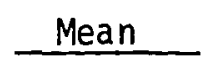

1.684

3.506

2.671

2.696

4.557

3.228

1.975

2.203

4.848

4.924
Std Dev

0.955

1.860

1.318

1.572

1.913

1.569

1.552

1.324

1.220

0.997

\section{TABLE XXVIII}

PAIRWISE CORRELATION FOR DEPENDENT VARIABLE $V_{62}$

\section{Independent}

$v_{42}$

$v_{54}$

$v_{47}$

$v_{46}$

$v_{39}$

$v_{50}$

$v_{51}$

$v_{48}$

$v_{11}$
Strength

0.820

0.812

0.795

0.787

0.761

0.744

0.730

0.716

0.621
Direction positive positive positive positive positive positive positive positive positive 
Predictive Model \#9: Utilization of the Provided Information

Tables XXIX and XXX show the most important statistical properties of this model. Table XXIX indicates that $V_{23}$ (privacy problem) has the lowest and $v_{47}$ (recency of data) the highest mean. It also shows that overall approximately $75 \%$ of the provided information has been utilized.

TABLE XXIX

MEAN AND STANDARD DEVIATION

FOR PREDICTIVE MODEL \#9

\begin{tabular}{ccc} 
Variable & Mean & Std Dev \\
\cline { 1 - 1 }$V_{1}$ & 2.481 & 1.663 \\
$V_{2}$ & 3.924 & 1.708 \\
$V_{11}$ & 1.684 & 0.955 \\
$V_{22}$ & 3.291 & 1.434 \\
$V_{23}$ & 1.114 & 0.320 \\
$V_{24}$ & 1.519 & 0.798 \\
$V_{39}$ & 3.506 & 1.860 \\
$V_{42}$ & 2.671 & 1.318 \\
$V_{46}$ & 2.696 & 1.572 \\
$V_{47}$ & 4.557 & 1.913 \\
$V_{48}$ & 3.228 & 1.569 \\
$V_{50}$ & 1.975 & 1.552 \\
$V_{51}$ & 2.203 & 1.324 \\
$V_{54}$ & 4.848 & 1.220 \\
$V_{63}$ & 5.228 & 1.062 \\
$V_{0}$ & &
\end{tabular}


Table $X X X$ shows the strength and direction of correlation which exists between the dependent variable, $v_{63}$, and the independent variables. $V_{47}$ (recency of data) has the strongest correlation with the dependent variable, and $V_{23}$ (privacy problem) has the weakest. Direction of correlation in this table is negative for some variables, positive for others.

TABLE $X X X$

$$
\begin{aligned}
& \text { PAIRWISE CORRELATION FOR } \\
& \text { DEPENDENT VARIABLE } V_{63}
\end{aligned}
$$

\begin{tabular}{|c|c|c|}
\hline Independent & Strength & Direction \\
\hline$v_{47}$ & 0.795 & positive \\
\hline$v_{54}$ & 0.759 & positive \\
\hline$v_{39}$ & 0.733 & positive \\
\hline$v_{42}$ & 0.714 & positive \\
\hline$v_{46}$ & 0.710 & positive \\
\hline$v_{22}$ & 0.663 & positive \\
\hline$v_{51}$ & 0.642 & positive \\
\hline$v_{50}$ & 0.595 & positive \\
\hline$v_{48}$ & 0.554 & positive \\
\hline$v_{11}$ & 0.515 & positive \\
\hline$v_{1}$ & 0.496 & positive \\
\hline$v_{2}$ & 0.469 & positive \\
\hline$v_{24}$ & 0.429 & negative \\
\hline$v_{23}$ & 0.153 & negative \\
\hline
\end{tabular}


Predictive Model \#10: Adaptability of the Present CBMIS to the Growing Technology

Tables XXXI and XXXII show the most important statistical properties of this model. As Table XXXI demonstrates, $V_{20}$ (the number of data processing training centers and their future plans) has the lowest mean, and $v_{45}$ (system documentation) has the highest. This indicates that most of the users believe that their systems are well documented. This table also indicates that approximately $50 \%$ of the users believe their CBMIS to be adaptable to the growing technology.

TABLE XXXI

MEAN AND STANDARD DEVIATION

FOR PREDICTIVE MODEL \#10

\begin{tabular}{ccc} 
Variable & Mean & Std Dev \\
\cline { 2 - 3 }$V_{20}$ & 2.063 & 1.125 \\
$V_{43}$ & 3.354 & 1.657 \\
$V_{44}$ & 3.671 & 1.654 \\
$V_{45}$ & 5.076 & 1.308 \\
$V_{64}$ & 4.494 & 1.249
\end{tabular}

Table XXXII presents the strength and the direction of the relationship which exists between the dependent and the independent variables. As this table shows, $V_{45}$ (system documentation) has the strongest correlation with the dependent variable; $V_{20}$ (number of data processing training centers and their future plans). 
TABLE XXXII

PAIRWISE CORRELATION FOR

DEPENDENT VARIABLE $V_{64}$

\begin{tabular}{ccc} 
Dependent & Strength & Direction \\
\hline$v_{45}$ & 0.894 & positive \\
$v_{44}$ & 0.867 & positive \\
$v_{43}$ & 0.844 & positive \\
$v_{20}$ & 0.762 & positive
\end{tabular}

Predictive Model \#11: Economic Difficulties in the Physical Acquisition of Computer Technology

Tables XXXIII and XXXIV present the most significant statistical properties of this model. As Table XXXIII indicates, all the variables in this instance have a very low mean. This indicates that neither taxes/tariffs nor transportation has been a barrier to computer utilization in Iran. The table also shows that although in some cases the users have had economic difficulties, these difficulties have not been caused by heavy taxes or tariffs and/or inefficient transportation.

Table XXXIV shows the strength and the direction of the relationship which exists between these variables and the dependent variable, $V_{65}$. As the table indicates, the strength of the relationship is very Tow. 
TABLE XXXIII

MEAN AND STANDARD DEVIATION

FOR PREDICTIVE MODEL \#11

$\begin{array}{cccc}\text { Variable } & \text { Mean } & \text { Std Dev } \\ v_{17} & & 1.013 & 0.113 \\ v_{18} & 1.051 & 0.221 \\ v_{19} & 1.152 & 0.361 \\ v_{65} & 1.684 & 0.671\end{array}$

TABLE XXXIV

PAIRWISE CORRELATION FOR DEPENDENT VARIABLE $V_{65}$

Independent

$v_{14}$

$v_{17}$

$v_{18}$
Strength

0.169

0.054

0.023
Direction

negative

positive

positive

\section{Predictive Model \#12: Manufacturer Satisfaction}

Tables XXXV and XXXVI present the most important statistical properties of this model. As Table XXXV indicates, all the independent variables have a relatively high mean. $V_{30}$ (availability of a backup) has the lowest mean. National political considerations has been a very important factor in the choice of a manufacturer. Approximately $76 \%$ of the users indicate satisfaction with the manufacturer of computer technology. 
TABLE XXXV

MEAN AND STANDARD DEVIATION

FOR PREDICTIVE MODEL \#12

\begin{tabular}{ccc} 
Variable & Mean & Std Dev \\
\cline { 3 - 3 }$V_{27}$ & 5.241 & 1.015 \\
$V_{28}$ & 5.494 & 1.048 \\
$V_{29}$ & 5.278 & 1.198 \\
$V_{30}$ & 4.101 & 1.524 \\
$V_{66}$ & 5.316 & 0.899
\end{tabular}

TABLE XXXVI

PAIRWISE CORRELATION FOR

DEPENDENT VARIABLE $V_{66}$

Independent

$V_{29}$

$v_{28}$

$v_{30}$

$v_{27}$
Strength

0.762

0.716

0.668

0.351
Direction

positive

positive

positive

positive

TEST OF HYPOTHESES

This section tests two different hypotheses. The first involves a global $F$ test, which shows the significance of a particular model. The criteria for this test are both the magnitude of the coefficient of determination and the value of $F$. If this test is passed, the second test--the test of an individual parameter coefficient within 
the multiple regression model--is run. The criterion for this test is the magnitude of $F$ comparing with the $F$ value within the $F$ table. If this value is greater than the value of $F$ from the table, a particular coefficient will be considered to be significant.

As mentioned earlier, the value of $\alpha$ has been set to be equal to $5 \%$. In order to perform these tests, the forced entry multiple regression model has been run. In this procedure, all the independent variables are forced into the model. The final value of the coefficient of determination shows whether a particular model is statistically significant. This value indicates the percent of variation in a dependent variable that is explained by all the independent variables included in the model. Table XXXVII presents a summary of the twelve different runs accomplished for the twelve predictive models.

Table XXXVII shows that all the null hypotheses are indeed rejected except for Model \#11. The acceptance of the null hypothesis for this model yields two indications: (1) as Table XXXIII shows (p 127), taxes, cost of transportation and/or duties/tariffs have not been barriers for the acquisition of computer technology in Iran; (2) in cases where specific installations have had economic difficulties, the difficulties have not been caused by taxes, transportatior, costs, and/or duties/tariffs. Therefore, these three independent variables (i.e., $v_{17}, v_{18}, v_{19}$ ) do not explain any degree of variation in dependent variable $v_{65}$. 


\section{TABLE XXXVII}

HYPOTHESIS TESTING FOR THE TWELVE PREDICTIVE MODELS

\begin{tabular}{|c|c|c|c|}
\hline Model & Test \#1 & $\mathrm{R}^{2}$ & Test \#2 \\
\hline Model \# $1\left(v_{55}\right)$ & rejected & 0.66184 & $v_{3}, v_{4}, v_{8}$ \\
\hline Mode $1 \# 2\left(v_{56}\right)$ & rejected & 0.78519 & $v_{21}, v_{38}$ \\
\hline Model \# $3\left(v_{57}\right)$ & rejected & 0.75277 & $v_{52}, v_{40}$ \\
\hline Model \# $4\left(v_{58}\right)$ & rejected & 0.80800 & $v_{13}$ \\
\hline Mode $1 \# 5\left(V_{59}\right)$ & rejected & 0.82957 & $v_{49}, v_{13}$ \\
\hline Model \# $6\left(v_{60}\right)$ & rejected & 0.76670 & $v_{47}, v_{60}, v_{46}$ \\
\hline Model \# $7\left(v_{61}\right)$ & rejected & 0.87350 & $v_{39}, v_{48}, v_{51}, v_{50}$ \\
\hline Model \# $8\left(v_{62}\right)$ & rejected & 0.81571 & $V_{54}$ \\
\hline Model \# $9\left(v_{63}\right)$ & rejected & 0.76943 & $v_{22}$ \\
\hline Model \#10 $\left(V_{64}\right)$ & rejected & 0.85190 & $v_{45}, v_{44}$ \\
\hline Model \#11 $\left(V_{65}\right)$ & accepted & 0.03114 & none \\
\hline Model \#12 (:66) & rejected & 0.63822 & $V_{29}$ \\
\hline
\end{tabular}

CHOOSING THE BEST PREDICTIVE MODEL

Several studies have shown that models with fewer numbers of independent variables are, in general, more accurate than models including the whole set of independent variables (see, for example, Halinski, 1970; Darlington, 1968; Hul1, 1981). Additionally, the study by Halinski shows that the stepwise and forward entry multiple regression in general produce a more accurate model, compared with that yielded with the backward elimination method. These three 
procedures are all used in this study to aid in selection of the best predictive model.

In the forward entry procedure, the independent variable which has the highest correlation with the dependent variable is entered into the model first. In each successive stage, a new variable which increases the coefficient of determination $\left(R^{2}\right)$ the most is added. This procedure continues until there is no change in $R^{2}$ for a particular level of significance.

In backward elimination, the regression model for the entire set of independent variables is initially established. Then, based on the value of $F$ and $R^{2}$, the least significant variables are deleted in each successive stage.

As mentioned in Chapter $V$, in the stepwise procedure it is possible to eliminate a variable at a stage subsequent to its entry if that particular variable is not significant any more.

Tables XXXVIII, XXXIX, and XL present summaries of the three procedures established for the twelve predictive models.

In order to show that a model with fewer predictors (independent variables) is more accurate than a model which includes the whole set of predictors, a different version of the forward entry procedure has been run for each predictive model. In this version, a less rigorous set of entry criteria have been established for the independent variables, giving each the opportunity to enter the model. For example, the pattern of $R^{2}$, adjusted $R^{2}$, standard error of estimate, and $F$ change for eleven different steps of predictive model \#2 is shown in Table XLI. This example has only eleven steps because there 


\section{TABLE XXXVIII}

FORWARD ENTRY MULTIPLE REGRESSION FOR

THE TWELVE PREDICTIVE MODELS

\begin{tabular}{|c|c|c|}
\hline Mode1 & $R^{2}$ & Variables in the Model \\
\hline Model \# $1\left(V_{55}\right)$ & 0.65198 & $v_{3}, v_{8}, v_{4}, v_{5}$ \\
\hline Mndel \# $2\left(V_{56}\right)$ & 0.76785 & $v_{38}, v_{21}, v_{37}$ \\
\hline Mode1 $\# 3\left(v_{57}\right)$ & 0.74183 & $v_{52}, v_{40}, v_{2}$ \\
\hline Model \# $4\left(V_{58}\right)$ & 0.79324 & $v_{13}, v_{16}$ \\
\hline Model \# $5\left(V_{59}\right)$ & 0.82373 & $v_{49}, v_{13}$ \\
\hline Model \# $6\left(v_{60}\right)$ & 0.76371 & $v_{46}, v_{47}, v_{50}$ \\
\hline Model \# $7\left(v_{61}\right)$ & 0.86871 & $v_{39}, v_{50}, v_{48}, v_{51}$ \\
\hline Model \# $8\left(V_{62}\right)$ & 0.80921 & $v_{42}, v_{54}, v_{50}, v_{47}$ \\
\hline Model $\# 9\left(v_{63}\right)$ & 0.70989 & $v_{47}, v_{54}, v_{22}$ \\
\hline Model \#10 $\left(v_{64}\right)$ & 0.84532 & $v_{45}, v_{44}$ \\
\hline Model \#11 $\left(V_{65}\right)$ & not significant & 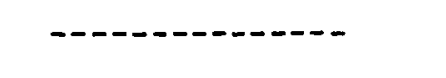 \\
\hline Model $\# 12\left(v_{66}\right)$ & 0.61862 & $v_{29}, v_{30}$ \\
\hline
\end{tabular}

are onty eleven independent variables included in this model. Table XLI presents the summary of all the statistics just mentioned.

Table XLI reveals a series of interesting facts. As the table shows, variables are entered into the regression model in the following order: $v_{38}, v_{21}, v_{37}, v_{36}, v_{35}, v_{25}, v_{33}, v_{34}, v_{2}, v_{1}$, and $v_{12}$. As each additional variable is entered, the multiple $R$ and the multiple $R^{2}$ increase, though by diminishing amounts. For example, for $V_{38}$, the $R^{2}$ value is 0.6628 , while for all independent variables in the model, the multiple $\mathrm{R}^{2}$ is 0.7852 . 
TABLE XXXIX

BACKWARD ELIMINATION MULTIPLE REGRESSION FOR

THE TWELVE PREDICTIVE MODELS

\begin{tabular}{|c|c|c|}
\hline Model & $R^{2}$ & Variables in the Model \\
\hline Model \# $1\left(V_{55}\right)$ & 0.65198 & $v_{5}, v_{3}, v_{4}, v_{8}$ \\
\hline Model \# $2\left(V_{56}\right)$ & 0.77855 & $v_{38}, v_{36}, v_{21}, v_{37}$ \\
\hline Model \# $3\left(V_{57}\right)$ & 0.74183 & $v_{40}, v_{2}, v_{52}$ \\
\hline Model \# $4\left(V_{58}\right)$ & 0.80111 & $v_{41}, v_{13}, v_{16}$ \\
\hline Model \# $5\left(V_{59}\right)$ & 0.82373 & $v_{49}, v_{13}$ \\
\hline Model \# $6\left(V_{60}\right)$ & 0.76371 & $v_{50}, v_{47}, v_{46}$ \\
\hline Model \# $7\left(V_{61}\right)$ & 0.86871 & $v_{51}, v_{48}, v_{39}, v_{50}$ \\
\hline Model \# $8\left(V_{62}\right)$ & 0.80921 & $v_{54}, v_{50}, v_{47}, v_{42}$ \\
\hline Model \# $9\left(V_{63}\right)$ & 0.75189 & $\begin{array}{c}v_{23}, v_{22}, v_{50}, v_{39}, v_{47}, \\
v_{1}\end{array}$ \\
\hline Model \#10 $\left(V_{64}\right)$ & 0.85187 & $v_{45}, v_{44}, v_{43}$ \\
\hline Model \#11 $\left(V_{65}\right)$ & not significant & $-\cdots-\cdots$ \\
\hline Miodel \#12 $\left(V_{66}\right)$ & 0.63610 & $V_{27}, V_{29}, V_{28}$ \\
\hline
\end{tabular}

In contrast, the adjusted $R^{2}$ does not increase beyond a certain point as independent variables are entered. In genera1, the adjusted $\mathrm{R}^{2}$ could be sensitive to a small sample size or to a relatively large number of independent variables (Hul1, 1981). The fact that the magnitude of adjusted $R^{2}$ declines after a certain point means that the eleven-variable model is worse than some others. By "worse" is meant that the final model may perform well for the given set of data, but is unlikely to do so well for a new set (Hul1, 1981). 
TABLE XL

STEPWISE SELECTION MULTIPLE REGRESSION FOR

THE TWELVE PREDICTIVE MODELS

\begin{tabular}{|c|c|c|}
\hline Model & $R^{2}$ & Variables in the Model \\
\hline Model \# $1\left(V_{55}\right)$ & 0.65198 & $v_{3}, v_{8}, v_{4}, v_{5}$ \\
\hline Mode $1 \# 2\left(V_{56}\right)$ & 0.76785 & $v_{38}, v_{27}, v_{37}$ \\
\hline Model \# $3\left(V_{57}\right)$ & 0.74183 & $v_{52}, v_{40}, v_{2}$ \\
\hline Model \# $4\left(V_{58}\right)$ & 0.79324 & $v_{13}, v_{16}$ \\
\hline Model \# $5\left(v_{59}\right)$ & 0.82373 & $v_{49}, v_{13}$ \\
\hline Model $\# 6\left(v_{60}\right)$ & 0.76371 & $v_{46}, v_{47}, v_{50}$ \\
\hline Model \# $7\left(V_{61}\right)$ & 0.86871 & $v_{39}, v_{50}, v_{48}, v_{51}$ \\
\hline Model \# $8\left(v_{62}\right)$ & 0.80921 & $v_{42}, v_{54}, v_{50}, v_{47}$ \\
\hline Model $\# 9\left(V_{63}\right)$ & 0.70989 & $v_{47}, V_{54}, V_{22}$ \\
\hline Model \#10 $\left(V_{64}\right)$ & 0.84532 & $v_{45}, v_{44}$ \\
\hline Model \#11 $\left(V_{65}\right)$ & not significant & $\cdots-\cdots$ \\
\hline Model \#12 $\left(V_{66}\right)$ & 0.61862 & $v_{29}, v_{30}$ \\
\hline
\end{tabular}

As Table XLI demonstrates, the standard error of the estimate behaves in a contrary fashion to the pattern of the adjusted $R^{2}$, but works to the same effect (Hu11, 1981). The pattern shows a decrease in value followed by an increase. Again, the message is that a model with three or four variables is likely to suffice.

This table also shows the pattern of $F$ change and its associated significance level. These two numbers provide a formal test of whether bringing in an additional variable results in an improved model. The pattern of significance levels, $0.000,0.000,0.001$, 
TABLE XLI

SUMMARY OF STATISTICS FOR PREDICTIVE MODEL \#2

\begin{tabular}{|c|c|c|c|c|c|c|c|c|c|c|c|c|c|}
\hline STEP & MULTR & RSQ & ADJRSQ & $F(E Q U)$ & SIGF & $\mathrm{RSQCH}$ & $\mathrm{FCH}$ & SIGCH & & RIABLE & BETAIN & CORREL & SE ST. \\
\hline 1 & 0.8141 & 0.6628 & 0.6584 & 151.326 & 0.000 & 0.6628 & 151.326 & 0.000 & IN: & v38 & 0.8141 & 0.8141 & 0.60609 \\
\hline 2 & 0.8538 & 0.7289 & 0.7218 & 102.179 & 0.000 & 0.0662 & 18.547 & 0.000 & IN: & V2i & 0.4202 & 0.8012 & 0.54696 \\
\hline 3 & 0.8763 & 0.7679 & 0.7586 & 82.690 & 0.000 & 0.0389 & 12.579 & 0.001 & IN: & v37 & 0.2829 & 0.7337 & 0.50952 \\
\hline 4 & 0.8824 & 0.7785 & 0.7666 & 65.039 & 0.000 & 0.0107 & 3.574 & 0.063 & IN: & V36 & 0.1275 & 0.5847 & 0.50100 \\
\hline 5 & 0.8835 & 0.7806 & 0.7656 & 51.940 & 0.000 & 0.0020 & 0.678 & 0.413 & IN: & V35 & -0.0653 & 0.5601 & 0.50209 \\
\hline 6 & 0.8841 & 0.7817 & 0.7635 & 42.958 & 0.000 & 0.0011 & 0.352 & 0.555 & IN: & v25 & 0.0470 & 0.6268 & 0.50434 \\
\hline 7 & 0.8845 & 0.7824 & 0.7609 & 36.462 & 0.000 & 0.0007 & 0.233 & 0.631 & IN: & v33 & -0.450 & 0.5906 & 0.50705 \\
\hline 8 & 0.8859 & 0.7848 & 0.7602 & 31.916 & 0.000 & 0.0025 & 0.802 & 0.373 & IN: & v34 & 0.1045 & 0.5557 & 0.50775 \\
\hline 9 & 0.8860 & 0.7849 & 0.7569 & 27.983 & 0.000 & 0.0001 & 0.037 & 0.848 & IN: & v2 & 0.0235 & 0.6275 & 0.51128 \\
\hline 10 & 0.8861 & 0.7852 & 0.7536 & 24.856 & 0.000 & 0.0002 & 0.078 & 0.781 & IN: & $v_{1}$ & -0.0395 & 0.6722 & 0.51473 \\
\hline 11 & 0.8861 & 0.7852 & 0.7499 & 22.264 & 0.000 & 0.0000 & 0.000 & 0.987 & IN: & V12 & 0.0026 & 0.8054 & 0.51856 \\
\hline
\end{tabular}


$0.063,0.413,0.555,0.631,0.373,0.848,0.781,0.987$, shows that at most, four independent variables have statistically significant impacts on the dependent variable. Analys is with the backward elimination method has yielded nearly identical results.

Based upon the discussion just presented and the work done by Halinski (1970) and Darlington (1968), stepwise regression has been determined to be the most appropriate method for selection of the best predictive model.

SUMMARY CF SIGNIFICANT FINAL STATISTICS FOR THE 12 PREDICTIVE MODELS

TabTes XLII through LII present the summaries for predictive models 1 through 10 and model 12. The predictive model equations, derived from these tables, are shown below. The approximate percentage of the total variation accounted for by the variables included in each model equation is given in brackets to the right of each equation. (The percentage is the $R$ square value multiplied by 100.) For a listing of the names associated with each variable, see Table XII on page 90 .

$$
\begin{aligned}
& Y_{7}\left(V_{55}\right)=3.39+0.25 V_{3}+0.20 V_{8}-0.16 V_{4}+0.14 V_{5} \\
& V_{2}\left(V_{56}\right)=2.46+0.16 V_{38}+0.33 V_{21}+0.18 V_{37} \\
& V_{3}\left(V_{57}\right)=6.44-0.55 V_{52}-0.41 V_{40}+0.11 V_{2} \\
& v_{4}\left(V_{58}\right)=0.35+0.66 V_{13}+0.31 V_{16} \\
& \gamma_{5}\left(V_{59}\right)=-0.19+0.55 V_{49}+0.44 V_{13} \\
& \gamma_{6}\left(V_{60}\right)=3.12+0.16 V_{46}+0.19 V_{47}+0.19 V_{50} \\
& V_{7}\left(V_{61}\right)=2.59+0.28 V_{39}+0.12 V_{50}+0.14 V_{48}+0.16 v^{51}
\end{aligned}
$$




$$
\begin{aligned}
& \gamma_{8}\left(v_{62}\right)=2.29+0.19 v_{42}+0.28 v_{54}+0.14 v_{50}+0.10 v_{47} \\
& \gamma_{9}\left(v_{63}\right)=2.40+0.25 v_{47}+0.24 v_{54}+0.16 v_{22} \\
& r_{10}\left(v_{64}\right)=0.67+0.54 v_{45}+0.30 v_{44} \\
& \gamma_{12}\left(v_{66}\right)=2.38+0.43 v_{29}+0.16 v_{30}
\end{aligned}
$$

\begin{tabular}{|c|c|c|c|c|c|}
\hline Variable & B & SE B & Beta & $\mathrm{T}$ & $\operatorname{Sig} T$ \\
\hline$v_{3}$ & 0.25393 & 0.04915 & 0.42446 & 5.167 & 0.0000 \\
\hline$v_{8}$ & 0.19599 & 0.05077 & 0.32395 & 3.860 & 0.0002 \\
\hline$v_{4}$ & -0.16368 & 0.04986 & -0.27050 & -3.283 & 0.0016 \\
\hline$v_{5}$ & 0.13674 & 0.06145 & 0.16263 & 2.215 & 0.0298 \\
\hline constant & 3.38983 & 0.32930 & & 10.294 & 0.0000 \\
\hline
\end{tabular}

\section{TABLE XLII}

PREDICTIVE MODEL \#1:

SUMMARY OF SIGNIFICANT FINAL STATISTICS

TABLE XLIII

\begin{tabular}{|c|c|c|c|c|c|}
\hline Variable & B & SE B & Beta & $T$ & Sig $T$ \\
\hline$v_{38}$ & 0.16201 & 0.05626 & 0.30036 & 2.880 & 0.0052 \\
\hline$v_{21}$ & 0.32692 & 0.07564 & 0.39412 & 4.322 & 0.0000 \\
\hline$v_{37}$ & 0.18230 & 0.05140 & 0.28289 & 3.547 & 0.0007 \\
\hline constant & 2.45550 & 0.23967 & & 10.245 & 0.0000 \\
\hline
\end{tabular}

PREDICTIVE MODEL \#2:

SUMMARY OF SIGNIFICANT FINAL STATISTICS

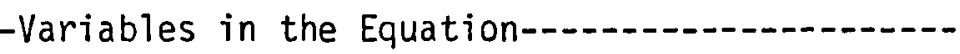


TABLE XLIV

PREDICTIVE MODEL \#3:

SUMMARY OF SIGNIFICANT FINAL STATISTICS

\begin{tabular}{|c|c|c|c|c|c|}
\hline Variable & B & SE B & Beta & $\mathrm{F}$ & $\operatorname{sig} T$ \\
\hline$v_{52}$ & -0.54566 & 0.06051 & -0.70236 & -9.018 & 0.0000 \\
\hline$v_{40}$ & -0.40714 & 0.10137 & -0.29737 & -4.016 & 0.0001 \\
\hline$v_{2}$ & 0.11426 & 0.04726 & 0.15622 & 2.417 & 0.0181 \\
\hline constant & 6.43799 & 0.39639 & & 16.242 & 0.0000 \\
\hline
\end{tabular}

TABLE XLV

PREDICTIVE MODEL \#4:

SUMMARY OF SIGNIFICANT FINAL STATISTICS

- Variables in the Equation-1.-

\begin{tabular}{|c|c|c|c|c|c|}
\hline Variable & $B$ & SE B & Beta & $T$ & Sig $T$ \\
\hline$v_{13}$ & 0.65835 & 0.09623 & 0.65840 & 6.842 & 0.0000 \\
\hline$v_{16}$ & 0.31147 & 0.11409 & 0.26272 & 2.730 & 0.0079 \\
\hline constant & -0.34806 & 0.34481 & & -1.009 & 0.3160 \\
\hline
\end{tabular}

TABLE XLVI

PREDICTIVE MODEL \#5:

SUMMARY OF SIGNIFICANT FINAL STATISTICS

$\begin{array}{ccccccc}\text { Variable } & \text { B } & \text { SE B } & \text { Beta } & T & \text { Sig T } \\ V_{49} & 0.55339 & 0.07292 & 0.52033 & 7.589 & 0.0000 \\ V_{13} & 0.43850 & 0.06530 & 0.46041 & 6.715 & 0.0000 \\ \text { constant } & -0.19048 & 0.26416 & & -0.721 & & 0.4731\end{array}$


TABLE XLVII

PREDICTIVE MODEL \#6:

SUMMARY OF SIGNIFICANT FINAL STATISTICS

-Variables in the Equation

\begin{tabular}{|c|c|c|c|c|c|}
\hline Variable & B & SE B & Beta & $I$ & $\operatorname{Sig} T$ \\
\hline$v_{46}$ & 0.16070 & 0.06545 & 0.26380 & 2.455 & 0.0164 \\
\hline$v_{47}$ & 0.19448 & 0.04801 & 0.38856 & 4.051 & 0.0001 \\
\hline$v_{50}$ & 0.19474 & 0.05087 & 0.31569 & 3.828 & 0.0003 \\
\hline constant & 3.11872 & 0.14035 & & 22.222 & 0.0000 \\
\hline
\end{tabular}

TABLE XLVIII

PREDICTIVE MODEL \#7;

SUMMARY OF SIGNIFICANT FINAL STATISTICS

\begin{tabular}{ccccccc} 
Variable & B & SE B & Beta & T & Sig T \\
\cline { 1 - 2 }$V_{39}$ & 0.28243 & 0.03778 & & 0.48202 & 7.476 & 0.0000 \\
$V_{50}$ & 0.11661 & 0.05254 & & 0.16612 & 2.219 & 0.0295 \\
$V_{48}$ & 0.13948 & 0.04831 & & 0.20079 & 2.887 & 0.0051 \\
$V_{51}$ & 0.16362 & 0.06137 & & 0.19883 & 2.666 & 0.0094 \\
constant & 2.58909 & 0.11371 & & 22.769 & 0.0000
\end{tabular}

TABLE XLIX

PREDICTIVE MODEL \#8:

SUMMARY OF SIGNIFICANT FINAL STATISTICS

\begin{tabular}{|c|c|c|c|c|c|}
\hline Variable & $B$ & SE B & Beta & $T$ & Sig T \\
\hline$v_{42}$ & 0.19884 & 0.07292 & 0.26279 & 2.727 & 0.0080 \\
\hline$v_{54}$ & 0.28458 & 0.06979 & 0.34833 & 4.078 & 0.0001 \\
\hline$v_{50}$ & 0.13772 & 0.05141 & 0.21440 & 2.679 & 0.0091 \\
\hline$v_{47}$ & 0.09912 & 0.04718 & 0.19019 & 2.101 & 0.0391 \\
\hline constant & 2.28965 & 0.22151 & & 10.337 & 0.0000 \\
\hline
\end{tabular}


TABLE L

PREDICTIVE MODEL \#9:

SUMMARY OF SIGNIFICANT FINAL STATISTICS

Variables in the Equation-

\begin{tabular}{ccccccc} 
Variable & B & SE B & Beta & S & Sig T \\
\cline { 5 - 6 }$V_{47}$ & 0.24700 & 0.05699 & 0.44515 & 4.334 & 0.0000 \\
$V_{54}$ & 0.24155 & 0.08986 & 0.27770 & 2.688 & 0.0089 \\
$V_{22}$ & 0.16186 & 0.06085 & 0.21858 & 2.650 & 0.0096 \\
constant & 2.39854 & 0.28049 & & 8.551 & 0.0000
\end{tabular}

TABLE LI

PREDICTIVE MODEL \#10:

SUMMARY OF SIGNIFICANT FINAL STATISTICS

$\begin{array}{lllllll}\text { Variable } & \text { B } & \text { SE B } & \text { Beta } & \text { T } & \text { Sig T } \\ V_{45} & 0.53760 & 0.07960 & 0.56305 & 6.754 & 0.0000 \\ V_{44} & 0.29755 & 0.06296 & 0.39398 & 4.726 & 0.0000 \\ \text { constant } & 0.67257 & 0.25049 & & 2.685 & 0.0089\end{array}$

TABLE LII

PREDICTIVE MODEL \#12:

SUMMARY OF SIGNIFICANT FINAL STATISTICS

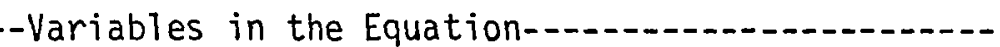

\begin{tabular}{cccccc} 
Variable & B & SE B & Beta & $\frac{T}{\text { Sig T }}$ \\
\cline { 5 - 6 }$V_{29}$ & 0.43216 & 0.07386 & 0.57549 & 5.851 & 0.0000 \\
$V_{30}$ & 0.15885 & 0.05804 & 0.26921 & 2.737 & 0.0077 \\
constant & 2.38378 & 0.28967 & & 8.229 & 0.0000
\end{tabular}




\section{ASSUMPTIONS OF MULTIPLE REGRESSION}

The assumptions of the multiple regression model are herein checked by the independence of residuals, normality, linearity, and colinearity. The first three are checked by a forced entry regression model with different plots. The plots include casewise plot of standardized residuals, normal probability studentized residuals, and a standardized scatter plot of predicted against residuals. These are employed for all the predictive models. Results show that in all cases there has been no serious violation of the assumptions of the regression model. The plots for Predictive Model \#1 will serve as an example. Figure 16 shows the casewise plot of the standardized residuals along with some related statistics.

As this figure shows, the standardized residuals fall mostly between two standard deviation limits and are positively and negatively signed with equal frequency.

The normal probability plot of studentized residuals (Figure 17) shows no dramatic departure from normality. The plot of the predicted values versus the residuals (Figure 18) reveals no clear model inadequacies.

In order to check for colinearity, all the zero-order correlation matrices have been investigated. In some cases, colinearity among variables was discovered. However, those instances were not among variables which were largely responsible for the explanation of a particular model. Therefore, this issue does not present any major obstacle to the general interpretation. 
TABLE LIII

CASEWISE PLOT OF STANDARDIZED RESIDUAL

\begin{tabular}{|c|c|c|c|c|c|c|c|c|c|c|}
\hline & -3.0 & 0.0 & 3.0 & & & & & & & \\
\hline SEQHEL & $0: \ldots \ldots$ & $\ldots .$. & $\ldots$ & U55 & TPRED & HRESID & T5RESID & SDRESIO & MAHA & tragk \\
\hline 1 & - & - & 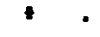 & 5.0000 & 4.0061 & 0.9939 & 1.8465 & $1.87: 4$ & :7.9353 & $0.2: 70$ \\
\hline $\begin{array}{l}2 \\
3\end{array}$ & : & i & : & $\begin{array}{l}4.0060 \\
5.0000\end{array}$ & $\begin{array}{l}4.5762 \\
5.0382\end{array}$ & $\begin{array}{l}-0.5762 \\
-0.0382\end{array}$ & $\begin{array}{l}-0.9737 \\
-0.066 \mathrm{i}\end{array}$ & $\begin{array}{l}-0.9734 \\
-0.0857\end{array}$ & $\begin{array}{l}6.066 \mathrm{E} \\
9.314 \mathrm{C}\end{array}$ & $\begin{array}{l}0.0: E 9 \\
0.00 \times 5\end{array}$ \\
\hline 4 & . & . & • & 4.0000 & 4.5935 & -0.5825 & -0.9574 & -0.9570 & 3.3092 & $0.6: 09$ \\
\hline $\begin{array}{l}5 \\
6 \\
7\end{array}$ & . & $\therefore$ & •. & $\begin{array}{l}5.0000 \\
4.0000\end{array}$ & $\begin{array}{l}5.5432 \\
4.1862\end{array}$ & $\begin{array}{l}-0.5432 \\
-0.1862\end{array}$ & $\begin{array}{l}-0.9259 \\
-0.3123 \\
-0.1260\end{array}$ & $\begin{array}{l}-0.9259 \\
-0.3 ! 04 \\
-0.095\end{array}$ & $\begin{array}{l}7.4169 \\
5.0317\end{array}$ & $\begin{array}{l}0.0207 \\
0.00 i E\end{array}$ \\
\hline 7 & - & 1. & - & 3.0000 & 3.2385 & -0.2395 & -0.4048 & -0.4025 & E.6826 & 0.0036 \\
\hline $\begin{array}{l}8 \\
9\end{array}$ & • & . & • & $\begin{array}{l}5.0000 \\
4.0000\end{array}$ & $\begin{array}{l}4.9296 \\
3.7942\end{array}$ & $\begin{array}{l}0.0704 \\
0.2055\end{array}$ & $\begin{array}{l}0.1199 \\
0.3413\end{array}$ & $\begin{array}{l}0.1191 \\
0.3392\end{array}$ & $\begin{array}{l}7.2354 \\
3.3441\end{array}$ & $\begin{array}{l}0.0063 \\
0.06: 1\end{array}$ \\
\hline 10 & - & เ. & - & 5.0000 & 5.4226 & -0.1226 & -0.7040 & $-0.701 E$ & 4.0226 & 0.6089 \\
\hline 11 & . &. & • & 6.0000 & 5. 6E:26 & 0.3274 & 0.5527 & $0.551:$ & 1.7773 & $0.00: 3$ \\
\hline 12 & - & + & - & 4.0000 & 3.9395 & $0 . \dot{0} 505$ & 0.0990 & $0.09 E ?$ & 1.3990 & $0.000:$ \\
\hline 13 & - & . & $*$ & 5.0000 & 3.7756 & 1.2242 & 2.0243 & $2.06 E 7$ & 2.9337 & 0.0438 \\
\hline $\begin{array}{l}14 \\
15\end{array}$ & : & : & $\dot{0}$ & $\begin{array}{l}6.0000 \\
6.0000\end{array}$ & $\begin{array}{l}6.0942 \\
5.9488\end{array}$ & $\begin{array}{r}-0.0942 \\
0.05: 2\end{array}$ & $\begin{array}{r}-0.1581 \\
0.0947\end{array}$ & $\begin{array}{r}-0.157 i \\
0.084 i\end{array}$ & $\begin{array}{l}5.109 E \\
2.9649\end{array}$ & $\begin{array}{l}0.0004 \\
0.3010:\end{array}$ \\
\hline 16 & - & .1 & - & 7.0000 & 6.7565 & 0.2435 & 0.4176 & $0.4: 52$ & $8.12 \Xi 4$ & C.OC:AE \\
\hline $\begin{array}{l}17 \\
18\end{array}$ & : & $\therefore$ & 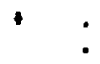 & $\begin{array}{l}6.0000 \\
4.0000\end{array}$ & $\begin{array}{l}5.1392 \\
4.359 i\end{array}$ & $\begin{array}{r}0.6508 \\
-0.358:\end{array}$ & $\begin{array}{r}1.4046 \\
-0.5520\end{array}$ & $\begin{array}{r}1.4 i 41 \\
-0.59=3\end{array}$ & $\begin{array}{l}0.0353 \\
2.480 .\end{array}$ & $\begin{array}{l}0.600 \\
\text { v.6:? }\end{array}$ \\
\hline i9 & - & . . & - & 5.0000 & 5.3590 & -0.3690 & $-0.6 E 27$ & -0.6562 & $: 4.2: 99$ & $0.32: 2$ \\
\hline $\begin{array}{l}20 \\
21\end{array}$ & : & $\therefore$ & • & $\begin{array}{l}4.0000 \\
5.0000\end{array}$ & $\begin{array}{l}4.945 ! \\
5.2265\end{array}$ & $\begin{array}{l}-0.545 ! \\
-0.2265\end{array}$ & $\begin{array}{l}-1.550= \\
-6.3735\end{array}$ & $\begin{array}{l}-1.5553 \\
-0.37: 3\end{array}$ & $\begin{array}{l}. .7: 2 E \\
2.4905\end{array}$ & $\begin{array}{l}0.9: 2 ? 2 \\
\text { Q.jc:? }\end{array}$ \\
\hline 22 & - & . & . & 5.0000 & 4.4952 & 0.5042 & 0.9227 & $0.99: 8$ & 0.9304 & c.0035 \\
\hline $\begin{array}{l}23 \\
24\end{array}$ & . & i & $\bullet$ & $\begin{array}{l}5.0000 \\
5.0000\end{array}$ & $\begin{array}{l}1.9249 \\
5.074 E\end{array}$ & $\begin{array}{r}1.075 ! \\
-0.0746\end{array}$ & $\begin{array}{r}1.805 i \\
-0.1249\end{array}$ & $\begin{array}{r}1.2337 \\
-0.1241\end{array}$ & $\begin{array}{l}5.1566 \\
4.7577\end{array}$ & $\begin{array}{l}0.0557 \\
0.0263\end{array}$ \\
\hline $\begin{array}{l}25 \\
26\end{array}$ & . &. & . & $\begin{array}{l}4.0000 \\
6.0000\end{array}$ & $\begin{array}{l}4.0: 77 \\
5.6442\end{array}$ & $\begin{array}{r}-0.0: 77 \\
0.355 E\end{array}$ & $\begin{array}{r}-0.029 ! \\
0.5934\end{array}$ & $\begin{array}{r}-0.0289 \\
0.5858\end{array}$ & $\begin{array}{l}1.6693 \\
2.962 ?\end{array}$ & $\begin{array}{l}0.0050 \\
0.0027\end{array}$ \\
\hline $\begin{array}{l}27 \\
28\end{array}$ & : & : & : & $\begin{array}{l}7.0000 \\
5.0000\end{array}$ & $\begin{array}{l}5.3154 \\
3.8768\end{array}$ & $\begin{array}{l}1.6816 \\
1.1232\end{array}$ & $\begin{array}{l}2.8302 \\
1.8567\end{array}$ & $\begin{array}{l}2.9757 \\
1.8955\end{array}$ & $\begin{array}{l}5.6984 \\
2.96: 2\end{array}$ & $\begin{array}{l}0.2452 \\
0.03 E ?\end{array}$ \\
\hline $\begin{array}{l}29 \\
30\end{array}$ & $:$ & - . & . & $\begin{array}{l}5.0000 \\
3.0000\end{array}$ & $\begin{array}{l}5.5062 \\
4.1678\end{array}$ & $\begin{array}{l}-0.5062 \\
-1.1678\end{array}$ & $\begin{array}{l}-0.8511 \\
-1.9478\end{array}$ & $\begin{array}{l}-0.8595 \\
-1.968:\end{array}$ & $\begin{array}{l}7.0091 \\
4.198 ?\end{array}$ & $\begin{array}{l}0.6: 53 \\
0.0535\end{array}$ \\
\hline $\begin{array}{l}3 ! \\
32\end{array}$ & $\dot{.}$ & . & • & $\begin{array}{l}4.0000 \\
7.0000\end{array}$ & $\begin{array}{l}3.9091 \\
6.6475\end{array}$ & $\begin{array}{l}0.0909 \\
0.3521\end{array}$ & $\begin{array}{l}0.1500 \\
0.5555\end{array}$ & $\begin{array}{l}0.1490 \\
0.5939\end{array}$ & $\begin{array}{l}2.5709 \\
6.4355\end{array}$ & $\begin{array}{l}0.0902 \\
0.0075\end{array}$ \\
\hline $\begin{array}{l}32 \\
34\end{array}$ & : & + & $\bullet$ & $\begin{array}{l}4.0000 \\
6.0000\end{array}$ & $\begin{array}{l}4.4078 \\
5.9165\end{array}$ & $\begin{array}{r}-0.4078 \\
0.0925\end{array}$ & $\begin{array}{r}-0.6702 \\
0.1376\end{array}$ & $\begin{array}{r}-0.5677 \\
0.1367\end{array}$ & $\begin{array}{l}2.0217 \\
2.406 \hat{0}\end{array}$ & $\begin{array}{l}0.0032 \\
0.0002\end{array}$ \\
\hline $\begin{array}{l}35 \\
35\end{array}$ & $\dot{.}$ & 1. & - & $\begin{array}{l}4.0000 \\
4.0000\end{array}$ & $\begin{array}{l}4.27 E 4 \\
4.7168\end{array}$ & $\begin{array}{l}-0.2764 \\
-0.7168\end{array}$ & $\begin{array}{l}-0.4574 \\
-1.1655\end{array}$ & $\begin{array}{l}-0.4 E 43 \\
-1.1 E 84\end{array}$ & $\begin{array}{l}6.1672 \\
0.3654\end{array}$ & $\begin{array}{l}0.0064 \\
8.3049\end{array}$ \\
\hline 37 & . & 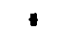 & - & 4.0000 & 4.1032 & -0.1032 & -0.1694 & $-c .1672$ & $0.87 ! 5$ & $0.300:$ \\
\hline 38 & . & . & $\checkmark$ & 5.0000 & 4.4353 & 0.5647 & 0.9185 & 0.9176 & 0.45 .36 & $0.10=5$ \\
\hline SEAX & $\begin{array}{l}0: \ldots \\
-3.0\end{array}$ & $\because \ldots$ & $\begin{array}{r}\ldots .0 \\
3.0\end{array}$ & 455 & IPRED & REESID & I5LES:S & 450RES:A & TMAHAL & toser. : \\
\hline
\end{tabular}

(Table LIII is continued on $p$ 145) 
TABLE LIII (continued)

CASEWISE PLOT OF STANDARDIZED RESIDUAL

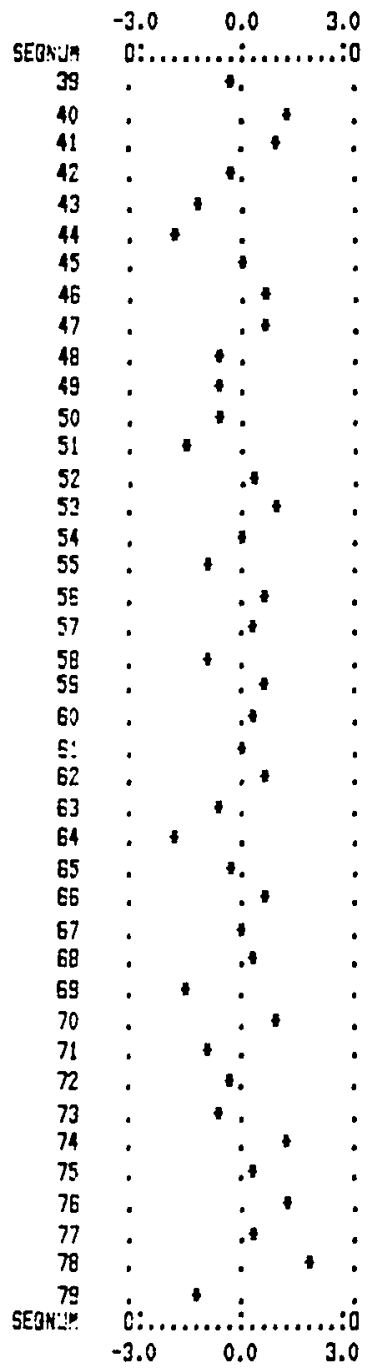

\begin{tabular}{|c|c|c|c|c|c|c|}
\hline $\begin{array}{r}155 \\
4.0000\end{array}$ & $\begin{array}{r}\text { IPAED } \\
4.2699\end{array}$ & $\begin{array}{r}\text { ARESSD } \\
-0.2659\end{array}$ & $\begin{array}{l}\text { ISRES:D } \\
-0.4357\end{array}$ & $\begin{array}{r}\text { +EDRES:D } \\
-0.4343\end{array}$ & $\begin{array}{l}\text { MAHAL } \\
1.3512\end{array}$ & $\begin{array}{r}+620 ! 0 \\
0.0012\end{array}$ \\
\hline $\begin{array}{l}5.0000 \\
5.0000\end{array}$ & $\begin{array}{l}4.2612 \\
4.4308\end{array}$ & $\begin{array}{l}0.8388 \\
0.5694\end{array}$ & $\begin{array}{l}1.3506 \\
0.9410\end{array}$ & $\begin{array}{l}1.3958 \\
0.9403\end{array}$ & $\begin{array}{l}3.305 \hat{0} \\
2.6380\end{array}$ & $\begin{array}{l}0.0233 \\
0.009 \mathrm{i}\end{array}$ \\
\hline 4.0000 & 4.2394 & -0.2394 & -0.3909 & -0.3897 & $1.06: 9$ & 0.0008 \\
\hline 4.0003 & 4.6853 & -0.8853 & -1.4398 & -1.4505 & 0.2332 & 0.0077 \\
\hline $\begin{array}{l}3.0000 \\
4.0000\end{array}$ & $\begin{array}{l}4.2659 \\
3.9579\end{array}$ & $\begin{array}{r}-1.2559 \\
0.0421\end{array}$ & $\begin{array}{r}-2.0730 \\
0.05 \subseteq 5\end{array}$ & $\begin{array}{r}-2.12: 5 \\
0.0592\end{array}$ & $\begin{array}{l}\therefore .35: 2 \\
2.9047\end{array}$ & 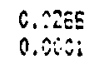 \\
\hline 5.0000 & e.5990 & 0.4010 & 0.6549 & $0.65: 4$ & 1.0958 & 0.0023 \\
\hline 7.0000 & 6.5485 & 0.4515 & 0.7874 & 0.7854 & 1C.396: & $0.62: 2$ \\
\hline 3.0000 & $3.489 E$ & -0.4896 & -0.8073 & -0.8054 & 2.5073 & $0.005:$ \\
\hline 6.0000 & 6.3940 & -0.3940 & -0.6580 & -0.6555 & 4.399! & $0.00=2$ \\
\hline 3.0000 & 3.4549 & -0.4845 & -0.8220 & $-0.920:$ & $6.53: 5$ & 0.0164 \\
\hline 4.0000 & 4.5404 & -0.9404 & $-1.54 ! 7$ & -1.5555 & 1.6450 & $0.0: 5 E$ \\
\hline 4.0000 & 3.8170 & 0.1830 & 0.3038 & 0.3019 & 3.4820 & $0.09: 2$ \\
\hline 5.0000 & 4.4151 & $0.5 E d g$ & $0.98 z 2$ & $0.5=20$ & $5 .: 799$ & $0.0: 55$ \\
\hline 5.0000 & 4.9535 & 0.0355 & 0.0603 & 0.06 .4 & 3.8036 & 0.90 \\
\hline 3.0000 & 3.7131 & -0.7131 & -1.1759 & -1.1600 & 2.EJNE & $0.0: 25$ \\
\hline 4.0000 & $3.653 ?$ & 0.3467 & 0.5716 & $0.5 E 90$ & $2.4 !: 1$ & $0.012:$ \\
\hline 5.0000 & 4.88 .5 & 0.1195 & 0.1955 & 0.1943 & 1.3Esis & 0.292 \\
\hline $\begin{array}{l}4.00090 \\
4.0000\end{array}$ & $\begin{array}{l}4.568 \mathrm{BE} \\
3.5922\end{array}$ & $\begin{array}{r}-1.5698 \\
0.4018\end{array}$ & $\begin{array}{r}-0.9232 \\
0.6 E \pm 5\end{array}$ & $\begin{array}{c}-0.913 n \\
0.587 !\end{array}$ & $\begin{array}{l}3.496 \mathrm{~B} \\
1.9 \mathrm{geE}\end{array}$ & 0.60 \\
\hline 5.0000 & 4.7795 & 0.2205 & 0.3627 & 0.30 .5 & $2.35 ? \varepsilon$ & An?: \\
\hline 4.0000 & $4.0 ! 53$ & $-0.0: 59$ & -0.6263 & $-0.026:$ & 3.8757 & 0.0000 \\
\hline 7.0000 & 6.6479 & $0.352 \mathrm{i}$ & 0.5955 & 0.5539 & $6.435 \%$ & $0 . \hat{ก} \cap$ \\
\hline 4.0000 & $4.459 !$ & $-0.459 !$ & -0.7702 & $-0.7 E 3:$ & 5.3470 & 0.0015 \\
\hline 3.0000 & 4.2118 & $-1.2:: 8$ & $-1.997:$ & -2.0392 & 2.42E5 & $3.33: 5$ \\
\hline 4.0000 & 4.1308 & -0.1308 & $-0.2 ! 52$ & -0.2139 & 2.2492 & $0.80 ? 2$ \\
\hline 6.0000 & 5.4989 & $0.50: 1$ & 0.8150 & 0.8171 & i..incs & 0.0639 \\
\hline 5.0000 & 4.9404 & 0.0596 & 0.0978 & 0.0971 & 1.5480 & a.cos \\
\hline 5.0000 & 4.8824 & 0.1176 & 0.1951 & 0.1939 & 3.4721 & $0.00 \% 5$ \\
\hline 4.0000 & 5.0186 & -1.0195 & -1.6817 & -1.7032 & 2.5 $5: \mathrm{:}$ & $0.02 E:$ \\
\hline $\begin{array}{l}5.0000 \\
6.0003\end{array}$ & $\begin{array}{l}4.4645 \\
6.5495\end{array}$ & $\begin{array}{r}0.5352 \\
-0.5485\end{array}$ & $\begin{array}{r}0.8991 \\
-0.956 \div\end{array}$ & $\begin{array}{r}0.8975 \\
-0.9559\end{array}$ & $\begin{array}{r}5.238: \\
\text { 10.295: }\end{array}$ & $\begin{array}{l}0.0: 40 \\
0.03: 2\end{array}$ \\
\hline 4.0000 & $4.2 E E 8$ & -0.2686 & -0.4460 & $-0,4435$ & $3.4 \div 80$ & 0.0024 \\
\hline 5.0000 & 5.3580 & -0.356 & -0.5920 & $-0.58 € \subset$ & 2.935: & 0.000 \\
\hline 6.0000 & 3.1022 & 0.8173 & 1.3649 & 1.3730 & 4.2952 & $6.92 ?:$ \\
\hline 5.0000 & 4.7187 & 0.2813 & 0.1653 & 0.4635 & $3.323=$ & 0.035 \\
\hline 5.0000 & 4.2589 & $0.73: 2$ & $1.2: 30$ & $1.2 ! 59$ & 3.40:0: & $0.0: 78$ \\
\hline 4.0000 & 3.7619 & $0.23 E 1$ & 0.3954 & 0.3942 & 3.9264 & 0.0021 \\
\hline 5.0000 & 3.8521 & 1.1479 & 1.9150 & $1.95: 0$ & 4.2235 & 0.0525 \\
\hline 4.0000 & 4.7444 & -0.7444 & -1.2234 & $-1.227 E$ & 2.0!53 & $0.0: 20$ \\
\hline U55 & —PFED & ARES:D & +SRESIJ & ISDEES:D & APAHA: & +COEK D \\
\hline
\end{tabular}




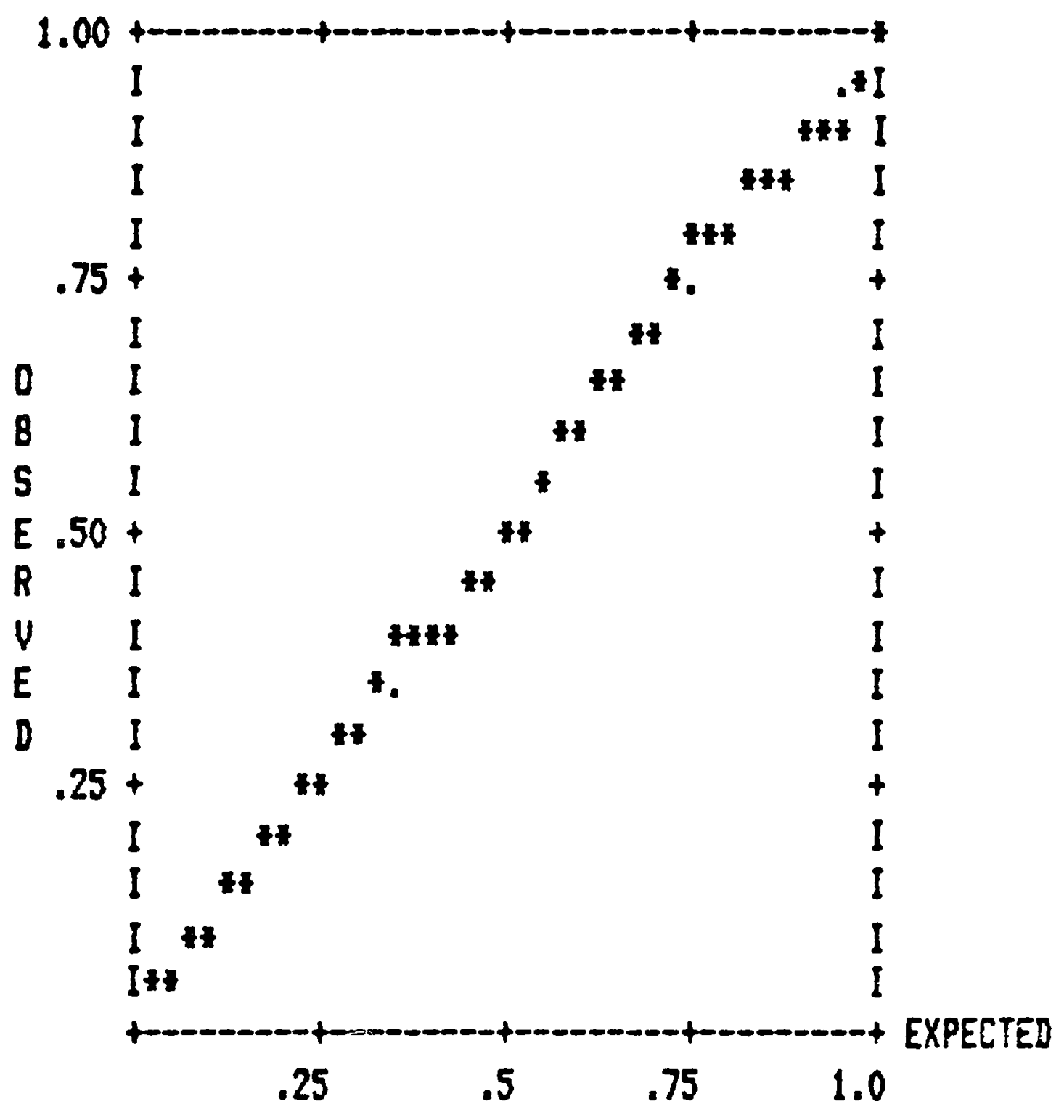

Fiqure 16. Normal Probability Plot of Studentized Residuals 


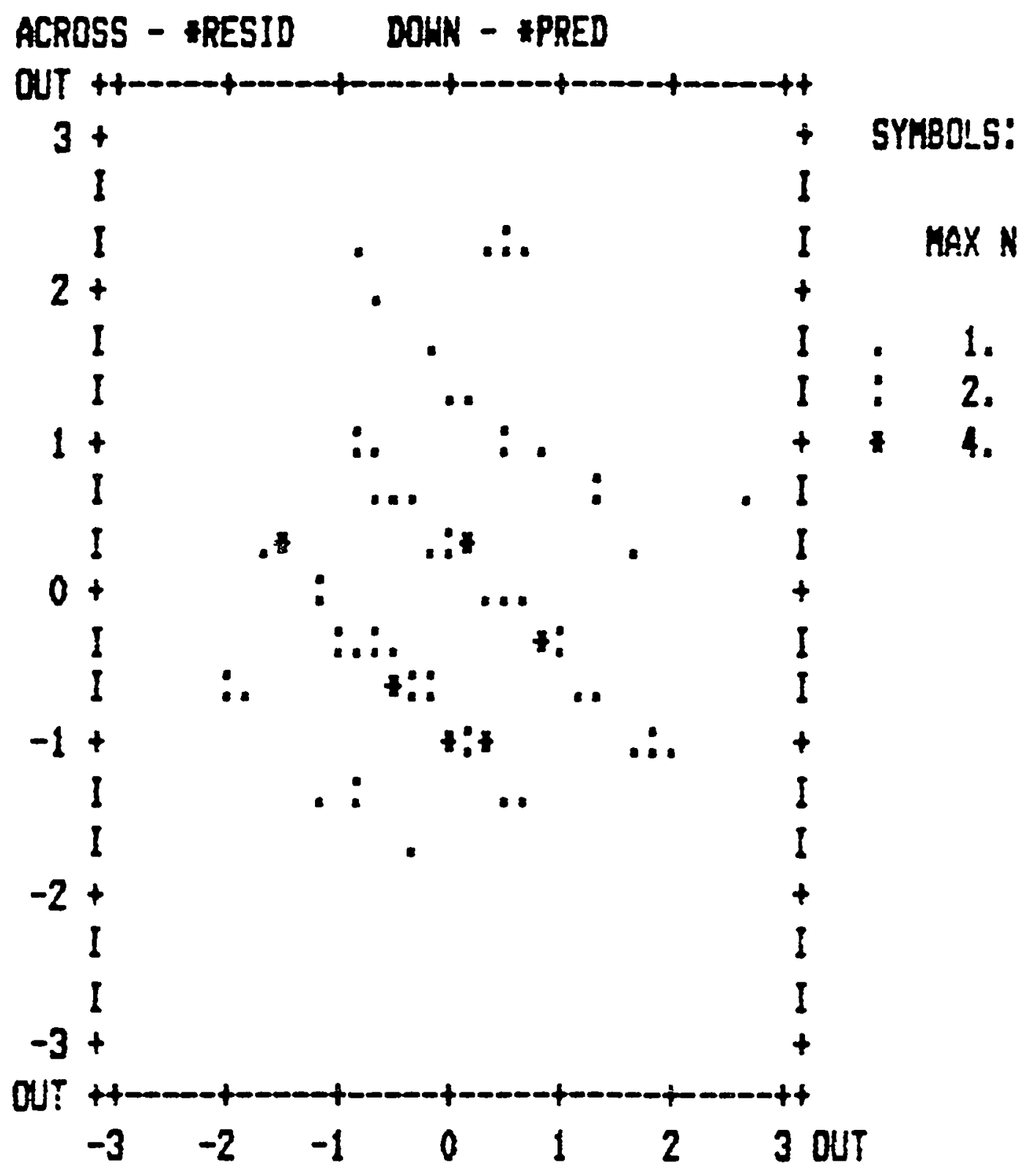

Figure 17. Standardized Scatter Plot of Predicted Values vs Kesiduals 
SUMMARY

This chapter analyzed the collected data. The most significant statistics for the predictive models were presented. By using different statistical procedures and different runs of multiple regression models, the most accurate predictive models were identified from among the possible choices. The final chapter of this study will utilize this information to answer the research questions posed at the outset and will recommend areas for future research. 


\section{CHAPTER VII}

\section{SUMMARY AND CONCLUSION}

This chapter summarizes the research problem, answers the research questions which were initially posed in Chapter $I$, and recommends areas of future research.

\section{SUMMARY OF THE RESEARCH}

The main objective of this study has been to identify the most decisive factors which impact the employment of a CBMIS in a developing country such as Iran. If properly identified, these factors can provide a series of guidelines, the most significant of which is whether or not a given country should begin to automate its business activities.

For the case of Iran, this project developed a descriptive model (Chapter III), identified the most decisive elements of the model (Chapter IV), designed a series of predictive equations (Chapter V), developed and utilized a questionnaire to measure the elements of the descriptive/predictive models (Appendix A), and analyzed the collected data (Appendix B and Chapter VI). Based upon these analyses, the research questions can now confidently be answered.

\section{ANSWER TO RESEARCH QUESTIONS}

of the 54 variables hypothesized to be important to the problem at hand, 51 proved to be relevant. Twenty-four of these variables 
are statistically significant at the $5 \%$ level, as Tables XLII - LII (Chapter VI) show. These may be termed the most crucial variables; they are as follows:

$V_{3}$ - acquisition criteria: complexity of the organization's activities

$V_{5}$ - acquisition criteria: economic considerations

$V_{8}$ - acquisition criteria: need for more accurate information

$V_{13}$ - standardization in data collection

$V_{16}$ - standardization in software selection

$V_{21}$ - existence of an appropriate number of data processing personnel

$V_{22}$ - unemployment of unskilled labor

$V_{29}$ - manufacturer selection criteria: availability of replacement parts

$V_{30}$ - manufacturer selection criteria: availability of back-up

$V_{37}$ - technical feasibility

$V_{38}$ - problem definition

$V_{39}$ - scope of the system

$V_{40}$ - existence of a debugged manual system

$V_{42}$ - types of design

$V_{44}$ - functional specifications and performance criteria

$V_{45}$ - system documentation

$V_{46}$ - internal vs external data

$V_{47}$ - recency of data

$V_{48}$ - aggregated vs disaggregated data

$V_{49}$ - existence of a data base

$V_{50}$ - availability of mathematical models

$v_{51}$ - output considerations 
$V_{52}$ - project management principles

$V_{54}$ - post-implementation audit

Another significant question posed in the early stages of this research project was: under what circumstances should a developing country such as Iran continue to operate manually? The analys is showed that the following circumstances are conditions under which a continuance of manual operation is advisable:

- If the acquisition criteria do not include complexity of the organization's activities, the need for more accurate information, economic considerations;

- If there are not adequate numbers of the appropriate data processing personnel;

- If the problem has not been clearly defined;

- If a technical feasibility study has not been performed in order to determine the suitability of an information system for automation;

- If the manual system has not been debugged;

- If standardization has not been employed at least in the the areas of data and software selection;

- If the problem of unemployment of unskilled labor has not been resolved.-

- If any of the foregoing apply, then computerization of a government's activities should not be attempted. 
The second series of questions posed in the early stages of this study has to do with circumstances under which the decision to automate has been made.

- What should the acquisition criteria be?

Table XLII ( $p$ 136) indicates that the acquisition criteria, from most to least important, should be:

-- complexity of the organization's activities;

-- the need for more accurate information;

-- economic considerations.

- What are some of the most important variables for the optimum utilization of existing computers?

As Table XLIII ( $p$ 137) shows, these variables from most to least important, are:

-- existence of appropriate numbers of data processing personne 1;

-- accurate problem definition (goals and objectives);

-- technical feasibility (suitability of different systems for automation).

- How should a developing country choose the manufacturer of computer technology?

Table LII ( $p$ 144) indicates that at least the following two factors should be considered in choosing a manufacturer:

-- availability of replacement parts for the manufacturer;

-- availability of a back-up for the manufacturer. 
- What are some of the most important variables for the timely and efficient implementation of a CBMIS?

According to Table XLIV ( $p$ 138), the following are the

most important factors for the timely implementation of a CBMIS:

-- project management principles (breakdown of activities);

-- existence of a debugged manual system.

- How can the level of experience sharing among the installations be improved?

On the basis of Table XLV ( $p$ 139), the following two factors could drastically improve the level of experience sharing among the installations:

-- standardization in data collection;

-- standardization in software selection.

Additional7y, as Table XX (p 117) shows, there is a significant correlation between standardization in hardware selection and cooperation among installations.

- How can the level of data migration be improved?

Table XLVI ( $p$ 139) demonstrates that the following two variables have a significant impact on the migration of data. Therefore, by improving the status of these variables, the level of data migration can also be improved.

-- existence of a data base;

-- standardization in data collection. 
- How Can the reliability of the provided information be improved?

Three factors, as shown in Table VLVII ( $p$ 140), have a significant impact on the reliability of the provided data. Therefore, by improving these variables, the reliability of the provided data can also be improved:

-- recency of the data;

-- availability of mathematical models;

-- internal vs external data (balance between the two).

- How can the usefulness of the provided information be improved?

The following four variables appear in Table XLVIII (p 14I) as the most important factors in terms of improving the usefulness of the provided information. From the most to the least important, these four factors are:

-- scope of the system: desired operating characteristics;

-- disaggregated vs aggregated data;

-- output considerations;

-- availability of mathematical models.

- How can the responsiveness of the CBMIS be improved?

Table XLIX (p 142) demonstrates that by improving the status of any or all of the following four factors, the responsiveness of the CBMIS will also be improved. These factors are listed from most to least important : 
-- post-implementation audit;

-- types of design (task force vs individual);

-- availability of mathematical models;

-- recency of data.

- How can the utilization of the provided information be improved?

As Table L (p 142) indicates, by improving the following factors, the utilization of the provided information can also be improved:

-- recency of the data;

-- post-implementation audit;

-- resolving the social issues of automation (e.g., the problem of unemployment among unskilled workers).

- What are some of the most important social issues for the employment of a CBMIS in a developing country?

Table L ( $p$ 142) shows that the overwhelmingly most important social issue is the unemployment of unskilled labor.

- How can the adaptability of the existing CBMIS to the growing technology be improved?

As Table LI ( $p$ 143) indicates, by improving the following factors, the adaptability of the existing CBMIS can also be enhanced:

-- system documentation

-- functional specifications ard performance criteria 
As a final word in terms of the analysis section of this project, this research shows that neither infrastructure nor economic issues have been serious problems in terms of computerization in Iran.

\section{RECOMMENDATION FOR FUTURE AREAS OF RESEARCH}

Now that a statistically significant set of guidelines has been developed for the employment of a CBMIS in developing countries and tested on the case of Iran, it would be quite useful to see the model tested on other developing nations. The countries studied in this project (i.e., Ethopia, Turkey, Brazil, Colombia, Korea, Nigeria, Uganda, Thailand, and The People's Republic of China) would provide interesting and helpful tests for the model. In addition to the information which would result from such applications, the hope is for a strengthening of cooperation and coordination among the various developing nations. This goal, of course, has been suggested several times by no less prestigious organizations than the United Nations. 


\section{REFERENCES}

Alter, Steven L, Decision Support Systems Current Practice and Continuing Chal Tenges, Addison-Wesley Publishing Company: Reading, Mass, 1980.

Alter, Steven L and Michael Ginzberg, "Managing Uncertainty in MIS Implementation," Sloan Management Review, Fall 1978, pp $21-31$.

Awad, Elias $1 \%$, Systems Analysis and Design, Richard Irwin \& Co: Homewood, Illinois, 1979.

Bariff, M L and E J Lusk, "Cognitive and Personality Tests for the Design of Management Information Systems," Management Science, v 23, no 8, April 1977, pp 820-828.

Berkeley, Edmund C, "How Do Computers Affect People?" Computers and People, Apri1 1975, p 6.

Blalock, Jr, Hubert M, Social Statistics, 2nd ed, McGraw-Hi11: NY, 1979.

Blaxter, C, "National Policies in Computer Education and Training Setting Guidelines forthe Developing Countries," The Jerusalem Conference on Information Technology, ILTAM Corporation for Planning and Research: Jerusalem, Israel, 1971.

Boehm, Barry $W$ and Benton Dexter Jr, "Software in Developing Countries," Datamation, September 1974, pp 73-78.

Bonn, T H, "Computer and Related Standards," The Jerusalem Conference on Information Technology, ILTAM Corporation for Planning and Research: Jersuatem, Israel, 1971.

Brandon, Dick $H$, Management Standards for Data Processing, D Van Nostrand Co, Inc: Princeton, NJ, 1963.

Burch, Jr, J G, F R Strater, and G Grudnitski, Information Systems Theory and Practice, 2nd ed, Wiley and Sons: New York, 1979.

Carper, William B, "Human Factors in MIS," Journal of Systems Management, November 1977, pp 48-50.

Chandrasekhar, P, "Application of Computer Technology for Economic Development of India," World Conference on Informatics in Government, Florence, Italy, October 16-20, 1972, part 2, pp 844-852. 
Chvalovsky, Vaclav, "Anything New in Data Base Technology?" Datamation, Anril 1976, pp 54-55.

Clover, Vernon $T$ and Howard L Balsley, Business Research Methods, Grid, Inc: Columbus, Ohio, 1974.

Conference Board (The), Information Technology: Some Critical Implications for Decision Makers, Rept \#537, New York, 1972.

Couger, Daniel $J$ and Fred $P$ McFadden, First Course in Data Processing With Basic, John Wiley \& Sons: NY, 1981.

Curtice, Robert M, "The Outlook for Data Base Management," Datamation, April 1976, pp 46-49.

Danet, B, "The Future of Privacy in Developing Countries," The Jerusalem Conference on Information Technology, ILTAM Corporation for Planning and Research: Jerusalem, Israel, 1971.

Darlington, Richard B. "Multiple Regression in Research and Practice," Psychological Bulletin, $v 69$, no 3, 1968, pp 161-182.

Date, C J, An Introduction to Database Systems, Addison-Wesley Publishing Company: Reading, Mass, 3rd ed, T98T.

Davis, Gordon B, Management Information Systems Conceptual Foundations, Structure, and Development, McGraw-Hi11: NY, 1974.

Davis, Gordon B and Clyde A Parker, Writing the Doctoral Dissertation, Barron's Educational Series, Inc: NY, 1979.

Dearden, John, Computer in Business Management, Dow Jones-Irwin: Homewood, Illinois, 1966.

Dearden, John and I $F$ Warren McFarlan, Management Information Systems: Text and Cases, Irwin, Inc: Homewood, I11, 1966.

Dearden, John, I F Warren McFarlan, and William M Zani, Managing Computer-Based Information Systems, Irwin, Inc: Homewood, I1T, 1971.

Dickson, GW and John K Simmons, "The Behavioral Side of MIS," Business Horizons, August 1970, pp 59-71.

Dock, Thomas $V$ and Edward L Essick, Principles of Business Data Processing with MIS... Including BASIC, SRA, Inc: Chicago, 4ith ed, 1981.

Edwards, Perry and Bruce Eroadwe11, Data Processing: Computers in Action, Wadsworth Publishing Company: Belmont, Ca, 1979. 
Elizur, D, "Social Impact of the Introduction of Computers," The Jerusalem Conference on Information Technology, ILTA1 Corporation for Planning and Research: Jerusalem, Israet, 1971, pp 35-36.

Finerman, A, "Education for Computing," The Jerusalem Conference on Information Technology, ILTAM Corporation for Planning and Research: Jerusalem, Israel, 1971, pp 112-123.

Fitzroy, Peter, Analytical Methods for Marketing Management, McGrawHi11: United Kingdom, 1976.

Foley, C, "Why Does Technology Transfer Fail: A Study Based on Administration Systems," Information Technology, J Moneta (ed), North Holland Publishing Co: New York, 1978, pp 119-124.

Foster, Geroge M, Traditional Societies and Technological Change, Harper and Row: New York, 1973.

Frienleib, Harold, "A Future for Information Systems," Information Technology, J Moneta (ed), North Holland Publishing Co: New York, 1978, pp 557-559.

Giannoni, R, "Social and Cultural Conditions Affecting the Use of Informatics by Government," World Conference on Informatics in Government, IBIDCC: Florence, ItaTy, 1972, pp 300-302.

Gildersleeve, Thomas R, Data Processing Project Management, Van Nostrand Reinhold: New York, 1974.

Golden, D A, "Technology Transfer From Developed to Less Developed Countries: An Analogy With the Technology Transfer from Government Laboratories to Industry," Information Technology, J Moneta (ed), North Holland Publishing Company: New York, 1978, pp 1-7.

Goldschmidt, Yaacov, "Review of a Decade of Computer Applications in Kibbutz Agriculture," The 2nd Jerusalem Conference on Information Technology: Computers for Social and Economic Development, Jerusalem, Israel, July 29-August 1, 1974, pp 77-90.

Good, Robert E, Course material from SySc 571, Information Systems I, Portland State University, Portland, Oregon, Fall 1979.

Grad, Burton, Thomas B Glars, David Holstein, William G Meyers, and Richard N Schmidt, Management Systems, The Dryden Press, Hinsdale, Illinois, 1979.

Halinski, Ronald S and Feldt S Leonard, "The Selection of Variables in Multiple Regression Analysis," Journal of Educational Measurement, v 7, no 3, Fal1 1970, pp 151-157.

Haq, Abdul A K M, A Dynamic and Spatial Model for Measuring Technology Transfer Potentials, D Engg Dissertation, Asian Institute of Technology: Bangkok, Thailand, 1979. 
Holland, Robert H, "DBMS: Developing User Views," Datamation, February 1980, pp 141-144.

Hul1, C Hadlai and Norman H Nie, SPSS--Update 7-9, McGraw Hi11: New York, 1981.

Huskey, Harry D, "The Transfer of Computer Technology," Information Technology, J Moneta (ed), North Holland Publishing Co: New York, 1978, PP 253-258.

Keen, Peter G and Michael S Scott-Morton, Decision Support Systems: An Organizational Perspective, Addison-Wesley Publishing Co: Reading, Mass, 1978.

Kerlinger, Fred N, Foundations of Behavioral Research, Holt, Reinhold, and Winston, Inc: New York, 2nd ed, 1973.

Kheir, Abubaker, Mstafa M, A Conceptual Model of Computer Based Information Systems Requirements for a Governmental Department in a Developing Country, DBA Dissertation, George Washington University: Washington, DC, 1979.

King, Leslie John and Edward L Schrems, "Cost-Benefit Analys is in Information Systems Development and Operation," Computing Survey, $\checkmark$ 10, no 1, March 1978, pp 19-34.

Lendaris, George G, course material from SySc 573, Information Systems III, Portland State University, Portland, Oregon, Spring 1980.

Lucas, Jr, Henry C, Computer Based Information Systems in Organization, SRA, Inc: Chicago, 1973.

Lucas, Jr, Henry C, Information Systems Concepts for Management, McGraw-Hi11: New York, 1978.

Lucena, C J, "Computer Education: A New Tool for Social and Economic Development," The 2nd Jerusalem Conference on Information Technology: Computers for Social and Economic Development, Jerusalem, Israel, July 29-August 1, 1974, pp 365-373.

Makridakis, S and S C Wheelwright, Forecasting Methods and Applications, John Wiley \& Sons: New York, $197 \overline{8}$.

Martino, Joseph, Technological Forecasting for Decision Making, Elsevier: New York, 1978.

McClave, $J T$ and $F$ H Dietrich, Statistics, Dellen Publishing Co: San Francisco, Ca, 1979.

MCFadden, F R and J D Surer "Costs and Benefits of a Data Based System," Harvard Business Review, Jan-Feb 1978, pp 131-138. 
McLeod, Jr, Raymond, Management Information Systems, SRA, Inc: Chicago, 1979.

Mead, G P, "Some Aspects of the Computer Education Requirement in Developing Countries," Information Technology, J Moneta (ed) North Holland Publishing Company: New York, 1978, pp 665-671.

Mintzberg, Henry, "Impediments to the Use of Management Information," Society of Industrial Accountants of Canada Journal, 1978, pp $1-23$.

Mollegaard, A G, "Centralization Versus Decentralization of EDP Functions in Governments," World Conference on Informatics in Government, IBIICC: Florence, Italy, 1972, pp 494-497.

Mumford, Enid, "Human Values and the Introduction of Technological Change," Information Technology, J Moneta (ed), North Holland Publishing Company: New York, 1978, pp 239-244.

Nie, Norman H, Hadlai C Hull, Jean G Jenkins, K Steinbrenner, and Dale $H$ Bent, Statistical Package for the Social Sciences, McGraw Hi11: New York, 2nd ed, 1970.

Nowtash, Ali, "Electronic Data Processing in Iran," International Seminar on Electronic Data Processing, United Nations, November 1971, pp 82-87.

Padunchwit, I and B Tamthai, "Computer Organization Effectiveness in Government," World Conference on Informatics in Government, IBIDCC: Florence, Italy, 1972, pp 546-547.

Plan and Budget Organization (PBO), Tehran, Iran, Fall 1977. (Documents were published in Persian language.)

Priebe, Kathie, "The Transfer of Computer Technology from Developed to Developing Countries," Information Technology, J Moneta (ed), North-Holland Publishing Co: New York, 1978, pp 109-113.

Sanders, Margaret $\mathrm{J}$, Computer Utilization in Public Administration in the Underdeveloped Countries, PhD Dissertation, New School for Social Research: New York, 1973.

Sexton, Jr, Donald E, "Computers in Developing Countries: The Case of Iran," Technos, Jan-Mar 1972, p 9-19.

Shay, E M, "The MSP: A Master Plan for Systems Design and Development," MIS in Action, Murdick, R G and J E Ross (eds), West Publishing Company: New York, 1975, pp 513-524.

Shelly, Gary B and Thomas J Cashman, Introduction to Computers and Data Processing, Anaheim Publishing: Fullerton, Ca, 1980. 
Simmons, Ralph A, Guidelines for the Use of Computer Technology in Developing Countries, NBSIR, \#73-432: Washington, DC; December 1972, pp 1-126.

SMLRP--Reference Manual for Step-wise Multiple Linear Regression, Portland State University, Portland, Oregon, pp ST 139-ST 148.

Sobczak, J J, "A Data Base Story," Datamation, September 1977, pp 139-150.

Spencer, Donald D, Data Processing: An Introduction, Charles $G$ Merrill Publishing Company: Columbus, Ohio, 1978.

Sprague, Jr, Ralph and Eric D Carlson, Building Effective Decision Support Systems, Prentice-Hall, Inc: Englewood Cliffs, New Jersey, 1982.

Taggart, Jr, William M, Information Systems: An Introduction to Computers in Organizations, AlTen and Bacon, Inc: Boston, 1980.

Testa, Charles J, "Behavioral Factors in Information Systems," Computers and People, Apri7 1974, pp 13-17.

Thomson, R J, "EDP Education for Varying National Priorities," World Conference on Informatics in Government, IBIIC: Florence, It $\bar{a}$ Ty, 1972, pp 947-949.

Tsichritzis, D C and F H Lochorsky, "Designing the Data Base," Datamation, August 1978, pp 147-151.

United Nations, Dept of Economic and Social Affairs, Application of Computer Technology for Development, 1st Report, 1971; 2nd Report, 1973, New York.

U S Department of Commerce, National Technical Information Service, The Market for Computers in Iran, Springfield, Va, March 1976, pp T-56.

Ward, B, J Runnells, and L D'Anjon (eds), The Widening Gap, Columbia University Press: New York, 1971.

Willoughby, T C, Business Systems, The Association for Systems Management: Cleveland, Ohio, T981.

Wiorkowski, G K and J J Wiorkowski, "Does a Data Base Management System Pay Off?" Datamation, April 1977, pp 109-114. 
APPENDIX A

REQUIREMENTS FOR THE EMPLOYMENT OF

COMPUTER BASED MANAGEMENT INFORMATION SYSTEMS

IN DEVELOPING COUNTRIES:

A QUESTIONNAIRE

Designed by Hossein Bidgoli

February 1983 
This questionnaire is part of a study wich is attempting to identify variables which have the most significant impact on the success or failure of Computer Based lianagement Information Systems (henceforth referred to as CLilIS) in developing countries such as Iran. Questions included are based upon a careful examination of current literature (including proceedings of several international conferences) relating to computer technology in developing countries and a close review of individual studies concerning computer status in ten developing countries, including Iran. The goal of this project is to develop a computer policy with a higher chance of success than those adopted in the past.

You have been selected to complete this questionnaire because of your knowledge of and key role in your organization's computer effort. An earlier contact with authorities in the Iranian government produced a list of computer executives from which you were selected. Your contribution is important and is very much appreciated. In repayment for your time and effort, a copy of the results of this study will be sent you. To aid you in completing this questionnaire, a Persian translation accompanies the English text; please feel free to complete whichever version is easiest for you.

\section{UIRECTIONS}

To determine the relative importance of each variable, a range of answers is possible, from 1 to 7 . Circle the number which best describes your response to each question.

Please answer ALL questions; if you are uncertain of a particular answer, estimate to the best of your ability. If a particular question does not apply to your organization in any specific way, answer the question based on your general knowledge of the application of computer support in Iran.

Please circle only Oile response to each question.

Again, thank you very much for your contribution. 
QUESTIONS 1 and 2 REFER TO THE DEGREE OF USER/TOP MANAGEMENT INVOLVEMENT IN THE ACQUISITION, DESIGN, AND IMPLEMENTATION PHASES OF A CBMIS.

1. How do you rate the degree of user (i.e., anyone utilizing a CBMIS for decisionmaking purposes) involvement in the acquisition, design, and implementation of your organization's CBMIS?

1

no user involvement
4

5

6 7 total user involvement

2. How do you rate the degree of top management (i.e., the primary decisionmakers in your organization) involvement in the acquisition, design, and implementation of a CBMIS?
1
2
3
4
5
6
7
total top mgmt involvement

no top mgmt

involvement

QUESTIONS 3 THROUGH 9 ARE CONCERNED WITH THE FACTORS WHICH MAY HAVE NECESSITATED THE ACQUISITION OF A CBMIS.

3. To what degree has the acquisition of a CBMIS in your organization been determined or influenced by the perceived complexity of your organization's activities?

$\begin{array}{lllllll}1 & 2 & 3 & 4 & 5 & 6 & 7\end{array}$

not a factor

at all

the overriding factor

4. To what degree has the acquisition of a CBMIS in your organization been determined or influenced by the perception that other organizations have already begun to use the computer?
1
2
3
4
5
6
7

not a factor

at all

the over-

riding factor 
5. To what degree has the acquisition of a CBMIS in your organization been determined or influenced by the belief that computers are cost efficient?
1
23
4
5
6
7

not a factor

at all

the overriding factor

6. To what degree has the acquisition of a CBMIS in your organization been determined or influenced by the need for better control of operations?
1
2
3
4
5
6
7

not a factor

at all

the overriding factor

7. To what degree has the acquisition of a CBMIS in your organization been determined or influenced by the need for a better capability to plan for the future?
1
2
3
4
5
6
7

not a factor

the overat all

riding factor

8. To what degree has the acquisition of a CBMIS in your organization been determined or influenced by the need for more accurate information?
1
2
3
4
5
6
7

not a factor

the overat all

riding factor 
9. To what degree has the acquisition of a CBMIS in your organization been determined or influenced by the need for more current information?
1
2
3
4
5
6
7

not a factor at all

the over-

riding factor

QUESTIONS 10 THROUGH 21 ARE CONCERNED WITH GENERAL POLICY CONSIDERATIONS FOR THE ACQUISITION OF A CBMIS.

10. Prior to the acquisition of your CMBIS, to what extent did you depend on consulting firms and/or vendors for advice regarding such information as price, applications, new developments, etc?

$\begin{array}{lllllll}1 & 2 & 3 & 4 & 5 & 6 & 7\end{array}$

did not use or none existed

relied on heavily

11. To what extent has your computer policy become centralized (one computer for the entire organization) vs decentralized (wherein each department has its own computer)?
1
2
3
4
5
6
7
equal mix
decentralized

centralized

12. Prior to the acquisition of your CBMIS, to what degree was a master system plan for defining objectives and needs utilized in your acquisition of computer technology?
1
2
3
4
5
6
7

did not use

used for every phase 
13. Prior to the acquisition of your CBMIS, to what degree did you create standardized data collection procedures (e.g., types of data, format, sources of data, etc)?
1
2
3
4
5
6 7

did not use

used for every phase

14. To what extent have inter- and intra-organizational data transmission procedures (e.g., data communication, line characteristics, data format) in your organization become standardized?
1
2
3
4
5
6
7

not at all

totally

15. To what extent have hardware selection procedures (e.g., hardware types, manufacturer, technical characteristics) in your organization become standardized?
1
2
3
4
5
6
7

not at al1

totally

16. To what extent have software selection procedures (e.g., software types, vendor, technical characteristics) in your organization become standardized?
1
2
3
4
5
6
7

not at a11

totally

17. To what extent did duties/tariff charges limit your ability to purchase/rent a computer system?

$\begin{array}{lllllll}1 & 2 & 3 & 4 & 5 & 6 & 7\end{array}$

not a

limitation

a significant

limitation 
18. To what extent did the cost of transportation limit your ability to purchase/rent a computer system?

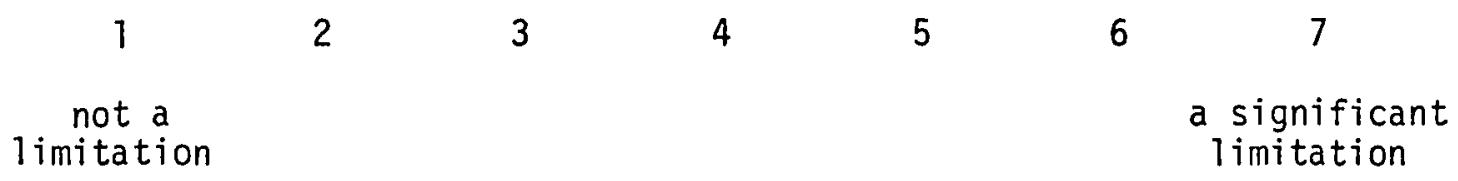

19. To what extent did taxes (other than tariffs) limit your ability to purchase/rent a computer system?

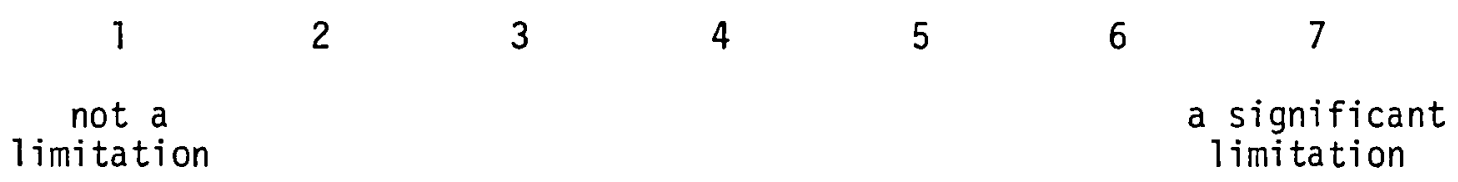

20. How important a consideration was the number of existing data processing training centers in Iran to your decision to acquire computer technology?

$\begin{array}{ccccccc}1 & 2 & 3 & 4 & 5 & 6 & 7 \\ \begin{array}{c}\text { not } \\ \text { important }\end{array} & & & & & \begin{array}{c}\text { very } \\ \text { important }\end{array}\end{array}$

21. How important a consideration was the availability of trained data processing personnel to your decision to acquire computer technology?

$\begin{array}{ccccccc}1 & 2 & 3 & 4 & 5 & 6 & 7 \\ \begin{array}{c}\text { not } \\ \text { important }\end{array} & & & & & \begin{array}{c}\text { very } \\ \text { important }\end{array}\end{array}$


QUESTIONS 22-26 ARE CONCERNED WITH SOCIAL ISSUES RELATED TO THE ACQUISITION OF A CBMIS.

22. Frequently, acquisition of computer technology results in a loss of jobs. Although not particularly important in the first stages of acquisition, this element can become an issue during the later stages. To what extent have you considered in advance the likelihood of loss of jobs?
1
2
3
4
5
6
7

did not

consider

strongly considered

23. Storing masses of data often creates problems in terms of protection of privacy. To what extent has this been a problem in your organization?
1
23
4
5
6
7

not a problem

at all

a very serious problem

24. Computer fraud and embezzlement have also been sources of problems. To what extent has this been a problem in your organization?
1
23
4
5
6
7

not a problem

at a11

a very serious problem

25. To what extent have your computer operations been managed by foreign consultants?
1
2
3
4
5
6
7
$\sim 10 \%$
$\sim 50 \%$
$\sim 90 \%$ 
26. Horking conditions are generally better and salaries higher for foreign consultants than for natives. To what extent has this been a problem in your organization?
1
2
3
4
5
6
7

not a problem at a 11

a very serious problem

QUESTIONS 27 THROUGH 30 ARE CONCERNED WITH FACTORS INVOLVED IN CHOOSING AN EXPORTER OF COMPUTER TECHNOLOGY.

27. How important were national political considerations to your choice of a manufacturer?
1
2
3
4
5
6
7

not important

very important

28. How important a consideration was the availability of maintenance personnel to your choice of a manufacturer?
1
2
3
4
5
6
7

not important

very important

29. How important a consideration was the availability of replacement parts to your choice of a manufacturer?
1
2
3
4
5
6
7

not important

very important 
30. How important a consideration was the availability of a back-up (to ensure that shutdowns do not occur) to your choice of a manufacturer?

$\begin{array}{lllllll}1 & 2 & 3 & 4 & 5 & 6 & 7\end{array}$

not important

very important

QUESTIONS 31 AND 32 ARE CONCERNED WITH ECONOMIC ISSUES INVOLVED IN THE ACQUISITION OF COAPUTER TECHNOLOGY.

31. To what extent did you rely on results of a detailed economic feasibility study to determine costs/benefits before you acquired computer technology?
1
2
3
4
5
6
7

not at all

totally

32. Since computer technology is generally imported from the industrialized part of the world, availability of foreign exchange may be a factor in the acquisition and utilization of computer technology. To what extent did you consider this factor before acquiring your CBMIS?
1
2
3
4
5
6
7

not at all

fully

QUESTIONS 33 THROUGH 36 ARE CONCERNED WITH AREAS OF TECHNICAL SUPPORT RELATED TO THE OPERATION OF A CBMIS.

33. Prior to acquiring computer technology, how important a factor did you consider the existence of communication technology (e.g., telephone lines, telex) to be in ensuring the success of your organization's CBMIS?
1
2
3
4
5
6 7

not at all

important

very
important 
34. Prior to acquiring computer technology, how important a factor did you consider the existence of air conditioning to be in ensuring the success of your organization's CBMIS?
1
2
3
4
5
6 7

not at all

important

very
important

35. Prior to acquiring computer technology, how important a factor did you consider a specially-designed building to be in ensuring the success of your organization's CBMIS?
1
2
3
4
5
6 7

not at all

important

very
important

36. Prior to acquiring computer technology, how important a factor did you consider reliable voltage to be in ensuring the success of your organization's CBMIS?
1
2
3
4
5
6
7

not at all

important

very important

QUESTIONS 37 THROUGH 51 ARE CONCERNED WITH FACTORS INVOLVED IN THE DESIGN OF A CBMIS.

37. To what extent did you rely on a technical feasibility study to aid you in determining the suitability of automating your manual system?
1
2
3
4
5
6
7

not at a 71

totally 
38. In acquiring computer technology, one may proceed by first acquiring the computer and then applying it to needs as they emerge, or by first defining a particular problem and then acquiring the computer to solve it. Which alternative reflects the way in which your organization acquired computer technology?

$\begin{array}{cccccc}1 & 2 & 3 & 4 & 5 & 6\end{array}$

39. To what degree did you undertake to accurately define the desired operating characteristics of the CBMIS during the design phase?
1
2
3
4
5
6
7

not at al1

totally

40. How effective was the manual system you employed prior to automation?

$\begin{array}{ccccccc}1 & 2 & 3 & 4 & 5 & 6 & 7 \\ \begin{array}{c}\text { not effective } \\ \text { at all }\end{array} & & & & & \begin{array}{l}\text { extremely } \\ \text { effective }\end{array}\end{array}$

41. To what extent did you attempt to contact other organizations or computer experience centers to discuss their areas of success/ failure?
1
2
3
4
5
6
7

none available

or

very extensive

did not contact 
42. CBMIS design may be accomplished either by individual data processing personnel or by a team of data processing personnel and others impacted by the CBMIS (task force). How was your design accomplished?
12
23
4
5
6
combination
of both
task force

individuals

43. To what extent have you attempted to employ modularity in the design and acquisition of your CBMIS?

$\begin{array}{ccccccc}1 & 2 & 3 & 4 & 5 & 6 & 7 \\ \text { no } & & & & & & \begin{array}{c}\text { totally } \\ \text { modular }\end{array}\end{array}$

44. To what extent did you create functional specifications and performance criteria (e.g., time, cost, report accuracy, etc) in your CBMIS design?
1
2
3
4
5
6
7
not
at all
strongly
considered

45. To what extent do you now consider your CBMIS to be comprehensively documented?
1
2
3
4
5
6
7
not
at all
strongly considered 
46. In organizational decisionmaking, do you rely more heavily on internally- or externally-collected data for future use?

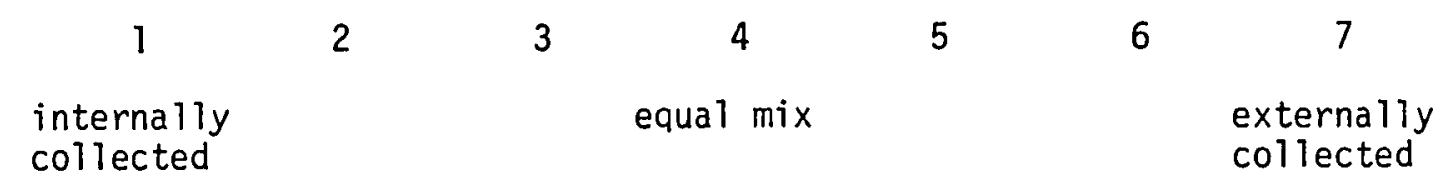

47. In organizational decisionmaking, to what extent do you determine use of up-to-date data to be an important consideration?

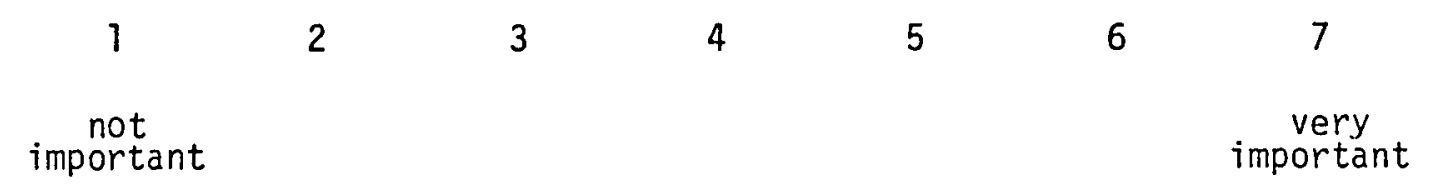

48. In organizational decisionmaking, are you more likely to collect detailed data (disaggregated) or summary data (aggregated)?

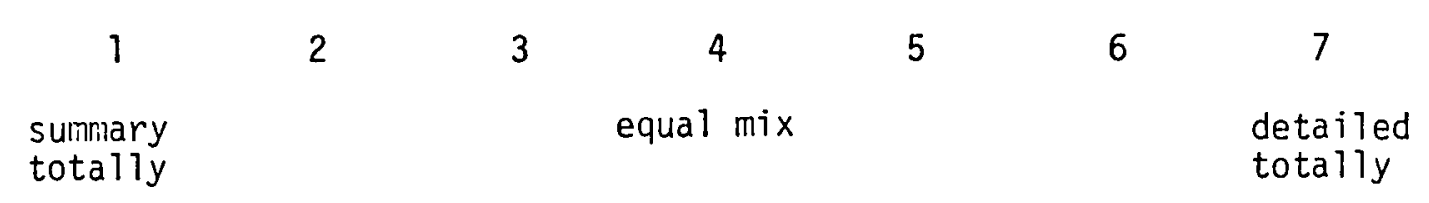

49. In the design phase of your CEMIS, to what extent did you choose to store related data centrally (as a data base)?

$\begin{array}{ccccccc}1 & 2 & 3 & 4 & 5 & 6 & 7 \\ \text { not } & & & & & & \text { totally } \\ \text { at all } & & & & & & \end{array}$

50. To what extent do you employ mathematical models (such as linear programming, regression, simulation, etc) to process data within the CBMIS?

$\begin{array}{ccccccc}1 & 2 & 3 & 4 & 5 & 6 & 7 \\ \text { not } & & & & & \text { totally } \\ \text { at all } & & & & & \end{array}$


51. To what extent have you considered varying the output formats and reporting types (e.g., graphical output, exceptional reporting, etc) to make the information provided more useful and receptive to a wide range of users?

$\begin{array}{ccccccc}1 & 2 & 3 & 4 & 5 & 6 & 7 \\ \text { not } & & & & & & \text { strongly } \\ \text { at all } & & & & & & \end{array}$

QUESTIONS 52 THROUGH 54 ARE CONCERNED WITH FACTORS RELATED TO THE IMPLEMENTATION OF A CBMIS.

52. To what extent did you apply "project management principles" (i.e., the dividing of all implementation activities into measurable tasks) when you implemented your CBMIS?
1
2
3
4
5
6
not
at all
completely

53. To what extent did you rely on project management tools such as PERT (Program Evaluation Review Techniques), CPM (Critical Path Methods), to assist you in the implementation of your CBMIS?
1
2
3
4
5
6
7
not
at all
extensively

54. To what extent did you conduct a "post-implementation audit" (a follow up phase) to assess whether or not predefined goals and objectives of the CBMIS were met?
1
2
3
4
5
6
7
not
at all
extensively 
QUESTIONS 55 THROUGH 66 ATTEMPT TO MEASURE THE OVERALL PERFORMANCE OF THE CBMIS.

55. To what extent would you say that the efficiency and effectiveness of your operation have been enhanced by the acquisition of computer technology?

$\begin{array}{ccccccc}1 & 2 & 3 & 4 & 5 & 6 & 7 \\ \text { not } & & & & & & \text { extensively } \\ \text { at all } & & & & & \end{array}$

56. Expressed in percentage terms, to what extent have you been able to utilize existing computers to their maximum capacity?

$\begin{array}{ccccccc}1 & 2 & 3 & 4 & 5 & 6 & 7 \\ \simeq 10 \% & \sim 50 \% & & & \simeq 90 \%\end{array}$

57. To what extent have delays in computer installation and utilization been a problem?
1
2
3
4
5
6
7
not
at all
considerably

58. To what extent have you been able to coordinate your efforts and cooperate with other organizations with which you have had contact?

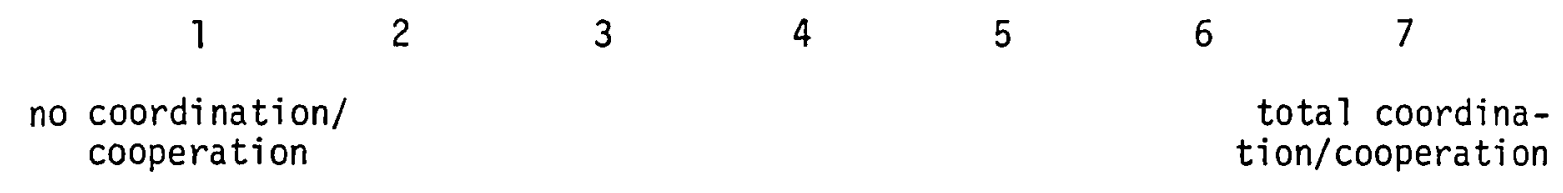


59. To what extent have you been able to utilize daily decisionmaking data acquired from other organizations?

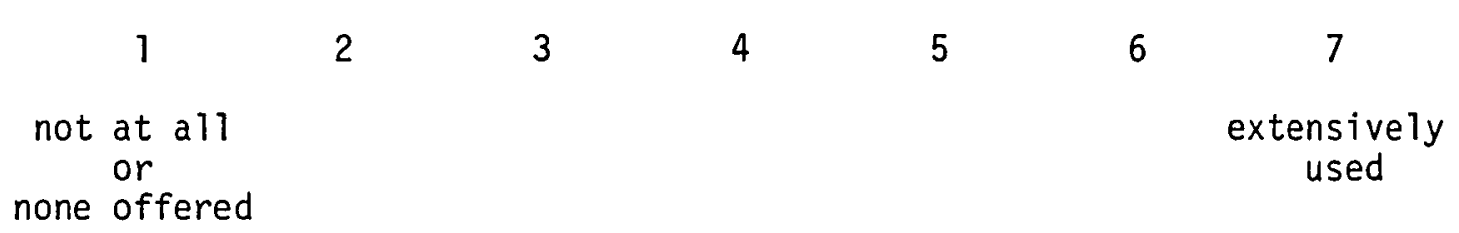

60. How reliable (i.e., empirically correct) is the information which you have received from your CBMIS?

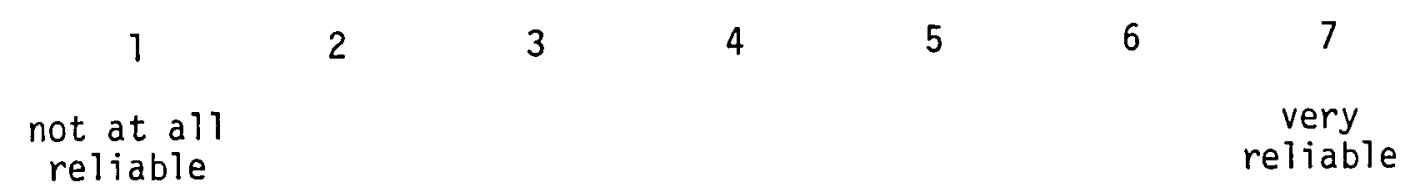

E1. How useful (i.e., helpful for decisionmaking) is the information which you have received from your CBMIS?

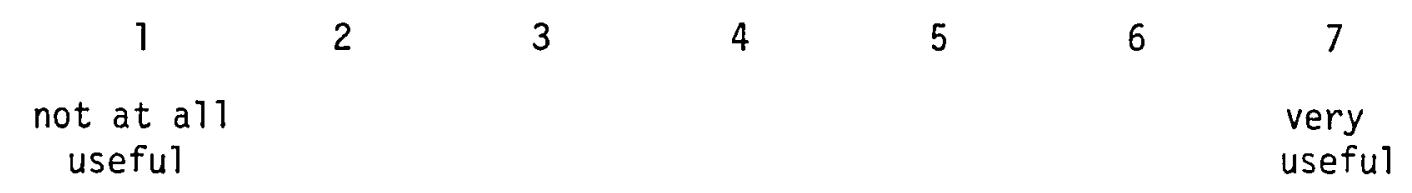

62. How do you rate the responsiveness of your CBMIS (i.e., to what extent does it reflect your organization's views and needs)?

$\begin{array}{lcccccc}1 & 2 & 3 & 4 & 5 & 6 & 7 \\ \text { not at all } & & & & & \begin{array}{c}\text { very } \\ \text { responsive }\end{array}\end{array}$

63. To what extent has your organization actually used the information provided by your CBMIS?

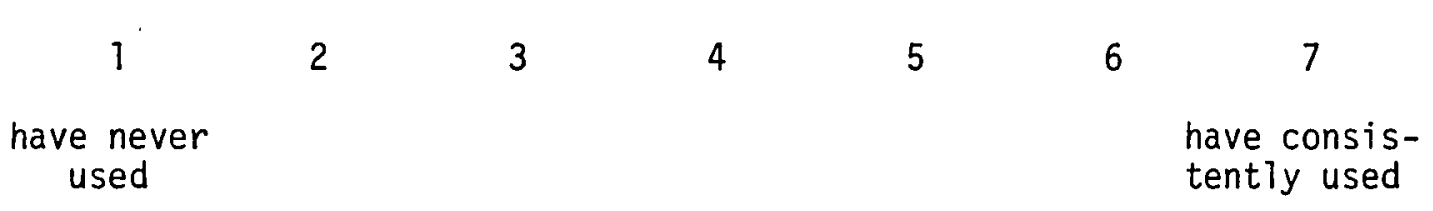


64. How do you rate the adaptability of your CBMIS, considering the rapid rate of growth in computer technology generally?

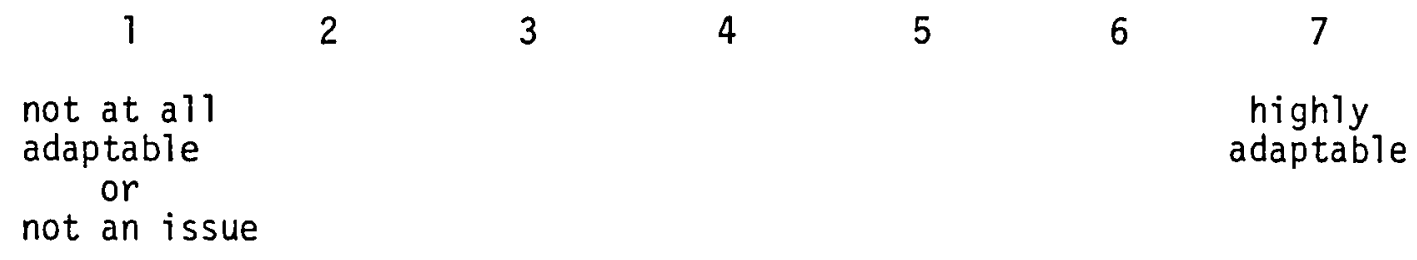

65. Overal1, how severe were the economic difficulties encountered in renting or purchasing your computer?

$\begin{array}{ccccccc}1 & 2 & 3 & 4 & 5 & 6 & 7 \\ \begin{array}{c}\text { very } \\ \text { easy }\end{array} & & & & & & \text { very } \\ \text { difficult }\end{array}$

66. Generally, how satisfied are you with the manufacturer(s) you chose?

$\begin{array}{ccccccc}1 & 2 & 3 & 4 & 5 & 6 & 7 \\ \begin{array}{c}\text { totally } \\ \text { dissatisfied }\end{array} & & & & & & \begin{array}{c}\text { totally } \\ \text { satisfied }\end{array}\end{array}$




\title{
APPENDIX B \\ PREDICTIVE/DESCRIPTIVE DATA MATRIX
}

\begin{abstract}
$: 5: 7: 22777: 135:: 11: 232: 5: 175551: 41433224145654245: 5415551454455515$ $2525545548: 3224411: 13212 ! 155422144452333: 233423341: 214445235354425$

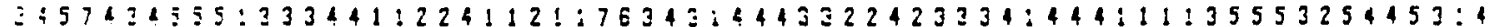
$14 \div 5344325242234111: 5113 !: 55433: 34432: 23: 3324 ! 333: 2214154224454325$

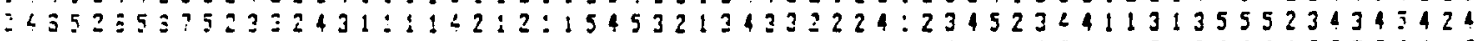
25:5:555552?2433:11233:1:1:5E652123342:34132343364:133:2444:255344:5

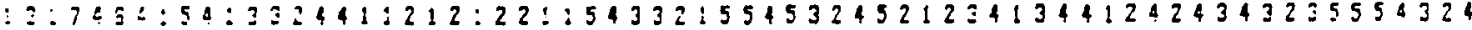

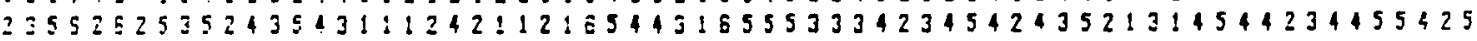
: $4: \vdots 2: 235: 42244: 1:: 42: 2117645214454322412223322411213445234444334$

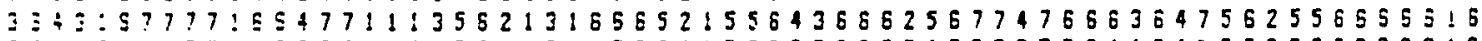
57:2577677375657!124721:2167654155685866545575756445456725555E55:5 $2: 2522: 355: 43: 55:: 1143: 2: 156553: 4342343412223353422414454255545425$ $34252343462642531 ! ! 1532 ! 1 ! 5564214342242312234254412313543254454525$ : 52:75:772577551::55E:13:755722677767655465747753555656!75E5S

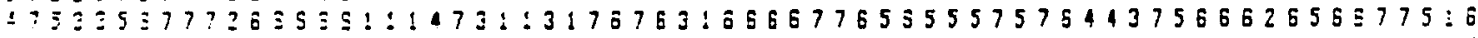
$37724777772: 77771: 1573114177673: 755677756447767556577777: 7577777: 7$ $77263535552556551133531: 427777515554575554455465654545552575555613$

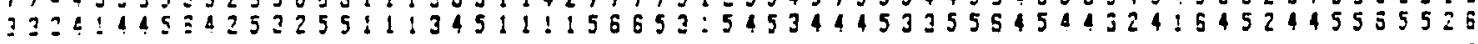
; $5: 25 a 575 \Xi 265776112353 ! 11145545: 44434754534563557436555625 E 565 E 515$ 3134225E55254255!113121111577541445335352324545442252545244555552E $4 \equiv 45: 2664 \equiv 475577 !: 1456 ! 12 ! 57764: 777677764666747674475757: 566567527$ $4291215564255355111353 ! 11155553: 55554 E 3535456354522525552445555525$

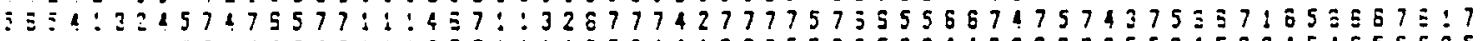

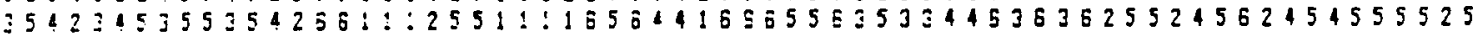
: : :5:23444:32:55!1!:441211654421444323!412235:2251:314443344445435

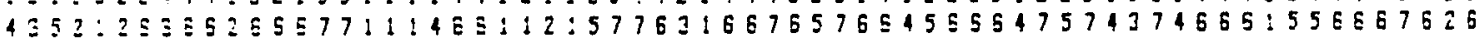
$573: 3=3577473775 ! 11354113: 6777515556675555445675756555771677777517$ 23:5:23:54:54255:1:254:2!:65542!555545252323522352:415552444455435

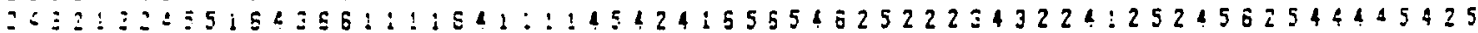
$: 2524: 555: 12243 !: 1 ! 232 ! 1: 55542: 2342222: 11212 ! 332: 11: 3347113343234$ $34: 4: 2245425425511: 254: 12: 55235285553525223352325: 14: 545234445425$ :77:27?777477777::13541:3167673:56557775E545657567676777!ミ77777516 1325655445:32244112:42:21:54452144432124!221423351:1:444523444:324

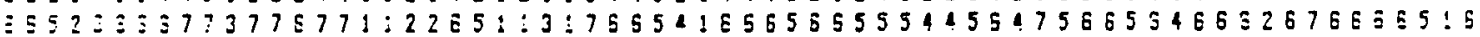

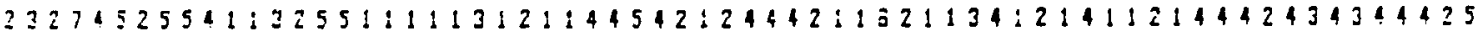

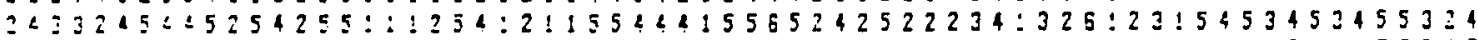
$: 324262355433244221: 4311114542214554241412234143411514443344455325$ $: 22 \div 345435: 44255: 21253: 11: 54523155653525222242424125: 5552444445425$ Z2:2234:415542E512:264:1114552426674242621235132511515452345445425 2?:4242235!43!55:1:15411:1555331554524:511235152512414552354445425
\end{abstract}

The numbers on this page and the following one constitute a matrix of 79 observations of 66 variables detailed in the questionnaire. 
